\title{
TRATAMIENTO QUIRÚRGICO DEL HIPERPARATIROIDISMO SECUNDARIO
}

Relato Oficial

$68^{\circ}$ Congreso Uruguayo de Cirugía

"Educación \& Cirugía" 


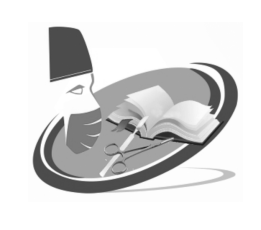

\section{RELATO OFICIAL}

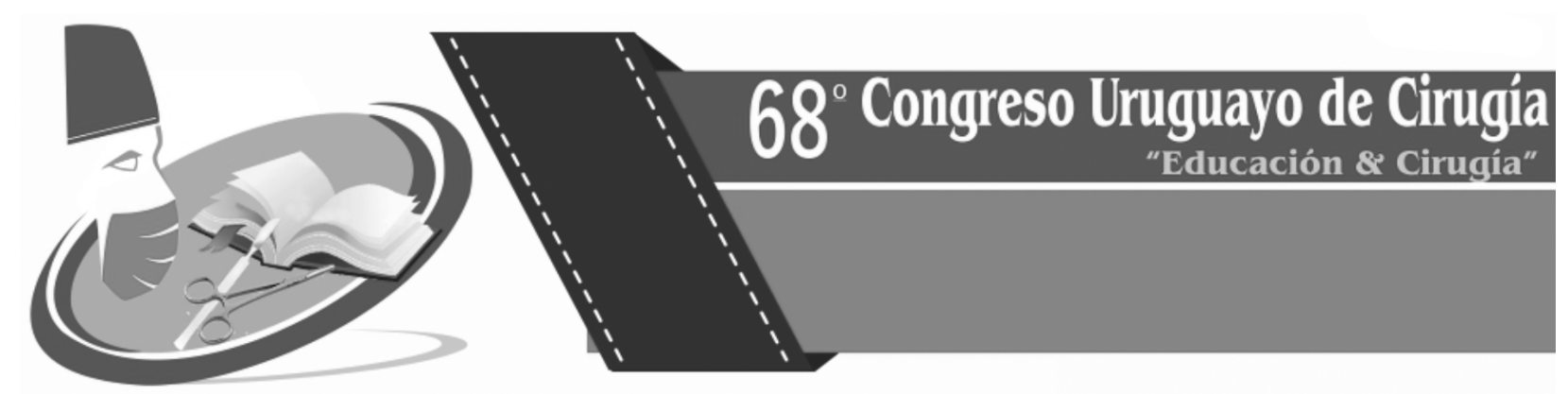

\section{TRATAMIENTO QUIRURGICO DEL HIPERPARATIROIDISMO SECUNDARIO}

Dr Patrick Lyford-Pike Bosch 
Dedico este relato a mi madre, siempre presente, el faro que guía mis pasos. A mi padre y hermano, que me enseñaron y me enseñan las cosas relevantes de la vida. A Sole, Ema, Vice y Sofi. Son mi vida y todo mi esfuerzo es para ellos.

\section{Editora: Grupo Elis}

Palmar 2240 - Montevideo, Uruguay

Tel.: (+598) 24010534

Impreso en Uruguay - Printed in Uruguay

Este libro se terminó de imprimir en Noviembre de 2017

Impresión y encuadernación: $\mathbf{m}$ msimpresos

www.msimpresos.com

Tiraje: 250 ejemplares

Depósito Legal Nº 372.859 
"It seems hardly credible that the loss of bodies

so tiny as de parathyroids should be followed

by a result so disastrous".

William S. Halsted, 1907

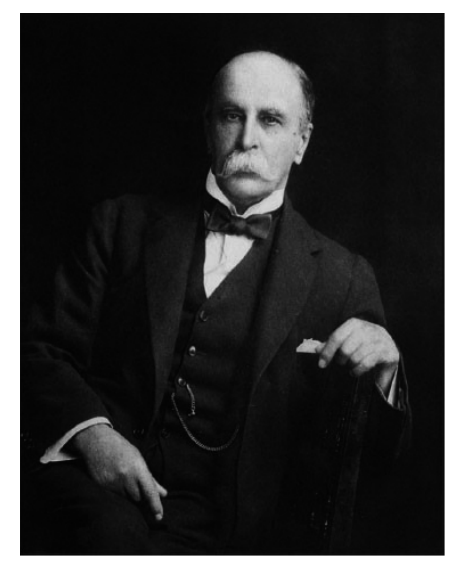

“E1 mejor tratamiento del

hiperparatiroidismo secundario es el

trasplante renal".

Mathias Rothmund

International Association of

Endocrine Surgeons. Congreso

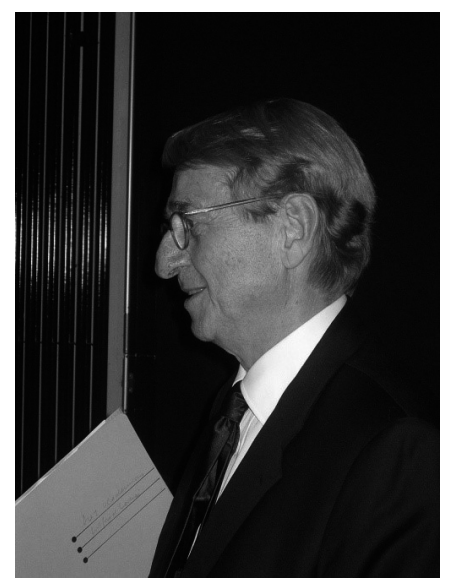

Uppsala; 2004. 


\section{ÍNDICE}

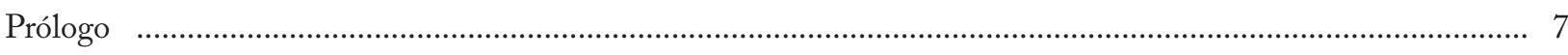

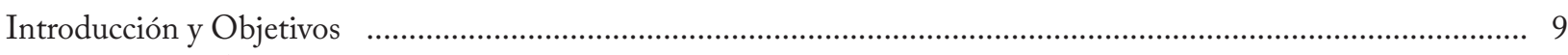

- Introducción

- Objetivos

Definiciones

Historia

Embriología y Anatomía

Fisiopatología del Hiperparatiroidismo (Dr. Ricardo Silvariño)

- Hiperparatiroidismo en pacientes con Enfermedad Renal Crónica

- Frecuencia del Hiperparatiroidismo Secundario en la Enfermedad Renal Crónica

Tratamiento Médico del Hiperparatiroidismo Secundario (Dr. Ricardo Silvariño)

- Control de los niveles de Fósforo y Calcio

- Control de los niveles de PTHi

- Indicación de Tratamiento Quirúrgico

Estado Actual del Tratamiento Quirúrgico del Hiperparatiroidismo Secundario

- Paratiroidectomía Subtotal vs Total, con o sin autotransplante

- Elección de la Táctica Quirúrgica

- Criopreservación

- Dosificación de PTH intraoperatoria

- Resección del Timo

- Nervio Laríngeo Recurrente

Experiencia Personal y de la Clínica Quirúrgica "F” del Hospital de Clínicas

- Técnica Quirúrgica

- Criopreservación

- Dosificación de PTH intraoperatoria

- Resección del Timo

Método de Localización Preoperatoria

- Ecografía

- Centellograma

- Tomografía Computada y Resonancia Nuclear Magnética

- Tomografía por Emisión de Positrones

Métodos de Localización Intraoperatoria (Dr. Juan P. Gambini)

Persistencia y Recurrencia 


\section{PROLOGO.}

\section{La soberanía del hombre está oculta en la dimensión de sus conocimientos.}

\section{Sir Francis Bacon.}

Por definición, relato es un conocimiento que se transmite, habitualmente en detalle, respecto a un cierto hecho.

Transmitir conocimiento es uno de los objetivos trascendentes del ser humano. Los cirujanos somos grandes transmisores de conocimiento y lo hacemos de varias formas, una de las cuales es durante nuestro Congreso Uruguayo de Cirugía. Existe un momento especial dentro de este congreso dedicado a la transmisión de conocimiento sobre un tema en particular, este es el momento del "Relato oficial".

Para el $68^{\circ}$ Congreso Uruguayo de Cirugía hemos elegido un tema que si bien desde el punto de vista estrictamente quirúrgico es de baja frecuencia, esto no le resta importancia, y no lo hace menos apasionante, se trata del "Tratamiento Quirúrgico del Hiperparatiroidismo Secundario"

El Hiperparatiroidismo Secundario es una patología relacionada con la secreción excesiva de hormona paratiroidea, por unas glándulas paratiroides hiperplásicas, siendo la causa más frecuente la Insuficiencia Renal Crónica.

Es todo un desafío transmitir conocimiento acerca del "Tratamiento Quirúrgico del Hiperparatiroidismo Secundario“, requiere conocimientos teóricos, de anatomía, embriología, patología y fisiopatología, pero esencialmente prácticos sobre técnica y destreza quirúrgica que el cirujano debe poseer al momento de enfrentarse a dicho tratamiento.

Han sido pocos los cirujanos Uruguayos que se dedicaron a este tratamiento, algunos de los cuales nos dejaron muchas enseñanzas que hemos adoptado y actualizado de acuerdo al estado del arte, durante todos estos años en los que nos hemos dedicado a este maravilloso tema.

Estamos convencidos que el correcto manejo del "Tratamiento Quirúrgico del Hiperparatiroidismo Secundario", habilita al cirujano para el tratamiento de las otras patologías del cuello, principalmente las relacionadas con la glándula Tiroides.

Hemos designado al Dr. Patrick Lyford-Pike para realizar este Relato Oficial del $68^{\circ}$ Congreso Uruguayo de Cirugía, sabemos que cuenta con las cualidades necesarias para hacerlo, responsabilidad, capacidad y conocimiento, pero especialmente experiencia y gusto por el Hiperparatiroidismo Secundario; al cual ha dedicado gran parte de su formación. Tenemos certeza que ha realizado un trabajo exhaustivo a lo largo de este año, en la búsqueda de bibliografía nacional e internacional, desde las primeras a las últimas publicaciones; actualización de datos de pacientes operados, redacción y edición de este Relato.

El Dr. Lyford-Pike, comienza el Relato enunciando alguno de los aspectos más importantes del desarrollo embriológico de las glándulas paratiroides, dado que conocer el recorrido descendente de las mismas a su posición final ayuda a su localización.

A continuación se hace necesario el abordaje de la anatomía descriptiva y topográfica de las glándulas. Sabemos que una de las limitantes del éxito en el Tratamiento del Hiperparatiroidismo Secundario es la localización de dichas glándulas, por lo tanto deben conocerse reperes anatómicos al respecto.

De la fisiología y fisiopatología, el Dr. Lyford-Pike, describe de manera sucinta los principales hechos homeostáticos de la hormona paratiroidea sobre el calcio y el fósforo.

Sobre la paraclinica utilizada menciona los exámenes más útiles en el diagnóstico y valoración del hiperparatioridismo, al tiempo que aconseja cuales usar y porque.

En cuanto al tratamiento, rápidamente se refiere a las bases principales del tratamiento médico. Luego se dedica de lleno, a describir las principales técnicas quirúrgicas, en forma pormenorizada, teniendo en cuenta las fortalezas y debilidades de cada una, para finalmente dar su opinión, basado en su experiencia. También comparte, lecciones aprendidas. 
Un hecho a destacar y que el Dr. Lyford-Pike desarrolla muy bien, es la utilización de la dosificación intraoperatoria de hormona paratoirodea, como evaluación del éxito del tratamiento quirúrgico. Es de mencionar que dicha dosificación se realizó por primera vez en nuestro medio, en el Hospital de Clínicas.

En otro capítulo, analiza la necesidad, de criopreservar tejido paratiroideo, con la finalidad de autotransplante en el caso de hipoparatioridismo, refiriéndose a los costos y su utilidad, y basándose en su experiencia.

Finalmente menciona algunos casos clínicos de interés.

De nuestra parte, estamos muy agradecidos con la concreción de este trabajo, felicitamos al Dr. Patrick Lyford-Pike, y esperamos que sea de utilidad para todos los cirujanos.

\section{Dr. Rubens Neirotti}




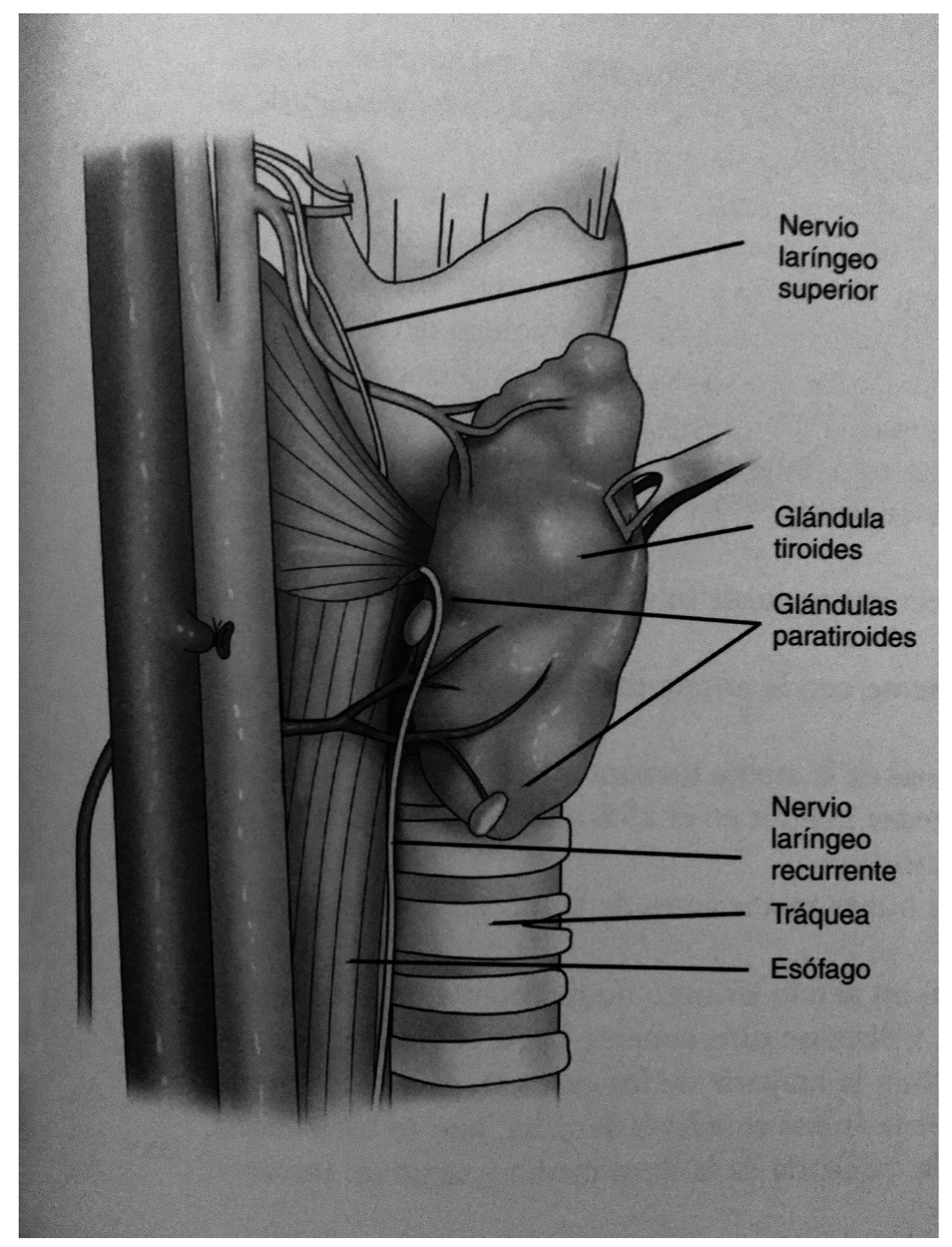

\section{INTRODUCCIÓNY OBJETIVOS}

\section{- Introducción}

\section{- Objetivos}




\section{1・INTRODUCCIÓN}

Debo comenzar este relato diciendo que es un gran honor para mí haber sido designado para llevar adelante el Relato Oficial del $68^{\circ}$ Congreso Uruguayo de Cirugía. Hemos dedicado gran parte de los últimos 15 años de nuestra actividad quirúrgica al estudio y tratamiento del hiperparatiroidismo. En esa tarea, tuvimos dos grandes maestros que se convirtieron en amigos con el pasar del tiempo, el Dr Raul Morelli y el Dr Rubens Neirotti. Además de un gran honor, lo asumimos como una gran responsabilidad y ha sido el motivo de nuestro desvelo en el último año.

Es además un desafío analizar y transmitir un tema que nos apasiona, de tal forma que sea de interés para el cirujano general y para el especialista.

En el Hiperparatiroidismo secundario (HPT2) hay una premisa que siempre debemos tener presente: Es una patología médica que ocasionalmente requiere tratamiento quirúrgico. Llega a esto solamente cuando se hace refractario al tratamiento médico o aparecen complicaciones vinculadas al exceso de hormona paratitoidea (PTH) como ser enfermedad ósea renal, calcifilaxis, prurito, etc.

Partiendo de este concepto es que debemos analizar esta patología, y teniendo claro que el roll del cirujano es secundario y en general tardío en la evolución del HPT2.

Esto determina un bajo volumen relativo de pacientes. Pacientes que además nos obligan a mantener un vínculo profesional íntimo con otros especialistas, además de ser esos especialistas los que "deciden“oportunidad, indicación y hasta táctica del tratamiento quirúrgico. Una vez que se opta por la resolución quirúrgica, el tratamiento de estos pacientes DEBE ser en el contexto de un equipo multidisciplinario, y nuestro gesto no solo será "operar al paciente".

Por estos motivos es que en general, el HPT2 no es una patología que genere demasiado interés en el colectivo quirúrgico.

Un segundo concepto clave en la comprensión de esta patología y su tratamiento quirúrgico, es que este, es un tratamiento PALIATIVO, y que tiene como único objetivo la reducción de la masa glandular, mejorando así el control del calcio.

Es una patología con la que hemos convivido desde el primer día de nuestra residencia, por motivos que analizaremos más adelante, y que siempre nos generó un gran interés. Cada paciente es un desafío táctico y técnico. El éxito, es a veces, muy fácil de alcanzar, pero el fracaso acecha, y siempre es una posibilidad cierta. El fracaso, nuestro fracaso quirúrgico, condena al paciente a una segunda cirugía, lo que en general implica la necesidad de re explorar un cuello operado, con el consabido riesgo de este procedimiento.

Existen, aún hoy, grandes controversias en cuanto a la táctica, técnica, métodos complementarios de estudio pre e intraoperatorios, controversias en las que intentaremos dar nuestra opinión, basado en nuestra experiencia y una extensa revisión bibliográfica. 


\section{$2 \cdot$ OBJETIVOS}

Nos planteamos varios objetivos en este relato.

El primero, es lograr trasmitir conceptos de esta patología. Nos interesa su fisiopatología, diagnóstico y tratamiento, partiendo de la base que no es algo habitual para la mayoría del colectivo quirúrgico.

En segundo lugar, analizaremos los puntos controversiales en el tratamiento quirúrgico de esta patología, basados en la literatura mundial y nuestra experiencia personal.

Nuestro tercer objetivo es realizar una revisión histórica de la cirugía del hiperparatiroidismo. Esto abarca su evolución a nivel mundial y en nuestro medio. De esta revisión surge también, el análisis de los cambios técnicos y tácticos en la cirugía del hiperparatiroidismo.

Por último, analizaremos el estado actual del diagnóstico, estudio y tratamiento quirúrgico del HPT2 en nuestro medio y en el mundo, transmitiendo nuestra experiencia personal. 


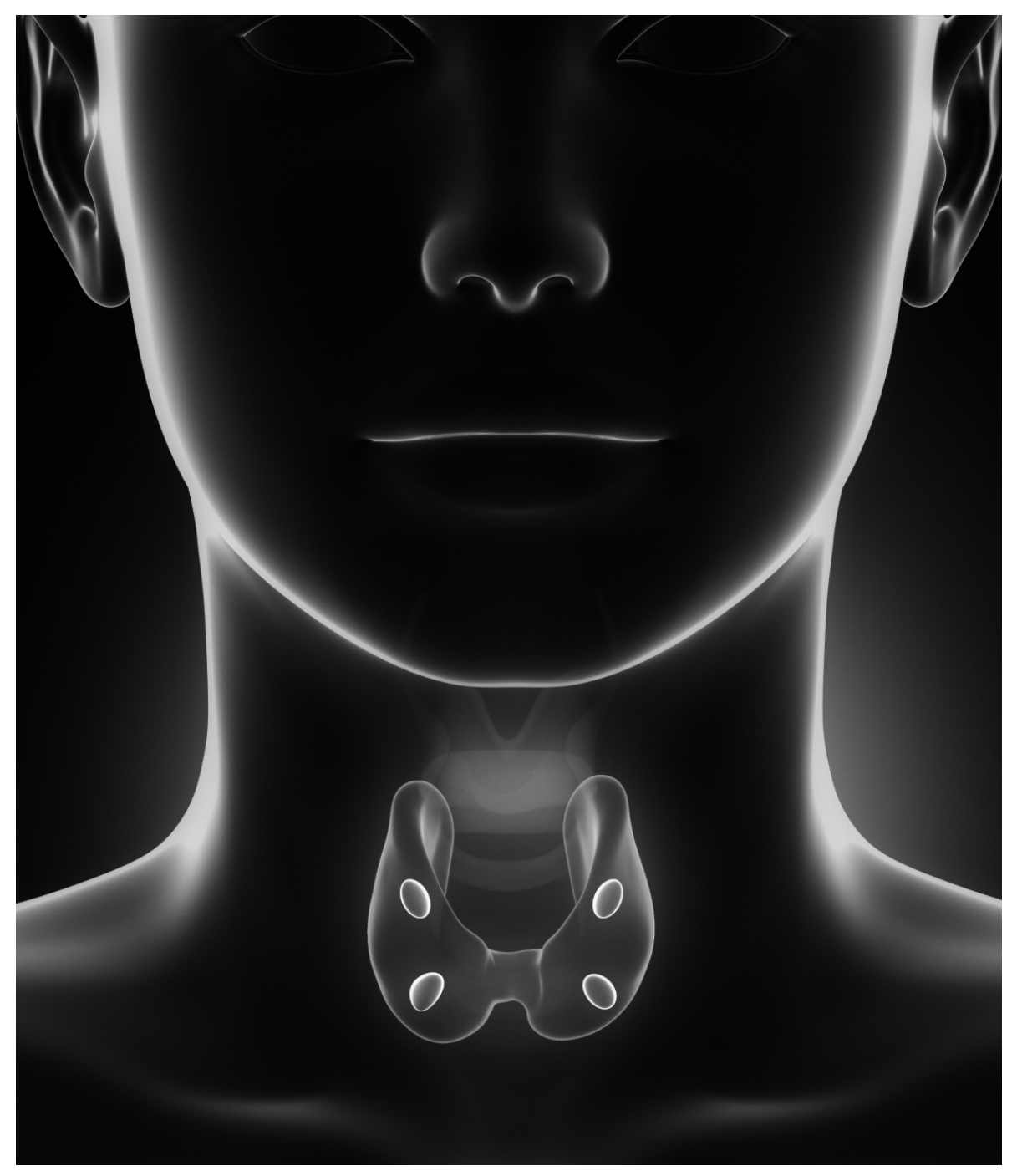

DEFINICIONES 


\section{$3 \cdot$ DEFINICIONES}

El hiperparatiroidismo se define como una alteración del funcionamiento de las glándulas paratiroides. Es un cuadro caracterizado por la secreción excesiva de hormona paratiroidea o paratohormona (PTH). La PTH es un péptido de 84 aminoácidos con una vida media muy corta, estimada en 2 a 4 minutos. Su gran mayoría (70\%) se metaboliza rápidamente en el hígado y en los riñones (20\%). El resto es metabolizado en otros tejidos periféricos. Su principal función es mantener la homeostasis del calcio. La PTH plasmática puede encontrarse en forma de molécula completa ("intacta") o de fragmentos terminales carboxilo, algunos de los cuales no son funcionantes. Los niveles séricos de PTH se determinan mediante inmunoradiometría (IRMA) o de inmunoquimoluminiscencia (ICMA) con un rango de normalidad entre 10 a $65 \mathrm{pg} / \mathrm{ml}$.

E1 Hiperparatiroidismo Primario (HPT1) se caracteriza por una anormalidad primaria de una o varias glándulas paratiroideas que conduce a una secreción inapropiada de la PTH, cuya característica es la hipercalcemia con niveles altos de PTH. Se identifican 3 procesos como posibles responsables de esta patología. Estos son: el adenoma paratiroideo que en general es único, la hiperplasia de las células principales que compromete las cuatro glándulas y el carcinoma paratiroideo, afección también de una única glándula. En la mayoría de las series (1), los adenomas son la causa más frecuente, llegando a ser un 80 a 85\% de los HPT1. La hiperplasia difusa en segundo lugar, llegando a un 15\%, y mucho menos frecuente, los carcinomas, representando menos de $1 \%$ del total. La clásica serie del Massachusetts General Hospital de 1960 (1) analiza 914 casos de HPT1. De ellos, 788 fueron adenomas (750 únicos y 8 dobles) representando un $82,9 \%$. Reportan 133 casos de hiperplasia difusa, 14,6\% y 23 carcinomas, 2,5\% del total. (1)(2)

En el hiperparatiroidismo secundario (HPT2), existe un aumento de la función de todas las glándulas paratiroides, pero consecuente a un estimulo extraglandular, es decir, que no es una patología primitiva de las glándulas paratiroides. La insuficiencia renal es la causa más frecuente de HPT2, pero se produce en toda condición en la cual existe menor disponibilidad de calcio iónico. Otras causas posibles son mal absorción de calcio, osteomalacia, raquitismo, pseudohipoparatiroidismo (respuesta deficiente a la PTH a nivel del receptor) y en la pérdida renal crónica de calcio (hipercalciuria idiopática). La PTH comienza a incrementarse para mantener niveles normales de calcio en sangre y fosforo sérico. En el HPT secundario no tratado se observa una progresiva alteración de los huesos, la osteítis fibrosa quística(3), fracturas y calcificación de tejidos blandos y vasculares, cuadro denominado osteodistrofia renal condición que presenta una alta morbimortalidad en estos pacientes. La mayoría de los pacientes con HPT secundario son tratados médicamente, con buenos resultados. Para ello se utiliza calcio y vitamina $\mathrm{D}$, calciomiméticos, administración de análogos de la vitamina $\mathrm{D}$ y la administración de quelantes de fosfato en el intestino para disminuir la hiperfosfatemia. Aproximadamente 1 a $2 \%$ de los pacientes con HPT2 requieren paratiroidectomía.

El hiperparatiroidismo terciario (HPT3) es en el que la secreción de PTH es autónoma, consecuencia de un HPT2 de larga data. Este fenómeno se debe a una marcada estimulación y conversión de las glándulas paratiroideas de un estado de hiperplasia reversible a un defecto de crecimiento irreversible. Se producen cantidades elevadas de PTH, independientemente de las niveles de calcio en sangre. El HPT3 se reporta hasta en el 50\% de los pacientes que se someten a trasplante de riñón y su ocurrencia se cree que está relacionado con el mayor tiempo de la duración de la diálisis antes del trasplante.(1)(2)(3)(4) 


\section{UPSALA LAKAREFÖRENINGS FÖRHANDLINGAR}

\section{Band. XV. $\quad 1879-1880 . \quad$ N:r $7 \& 8$.}

Fredagen den 5 Mars.

Sandstróx, Glandulz parathyreoidez. - BLIX, Myograf. SANDstróM, Prostatspreparat. - WCDE, Lefverprepsrat. - HoLMGREN, Retinaströmmen. - Svar till H. Cohn on färgblindheten. Föreningens yttrande mot $\boldsymbol{K}$. Wicksells töredrag om dryckenskap.

1. Om en ny körtel hos menniskan och atskilliga däggdjur

af

IVAR SANDSTRör.

För snart tre år sedsn påträffiade jag å sköldkörteln af en hund en liten, knappt hampfröstor bildning, som lăg innesluten

\section{HISTORIA}




\section{$4 \cdot$ HISTORIA}

Las glándulas paratiroides como estructura anatómica fueron descritas por primera vez en 1852 por Sir Richard Owen, Profesor de Anatomía Comprada del "Royal College of Surgeons of England" al realizar la autopsia de un rinoceronte de India muerto en el parque zoológico de Londres, en marzo de 1852 (5).(Figura 1)

Esta descripción fue en simultáneo a las primeras publicaciones de cuadros clínicos de tetania consecuente a la realización de las primeras tiroidectomías (6). En 1879, I.V. Sandström (1852-1889), un estudiante de medicina sueco de Uppsala, descubre y publica el hallazgo de una "nueva glándula" en el tiroides del perro así como en el ser humano, donde describe dos glándulas, a cada lado del cuello, en 50 autopsias. Sugirió denominarlas glandulae parathyroidea por su proximidad a la Tiroides (7). El trabajo de Sandström fue publicado en una revista sueca local, poco conocida, lo que hizo que su descripción pasara desapercibida durante 10 años. (Figura 2)

El primer caso de tetania descrito en la literatura mundial es de un paciente sometido a una tiroidectomía total por T. Billroth en 1891.(Figura 3)

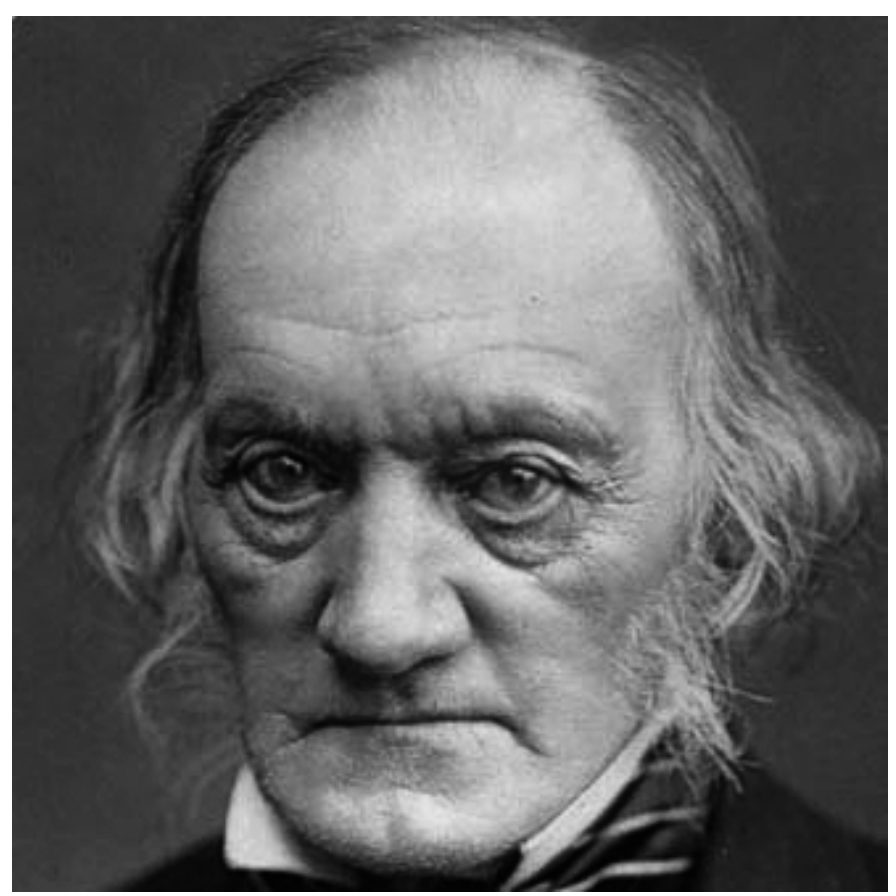

Figura 1. Sir Richard Owen. 1804-1892

El paciente sobrevive a la cirugía y sufre una tetania postoperatoria inmediata, descrita por Anton Wolfer. (5) En ese mismo año se asocia en Paris, la tetania a la tiroidectomía total con paratiroidectomia accidental. (8) Se creía que las glándulas paratiroides eran las encargadas de detoxificar alguna sustancia endógena desconocida, y que la ausencia de esa detoxificación era la causa de la tetania por acumulación de esa sustancia desconocida. En el año 1903, W.J. Mac Callum confirma esta teoría al controlar la tetania en perros con la inyección de extractos de glándulas paratiroides. Logró también asociar esa sustancia endógena toxica con una disminución de la calcemia postoperatoria y utilizando ya el termino Hipoparatiroidismo. (9)(10) 


\section{UPSALA LAKAREFÖRENINGS FÖRHANDLINGAR

\begin{tabular}{lcc}
\hline Band. XV. & 1879-1880. & N:r $7 \& 8$. \\
\hline & Fredagen den 5 Mars.
\end{tabular}

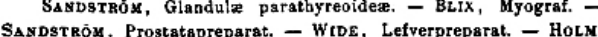
GREs, Betingströmmen - Svar till $H$. Cohn om tärghlindheten. Föreningens yttrande mot $K$. Wicksells föredrag om dryckenskap.

1. Om en ny körtel hos menniskan och atskilliga dăggdjur

af

IVAR SANDSTRöM.

För snart tre år sedsn påträffiade jag à sköldkörteln af en hund en liten, knappt hampfröstor bildning, som låg innesluten

Figura 2. Publicación de I.V. Sandström

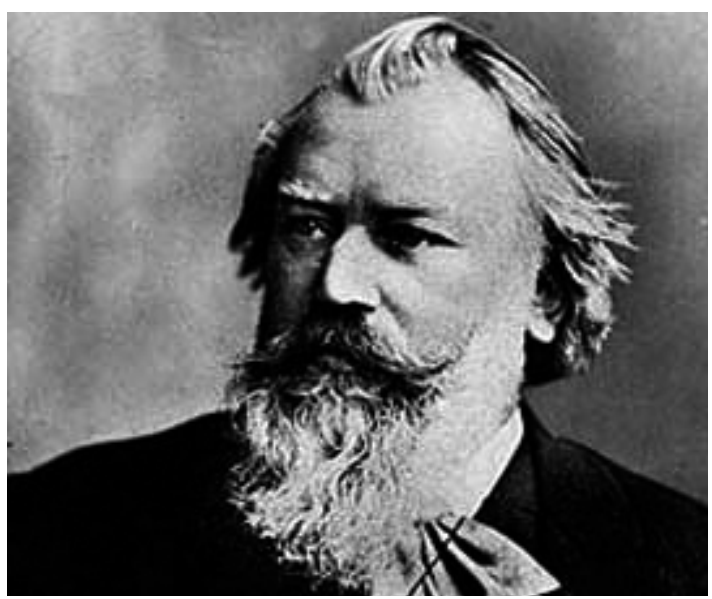

Figura 3. Theodor Billroth. 1829-1894

La primera paratiroidectomia terapéutica por hiperparatiroidismo fue realizada en Viena por Felix Mandl, joven cirujano, en 1925. (11). El paciente, Albert G., era portador de un cuadro clínico y radiológico compatible con osteítis fibrosa quística. Se realizó una exploración cervical con anestesia local resecándose un tumor de $2,5 \times 1 \mathrm{~cm}$ en la topografía de la paratiroides inferior derecha. El paciente tuvo una clara mejoría en el postperatorio pero con una recidiva a los 5 años que determino su muerte. El primer paciente tratado con cirugía por un hiperparatiroidismo en EEUU data de 1926, en Nueva York, por el Profesor E.F. Dubois. (12)

En 1934, Albright describe varios casos intervenidos por hiperparatiroidismo primario destacando la presencia de hiperplasia de células claras en el estudio histopatológico (13). En 1958, Cope realiza un importante aporte con la descripción de la presencia de hiperplasia de células principales en el hiperparatiroidismo primario, afectando las cuatro glándulas. Hasta ese momento, solo se conocía el adenoma único como causa de HPT1. Se plantea entonces, la necesidad de resecar tres o más glándulas en estos pacientes (14). En la década del 60 comienza a ser accesible la dosificación de calcio en sangre con lo que el número de pacientes diagnosticados con hiperparatiroismo aumenta considerablemente (15). Hasta ese momento se consideraba que el hiperparatiroidismo era una patología relativamente infrecuente, definiéndose una tasa aproximda de 1 por 1000 pacientes (16). En 1963 se desarrollan técnicas de inmunoensayo para la detección de la hormona paratiroidea completándose así el diagnóstico de esta patología (17). A partir de entonces se suscita la polémica sobre el tratamiento quirúrgico más adecuado para el hiperparatiroidismo asociado a insuficiencia renal crónica (18). 
E1 tratamiento quirúrgico de HPT2 fue originalmente descrito por W.S. Stanbury en 1960 (19) quien realizaba Paratiroidectomia subtotal a sus pacientes. Esta fue la técnica de elección hasta 1975, año en que Wells (20), describe la Paratiroidectomia Total con implante de tejido paratiroideo en antebrazo. A su favor se destacaba el hecho de no volver a explorar el cuello ante una recidiva o recurrencia y así evitar un procedimiento de alta morbilidad.

A partir de ahí, las variantes tácticas fueron múltiples. (21)(22)(23)(24)(25)

En nuestro medio, la historia del hiperparatiroidismo es más reciente. El primer registro de tratamiento quirúrgico de las glándulas paratiroides es de L.A. Cazaban, publicado en el año 1972, y orientado específicamente a el implante de glándulas paratiroides con el objetivo de corregir el hipoparatiroidismo iatrogénico post cirugía de cuello. (26)

Posteriormente, en el 1994 se publica la primera serie nacional de pacientes portadores de HPT2, tratados quirúrgicamente, entre 1985 y 1994 del Dr Raul Morelli. Publican un total de 73 pacientes, de los cuales los primeros 14 son excluidos y son considerados por los autores como "casos históricos". En estos primeros pacientes, la falta de experiencia nacional e internacional los llevo a realizar un procedimiento insuficiente en lo que se refiere a disminución de volumen glandular. Se realizaron paratiroidectomias subtotales con implante en antebrazo. La persistencia fue la regla en estos pacientes y no fueron incluidos en la publicación final. Luego de esta primera etapa, los autores optaron por realizar la Paratiroidectomia total con implante y en los últimos pacientes la Paratiroidectomia Subtotal, lográndose la criopreservación en los últimos pacientes de la serie (27). 


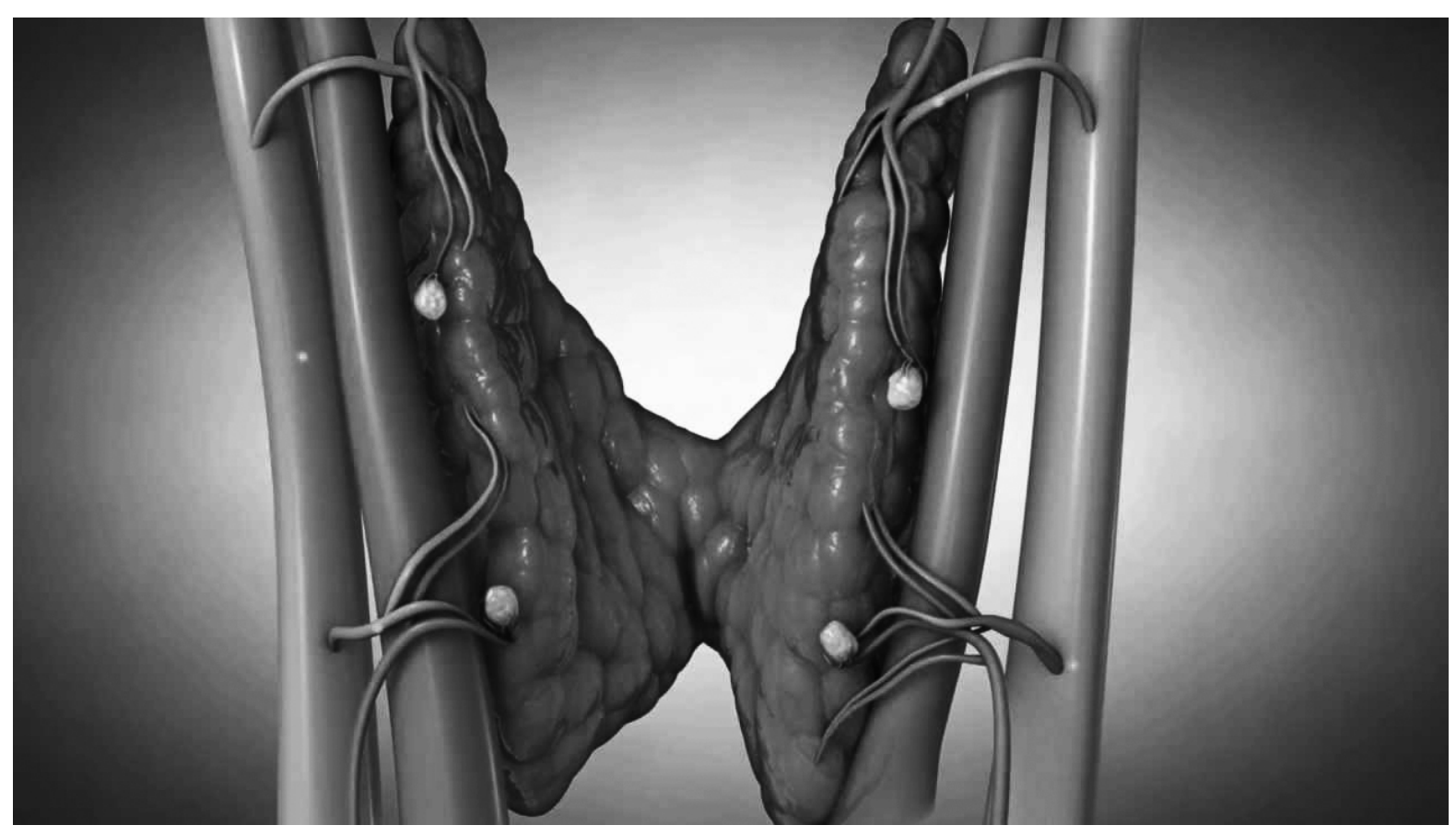

EMBRIOLOGÍA y ANATOMÍA 


\section{5 • EMBRIOLOGÍA Y ANATOMÍA DE LAS GLANDULAS PARATIROIDES}

Consideramos fundamental este capítulo. El cirujano dedicado a cuello y principalmente el que debe tratar el HPT (primario, secundario y terciario) debe conocer extensamente la embriología y anatomía de las glándulas paratiroides. Esto es una herramienta importante a la hora realizar una exploración de cuello, especialmente cuando se presenta alguna dificultad en localizar las glándulas. El conocimiento embriológico y anatómico será, en ese momento, un conocimiento teórico que deberemos aplicar para identificar glándulas ectópicas y así culminar con éxito el tratamiento quirúrgico.

Las glándulas paratiroides derivan del endodermo faríngeo a las 5 semanas de gestación; las paratiroides superiores derivan de la 4ta bolsa branquial junto con los lóbulos laterales de la tiroides y las inferiores derivan de la 3era. Ambas paratiroides inferiores derivan de la porción dorsal de la 3ra bolsa branquial; de la porción ventral deriva el timo. Esto explica la ubicación de las paratiroides tímicas o paratímicas. Cuando el embrión mide 13 a 14 mm, comienza la migración de las glándulas. Las superiores con los cuerpos branquiales y las inferiores con el timo. El complejo paratiroides inferiores-timo de separa de la pared faríngea y progresa en sentido caudal y mediano. Con el descenso del corazón y grandes vasos, ambas estructuras se introducen en el mediastino superior. En el embrión de $20 \mathrm{~mm}$, la regresión cefálica del timo lo separa de las paratiroides inferiores que quedan relacionadas con el polo inferior de los lóbulos tiroideos o en el ligamento tirotimico.

Las paratiroides superiores siguen la migración tiroidea. Su trayecto es un corto descenso lo que explica la ubicación relativamente estable. Así quedan en íntimo contacto con la porción posterior del tercio medio de los lóbulos tiroideos. Las paratiroides inferiores cruzan a las superiores en su descenso, lo que puede explicar el agrupamiento a nivel de la arteria tiroidea inferior, en la unión del tercio medio con el tercio inferior del lóbulo tiroideo, por su cara posterior. Si el cruce es muy estrecho, la paratiroides homolaterales pueden quedar al mismo nivel, siendo casi imposible, en el intraoperatorio, poder definir si se trata de una única glándula aumentada de tamaño o de 2 glándulas. Si esto sucede, la única forma de definirlo es porque cada glándula conservara un pedículo vascular propio. (figura 4)

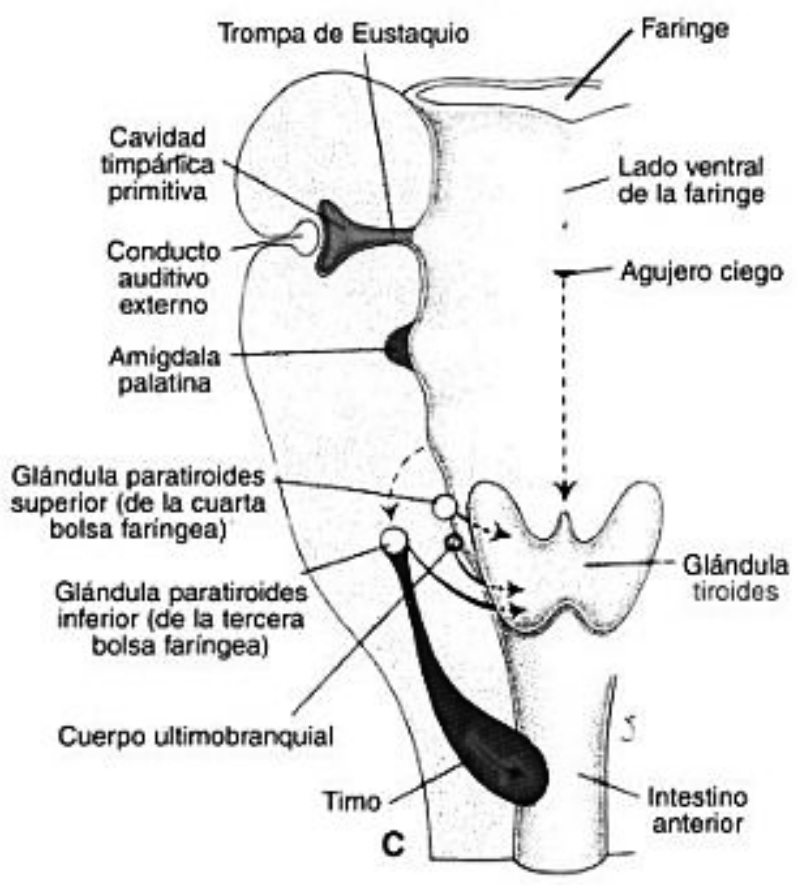

Figura 4. Descenso de Glándulas Paratiroides 
Su color es variable y depende de su contenido graso, su vascularización y de sus células oxifilcas. Son de superficie lisa, brillante, de aspecto lobulado. El peso promedio de una glándula normal es de 30 a $40 \mathrm{mg}$ con un amplio rango de variabilidad. El peso combinado de todas las glándulas en un hombre sano es de alrededor $120 \mathrm{mg}$ mientras que en mujeres sanas será de alrededor $145 \mathrm{mg}(28)$. Sus medidas habituales son $5 \times 3 \times 1 \mathrm{~mm}$. En el $80 \%$ de los casos su forma es ovalada, en $11 \%$ alargadas, $5 \%$ bilobuladas y $1 \%$ multilobuladas. Su forma, tamaño y aspecto macroscópico se modifican francamente en la ocurrencia de un HPT2. En general encontramos glándulas más grandes, ovaladas, de color oscuro. Las glándulas son 4 en el 90\% de los casos, 2 superiores y 2 inferiores. Estudios realizados en necropsias de individuos sin patología paratiroidea arrojaron las siguientes cifras: se hallaron un total de 4 en 84-87\%, 3 glándulas en hasta un 16\%, 5 en 6\% y glándulas supernumerarias en 13-20\%; sin embargo, si se incluyen glándulas con peso inferior a $5 \mathrm{mg}$ este porcentaje aumenta mucho mas. Raramente existen 2 o 6 glándulas. (29)(30)(31)(32)

Anatómicamente, la ubicación de las paratiroides superiores es más o menos estable. En el 80\% de los casos contacta la capsula tiroidea, en un área de aproximadamente $2 \mathrm{~cm}$ cuadrados, cuyo centro se ubica $1 \mathrm{~cm}$ por encima de la unión del nervio Laríngeo Recurrente (en su entrada a la laringe) y la arteria tiroidea inferior. Aproximadamente el 10\% se ubica adyacente al polo superior tiroideo o los vasos tiroideos superiores, $7 \%$ en la intersección entre el nervio laríngeo recurrente por arriba y la arteria tiroidea inferior por debajo, y hasta un 3\% en el espacio parafaríngeo o paraesofágico. La ubicación de las paratiroides inferiores es más variable. En la mitad de los casos (50 a 60\%) se encuentran en la cara lateral, posterior o anterior de los polos inferiores de la tiroides. Están generalmente relacionadas con el nervio laríngeo recurrente; del 20 al $26 \%$ se sitúa en los ligamentos tirotímicos o en la porción superior cervical del timo. Hasta un 7\% presenta una ubicación más alta, a nivel del tercio medio de la cara posterior de los lóbulos tiroideos, pudiendo confundirse con las paratiroides superiores, y hasta un 9\% se halla entre el manubrio esternal y el timo. (29)(30)(33) Las glándulas ectópicas tienen una ubicación más variable. Un $43 \%$ de las ectopias de paratiroides superiores se hallaron en el ángulo traqueoesofágico, $22 \%$ en posición retroesofágica, $14 \%$ en el mediastino posterosuperior, $7 \%$ intratiroideo, $7 \%$ dentro de la vaina carotidea, y $7 \%$ paraesofágico. En cuanto a ectopias de las paratiroides inferiores: $30 \%$ en el timo, $22 \%$ en el mediastino anterosuperior, $22 \%$ intratiroideo, $17 \%$ en el ligamento tirotímico, y $9 \%$ en región submandibular (por tanto, no descendieron).(34)(35) (figura 5)

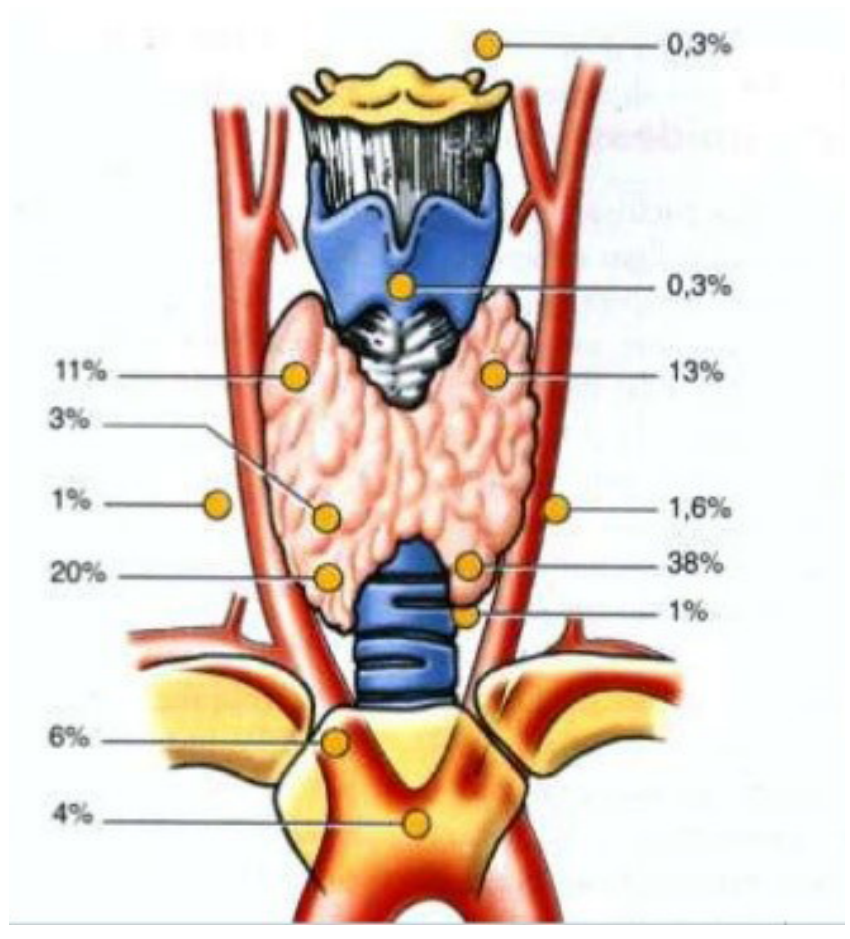

Figura 5. Ectopías más frecuentes en relación con Paratiroides Inferiores

En cuanto a su irrigación, la gran mayoría (80\%) recibe una sola rama arterial, originada de la arteria Tiroidea Inferior. El drenaje venoso es en paralelo a los pedículos arteriales y drena finalmente en el sistema yugular interno. El drenaje linfático es compartido con la tiroides hacia sistema paratraqueal y cervical profundo. (29)(31)(33)(34)(36) 


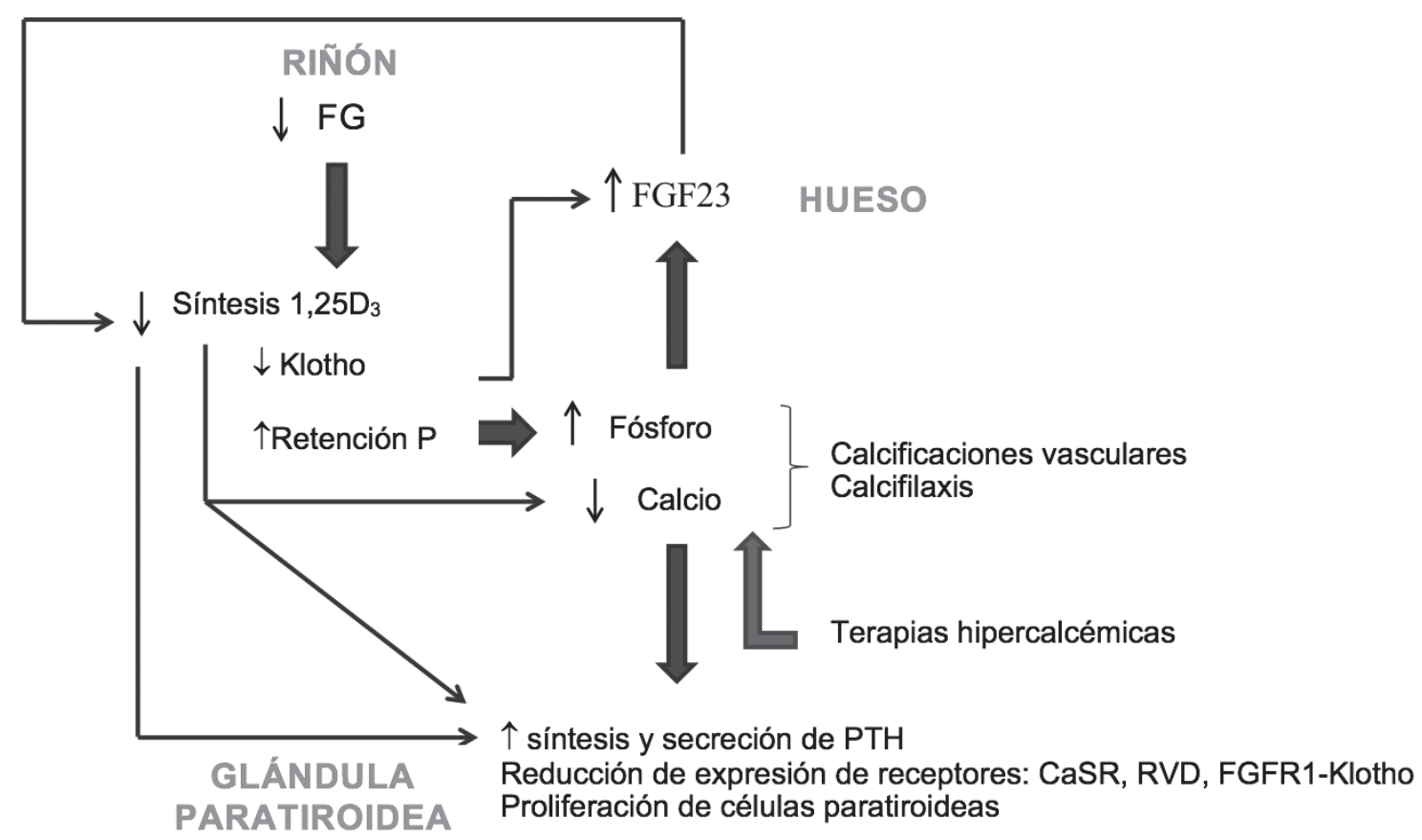

FISIOPATOLOGÍA DEL HIPERPARATIROIDISMO

Dr. Ricardo Silvariño

- Hiperparatiroidismo en pacientes con Enfermedad Renal Crónica

- Frecuencia del Hiperparatiroidismo Secundario en la Enfermedad Renal Crónica 


\section{6• FISIOPATOLOGÍA DEL HIPERPARATIROIDISMO}

El calcio iónico en el plasma está estrechamente regulado. Sus valores oscilan entre 1,1 y 1,3 mmol/L. Es necesario un control estricto del calcio iónico para asegurar la función óptima de los procesos fisiológicos, particularmente la señalización celular, la función neural y muscular, y el metabolismo óseo. El pivot en la regulación del calcio iónico es la secreción de la hormona paratiroidea. La misma se libera de las glándulas paratiroides, que responden a los cambios en el calcio iónico circulante a través del receptor de detección de calcio (CaSR) situado en la superficie de las células principales(37). La hormona tiene una importante función biológica en el mantenimiento del calcio iónico y del fósforo plasmático dentro del rango de referencia mediante la estimulación de receptores específicos. Si ocurre una disminución en el calcio iónico circulante, la hormona paratiroidea aumenta y tiene tres funciones principales que ayudan a restaurar una concentración plasmática normal: 1- reabsorción tubular de calcio mediada por receptores de calcio (riñón), 2- estimulación de los osteoclastos para liberar calcio esquelético (hueso), y 3- el aumento de la actividad de la 1-hidroxilasa renal, dando como resultado la producción de 1,25-dihidroxivitamina $\mathrm{D}$ con aumento de la absorción digestiva de calcio (intestino). El aumento del calcio en respuesta a estos efectos mediados por la hormona paratiroidea, actúa a través de un circuito de retroalimentación endocrina sobre el CaSR, disminuyendo la secreción de la hormona paratiroidea.(38)

Los componentes de este sistema regulador pueden generar una secreción excesiva de hormona paratiroidea o hiperparatiroidismo. Además de la hormona paratiroidea, otros factores importantes que mantienen la normocalcemia son la 1,25-dihidroxi-vitamina D (promueve la absorción de calcio y fosfato a través del intestino), y la calcitonina, producida por las células $\mathrm{C}$ del tiroides, que actúa sobre los osteclastos, inhibiendo su actividad y reduciendo la liberación de calcio $\mathrm{y}$ fosfato del hueso (figura 5).(38)

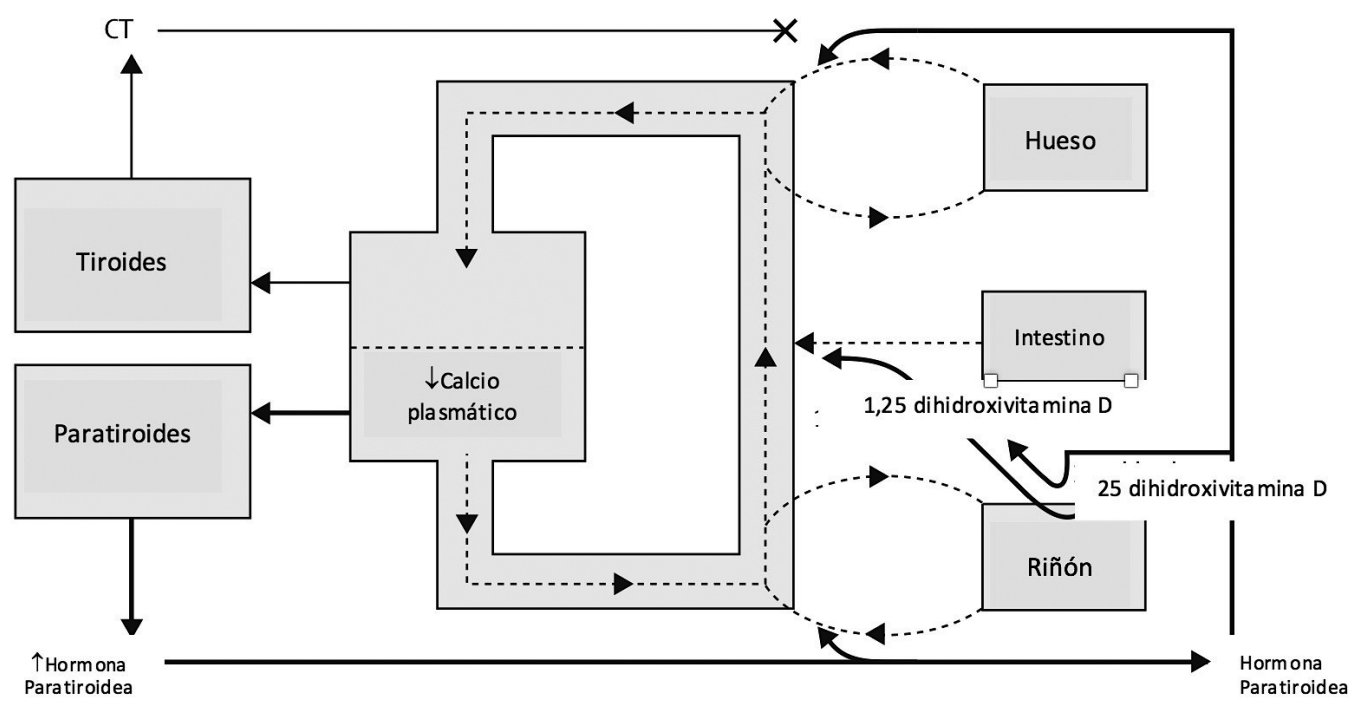

Figura 5. Respuesta de la PTH al descenso del calcio iónico

\section{1 • Enfermedad Renal Crónica}

Hay acuerdo en definir la Enfermedad Renal Crónica (ERC) como la presencia durante al menos tres meses de: filtrado glomerular estimado inferior a $60 \mathrm{ml} / \mathrm{min} / 1,73 \mathrm{~m} 2$ o lesión renal, entendiendo por lesión renal el hallazgo de lesiones histológicas, alteraciones del sedimento urinario o la presencia de anomalías macroscópicas en los estudios de imagen renal.(39) En función del filtrado glomerular estimado y la presencia (y cuantía) de albuminuria se ha estratificado la ERC en 5 estadios o grupos (figura 6). (39)Cada estadio se vincula al riesgo de mortalidad global, mortalidad cardiovascular, necesidad de tratamiento sustitutivo de la función renal, injuria renal aguda y progresión de la enfermedad renal crónica. Asimismo, y en función de lo expuesto, se han propuesto estrategias de seguimiento y tratamiento para cada estadio de ERC.(40) 


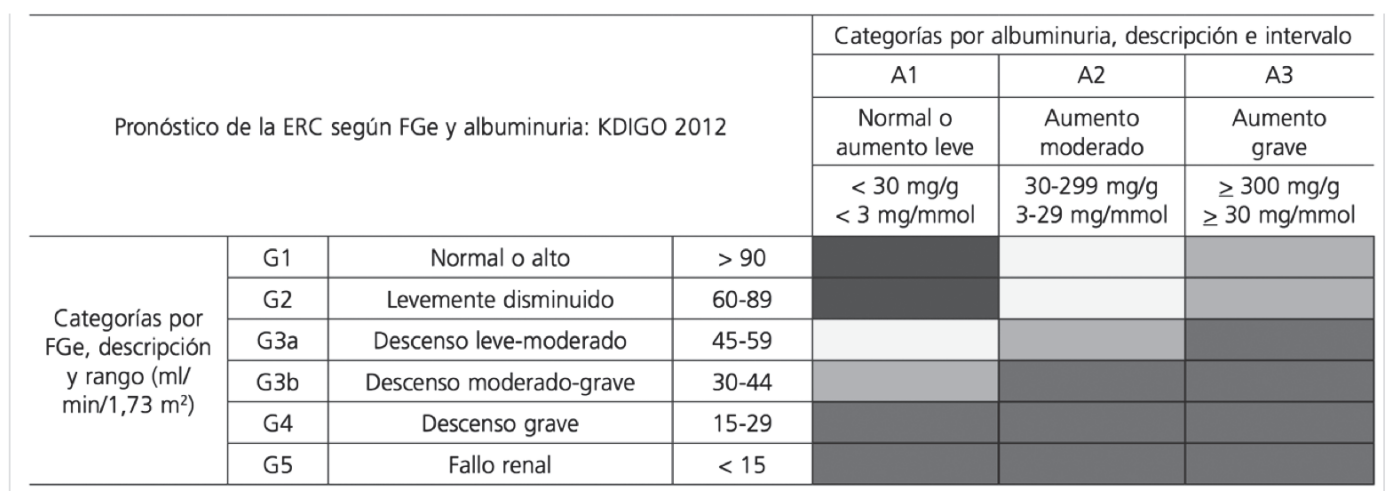

Figura 6. Categorías de la ERC en función del filtrado glomerular estimado y albuminuria.

ERC: Enfermedad Renal Crónica; FGe: Filtrado Glomerular Estimado; KDIGO: Kidney Disease Improving Global Outcomes.

Varios estudios recientes de diferentes partes del mundo mencionan una prevalencia de ERC en la población general entre 8 y 13\%.(41)(42)(43). Los datos de prevalencia mencionados surgen de diferentes iniciativas de registros de ERC en distintos países del mundo. Las diferencias en las prevalencias reportadas derivan de inhomogeneidades en los criterios y definiciones adoptados por los diferentes registros. Asimismo el uso de un umbral arbitrario para definir ERC (eFeG $<60 \mathrm{ml} / \mathrm{min} / 1,73 \mathrm{~m} 2$ ) determina un "sobrediagnóstico" (falsos positivos) en los ancianos (mayores de 65 años), y un "subdiagnóstico" (falsos negativos) en individuos jóvenes con un eFeG $>60 \mathrm{~mL} / \mathrm{min} / 1,73 \mathrm{~m} 2$.(43) La prevalencia e incidencia de pacientes con ERC en etapa 5 que requieren tratamiento sustitutivo de la función renal es también conocida a partir de los diferentes registros de diálisis implementados en diferentes partes del mundo. A diferencia de los datos epidemiológicos de pacientes en etapas 1-4 de ERC, la necesidad de tratamiento sustitutivo es una variable más fácilmente medible en las poblaciones en que se ha querido registrar.(41) En la figura 7 se muestra la incidencia y prevalencia de ERC en tratamiento sustitutivo de la función renal reportada en diferentes registros internacionales. Uruguay cuenta con dos registros nacionales que han permitido un mejor conocimiento de la población con ERC, así como un mejor seguimiento y cumplimiento de objetivos terapéuticos que han repercutido en la sobrevida renal y global de esta población. 

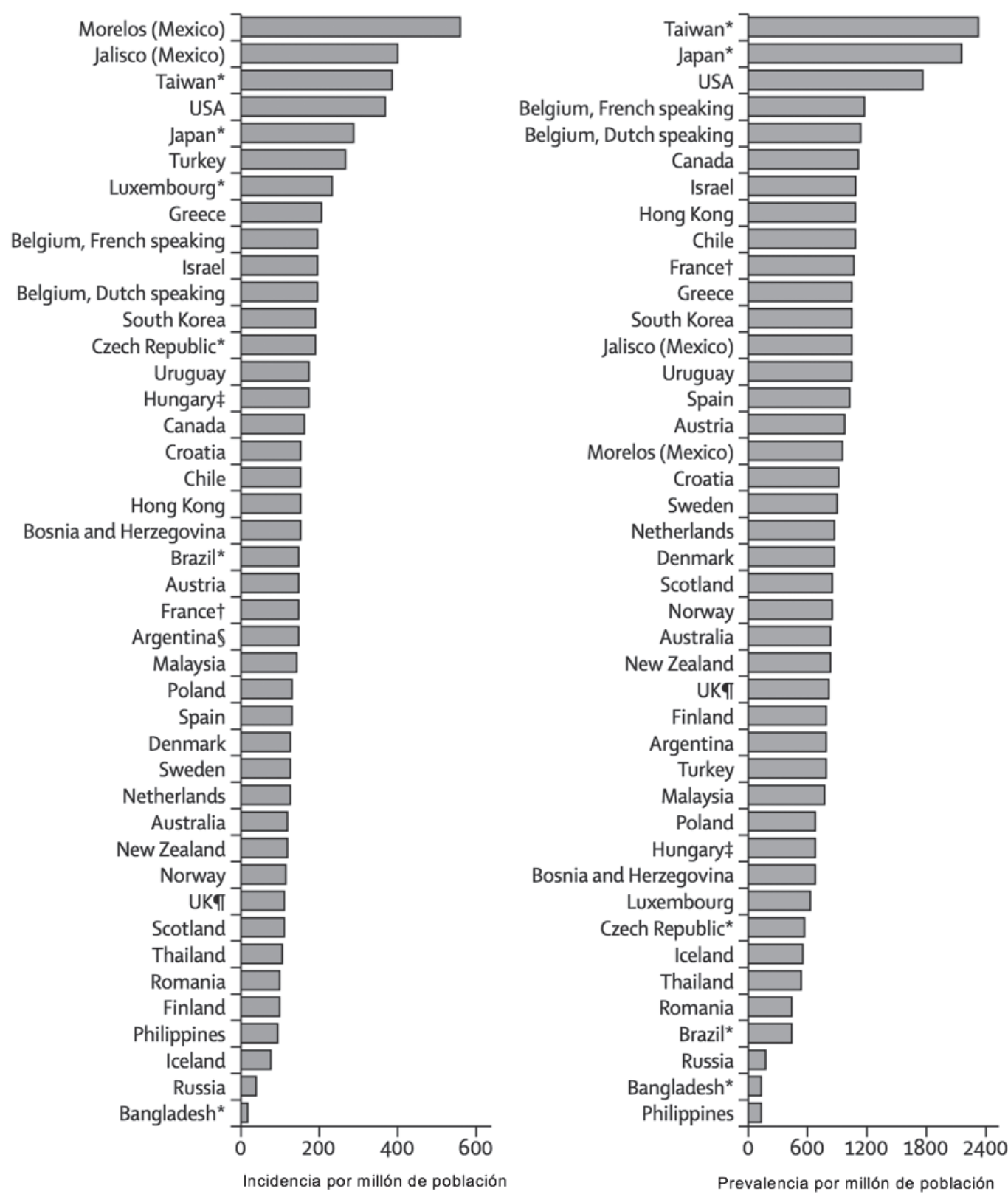

Figura 7. Incidencia y prevalencia de ERC en tratamiento sustitutivo de la función renal (diálisis y trasplante renal)

Registro Uruguayo de Diálisis (RUD). El RUD comenzó su actividad en 1981 y es actualmente un registro obligatorio que incluye a todos los pacientes que reciben tratamiento dialítico crónico en el país.(44) La recolección de datos se organiza en una base de datos de pacientes que proceden de tres archivos: 1-el de datos de solicitud de ingreso a plan de diálisis, 2-el de datos de evolución que se recogen mensualmente agregándose una vez por año los datos relacionados con la comorbilidad y 3-el de datos de diálisis que se envían diariamente en el caso de los centros de hemodiálisis y mensualmente en los centros de diálisis peritoneal. Se denomina Insuficiencia renal extrema (IRE) a la situación clínica de los pacientes con insuficiencia renal severa que requieren tratamiento sustitutivo de la función renal. La incidencia de IRE puede expresarse como población incidente (número absoluto de pacientes nuevos en el año) o como tasa de incidencia (relación entre el número de pacientes nuevos y una población determinada, medida a mitad del año analizado y expresada por millón de población (pmp)). La prevalencia de IRE también puede expresarse como población prevalente (número absoluto de la población prevalente) o como tasa de prevalencia (relación entre el número total de pacientes y la población de una zona geográfica tomada a mitad de año y expresada por millón de población (pmp). En la figura 4 se muestran la incidencia y prevalencia de ingreso a diálisis en el Uruguay en el periodo 1981-2015. Este registro por tanto nos permite conocer incidencia y prevalencia de ERC extrema que requiere tratamiento sustitutivo de la función renal. 
Programa de Salud Renal (PSR). Es un programa desarrollado por el Fondo Nacional de Recursos, el Ministerio de Salud Pública, la Cátedra de Nefrología y la Sociedad Uruguaya de Nefrología. Se lleva a cabo en una parte importante de Uruguay y su objetivo es prevenir la aparición de la enfermedad renal y evitar que progrese en aquellos casos en que ya está instalada. Para ello se facilita el acceso a la atención nefrológica y se garantiza la medicación nefroprotectora (http://www.fnr.gub.uy/descripcion_renal). Son criterios de ingreso al programa: tener un filtrado glomerular estimado menor a $60 \mathrm{ml} / \mathrm{min}$ o una proteinuria > $300 \mathrm{mg} /$ día, ó en el caso de pacientes con diabetes mellitus tener una microalbuminuria $>30 \mathrm{mg} /$ día. El programa lleva adelante un registro de los pacientes ingresados que incluye datos patronímicos, datos vinculados a la presencia de factores de riesgo para inicio y progresión de la enfermedad renal, datos vinculados a la enfermedad renal de base, filtrado glomerular, proteinuria y repercusiones vinculadas a la ERC. A julio de 2017 había 20.000 pacientes ingresados(45). Si bien este registro ha aportado mucho en lo que refiere al conocimiento de la ERC en nuestro medio, sus datos no permiten estimar incidencia o prevalencia de ERC ya que se trata de un registro voluntario en el que lamentablemente no participan todas las instituciones del país.

En función de lo analizado es posible que la prevalencia de ERC sea próxima al 10\% en nuestra población acorde a los datos publicados en registros internacionales.

\section{2 • Hiperparatiroidismo en pacientes con Enfermedad Renal Crónica}

Bajo el término "alteraciones del metabolismo mineral y óseo asociados a la enfermedad renal crónica" (MMO-ERC) se incluyen: 1: alteraciones bioquímicas (calcio, fósforo, hormona paratiroidea, vitamina D), 2: alteraciones del recambio, mineralización, volumen, crecimiento lineal y resistencias óseas, y 3: presencia de calcificaciones vasculares y de tejidos blandos.(46) El hiperparatiroidismo secundario es una de las posibles manifestaciones del MMO-ERC. Es el resultado de la falla de uno o más componentes de los mecanismos homeostáticos antes descritos (figura 5).

Fisiopatología del hiperparatiroidismo secundario en la Enfermedad Renal Crónica. El hiperparatiroidismo secundario (HPT2) es un proceso adaptativo en respuesta al deterioro de la función renal. Se caracteriza por síntesis y secreción de PTH anormalmente elevada, así como por hiperplasia de la glándula paratiroidea. La secuencia de eventos que participan en el desarrollo de HPT2 se muestra en las figuras 8 y 9.

La persistencia de bajos niveles de vitamina $\mathrm{D}$ (secundario a hiperfosfatemia persistente) estimula la producción de PTH, que se requiere para mantener la concentración normal de Ca. El estímulo continuo de las células paratiroides conduce al desarrollo de hiperplasia paratiroidea. La hiperplasia es inicialmente difusa pero finalmente se convierte en nodular. Una característica común de las glándulas paratiroides hiperplásicas es la baja densidad de los receptores sensores de calcio (CaSR), vitamina D (RVD), y factor de crecimiento de fibroblastos 23 (FGF-23), lo que las hace menos sensibles a la acción inhibitoria del calcio $(\mathrm{Ca})$, calcitriol $(1,25 \mathrm{D} 3)$ y factor de crecimiento de fibroblastos 23 (FGF23), respectivamente (47)(48).

A continuación, se explicará la contribución específica de cada uno de los principales elementos que modulan el metabolismo mineral y determinan el desarrollo y progresión del HPT2. (Figura 8)

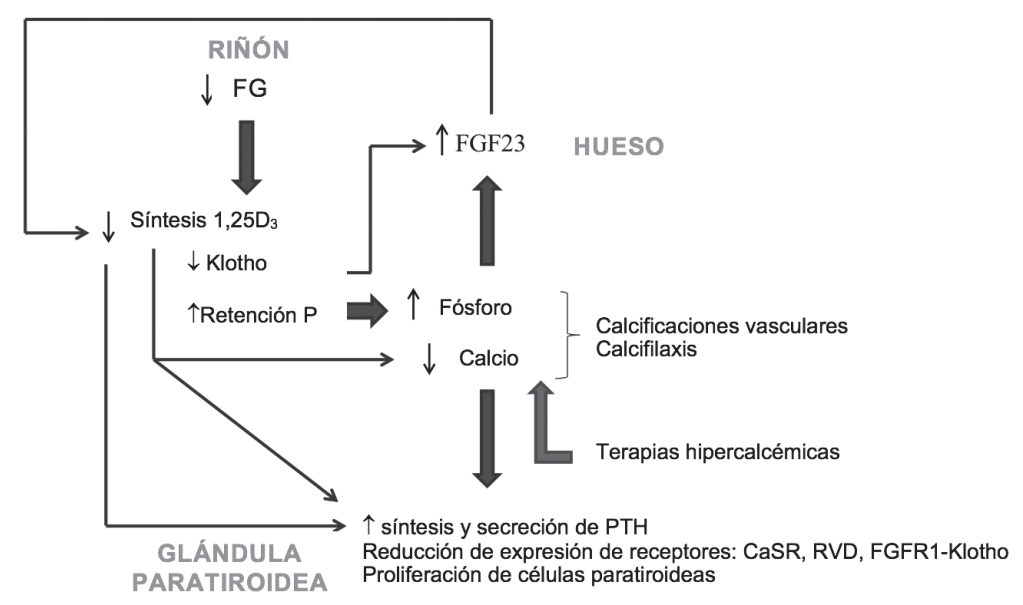

Figura 8. Conjunto de eventos que contribuyen al desarrollo del HPT2.

FG: Filtrado glomerular; FGF-23: factor de crecimiento fibroblastico 23; PTH:

paratohormona; CaSR: receptor calcio sensible; RVD: receptor de vitamina D. 
Calcio. En el HPT2 la hipocalcemia es excepcional ya que la PTH está persistentemente elevada(49). Hay varios factores que tienden a reducir la concentración de Ca plasmático: 1) la reducción de la absorción intestinal de Ca causada por los bajos niveles de 1,25D3, 2) la resistencia ósea a la acción calcémica de la PTH(50), y 3) la precipitación en forma de complejos de fosfato de calcio debido a la alta concentración de fósforo $(\mathrm{P})$ en el plasma. Cuando se establece el hiperparatiroidismo, la expresión del receptor sensible al calcio CaSR paratiroideo se reduce (51) y hay resistencia de las paratiroides al efecto inhibidor del $\mathrm{Ca}$. Por lo tanto, la inhibición de las paratiroides requiere una mayor concentración de Ca plasmático(52). Se han identificado receptores de la vitamina $\mathrm{D}(\mathrm{RVD})$ en promotores del gen del receptor $\mathrm{CaSR}(53)$, lo que traduce que la vitamina $\mathrm{D}$ modula la transcripción del receptor CaSR. Por tanto, la deficiencia de $1,25 \mathrm{D} 3$ causa una reducción en la expresión del receptor CaSR paratiroideo.

Fósforo. A medida que disminuye el filtrado glomerular la retención de fósforo $(\mathrm{P})$ se convierte en un factor clave en el desarrollo y progresión del HPT2. Las concentraciones elevadas de $\mathrm{P}$ en plasma estimulan la síntesis y secreción de PTH(54)(55). Además, el P inhibe la expresión de la 1a-hidroxilasa renal (enzima encargada de hidroxilar la vitamina $\mathrm{D}$ nutricional), contribuyendo a la deficiencia de 1,25D3 en la enfermedad renal(56). Esta reducción de la actividad de la 1 $\alpha$-hidroxilasa renal vinculada al $\mathrm{P}$ alto responde a la elevación en FGF23 producida por la retención de $\mathrm{P}(57)$. Los altos niveles de $\mathrm{P}$ también son responsables de la resistencia ósea a la acción calcémica de la PTH(50). El incremento del P plasmático estimula la proliferación de las células paratiroideas(58). La restricción dietética de $\mathrm{P}$ previene el crecimiento de células paratiroideas(55).

Vitamina D. La forma activa de la vitamina D, (1,25D3), es un regulador negativo de la función paratiroidea, por un efecto directo sobre el receptor de células paratiroideas específicas y por un aumento de la concentración sérica de $\mathrm{Ca}$ que resulta del aumento de su absorción intestinal(48). El calcitriol (1,25D3) ejerce además un efecto antiproliferativo en las células paratiroideas(59), mediado por la regulación del oncogen c-myc(60). Por lo tanto, la reducción de $1,25 \mathrm{D} 3$ asociada a la uremia provoca la estimulación de la proliferación de las células paratiroideas. La contribución de la deficiencia de vitamina $\mathrm{D}$ al desarrollo y progresión del HPT-S no sólo depende de los niveles de 1,25D3 sino también de otros factores que afectan la expresión y funcionalidad del receptor de vitamina D paratiroideo (VDR). Se ha observado una disminución de la expresión del VDR en las glándulas hiperplásicas de los pacientes con ERC, siendo esta expresión aún más baja en la hiperplasia nodular(61). Los bajos niveles de 1,25D3 y la hipocalcemia contribuyen a la pérdida de VDR en las células paratiroideas(62). Además, el medio urémico causa deterioro en la función VDR en las células paratiroideas(48).

Factor de crecimiento fibroblástico-23 (FGF-23). El FGF23 aumenta progresivamente a medida que disminuye la función renal en un intento de aumentar la fosfaturia y compensar la reducción de la filtración glomerular de $\mathrm{P}(63)$. La acción de FGF-23 requiere la expresión óptima de su receptor FGFR1-Klotho. En modelos experimentales de ERC, la activación del FGFR1 es esencial para que se eleve el FGF23(64). El aumento del FGF-23 en la ERC es responsable de la reducción de la síntesis renal de 1,25D3. Por otro lado, la expresión renal de Klotho disminuye en la ERC, lo que altera el efecto fosfatúrico del FGF23(65). En las glándulas paratiroides se observa una resistencia al FGF-23 similar a la que ocurre a nivel renal, lo que perjudica la acción inhibidora del FGF23 sobre la síntesis de PTH y el crecimiento celular, contribuyendo al desarrollo de HPT-S(66).

La secuencia de acontecimientos que conducen al desarrollo de HPT2 ha sido motivo de debate. En la ERC temprana, se producen cambios adaptativos para compensar el aumento de la carga de P. Por lo tanto, la excreción fraccional de $\mathrm{P}$ aumenta como resultado de la producción elevada de FGF-23 y PTH. El FGF-23 aumenta de forma más temprana que la PTH en pacientes con ERC(67). Las reducciones concomitantes de 1,25D3 y Klotho (proteína transmembrana que mejora la afinidad del receptor de FGF-23) también contribuyen a elevar FGF-23 y PTH. Cuando la ERC progresa y la masa renal funcional se reduce, FGF23 y PTH ya no son capaces de mantener el P dentro del rango normal; en consecuencia el nivel sérico de P aumenta, lo que eleva aún más FGF23 y PTH. La deficiencia de vitamina D y la tendencia a la hipocalcemia se exacerban por el efecto inhibidor de FGF-23 sobre la actividad de la 1a-hidroxilasa en los riñones. (figura 8 y figura 9). 


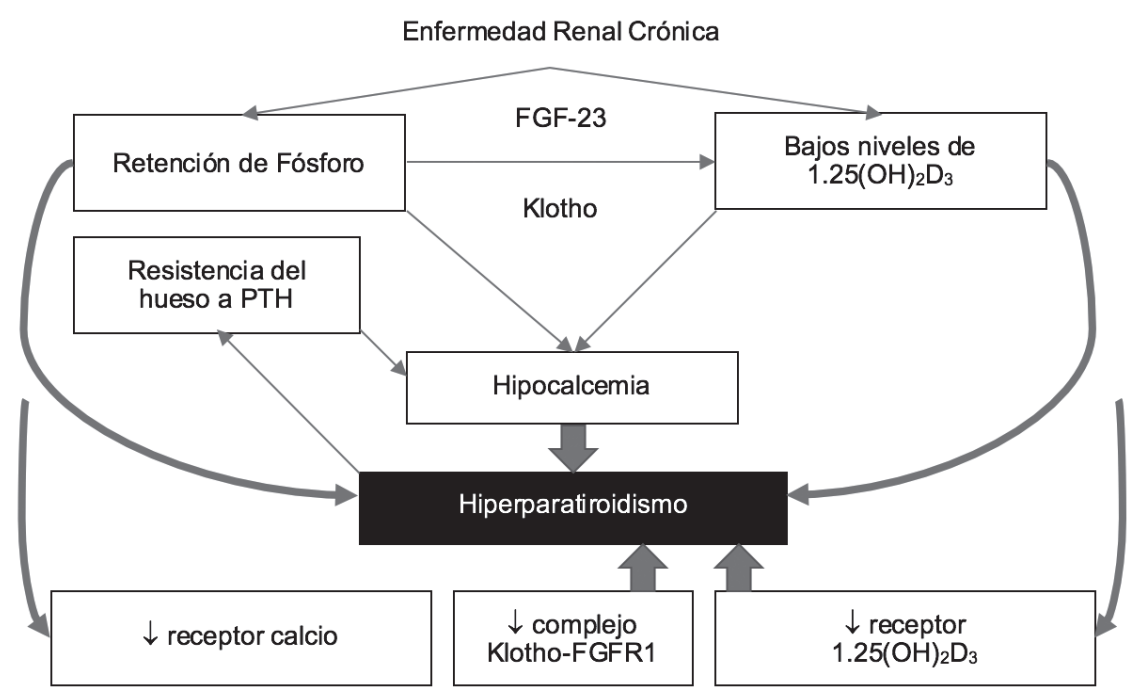

Figura 9. Factores asociados al desarrollo de HPT2 en pacientes con ERC.

La disminución del calcio ionico es crucial en el desarrollo del HPT2.

$\mathrm{E} 1$ calcio ionico disminuye por la retención de fosfatos y niveles bajos de 1,25(OH)2D3

\section{3 - Manifestaciones clínicas del hiperparatiroidismo secundario.}

Esta situación de HPT2 tiende a mantener la calcemia dentro de valores fisiológicos mediante el estímulo de la reabsorción subperióstica de hueso, la producción renal de 1,25 dihidroxicolecalciferol y la reabsorción tubular de calcio. Si bien este mecanismo compensador puede lograr normalizar la calcemia y la fosfatemia temporalmente lo hace a expensas de inducir alteraciones en el recambio óseo(68).

Asimismo ocurre una calcificación inadecuada de los huesos (osteomalacia) que responde al déficit de calcitriol.

Se considera como osteodistrofia renal al conjunto de lesiones histológicas óseas secundarias a las alteraciones del metabolismo mineral y óseo, que incluyen: hiperparatiroidismo secundario, osteomalacia, enfermedad ósea adinámica y enfermedad mixta. Usualmente los síntomas asociados a osteodistrofia se hacen presentes en pacientes bajo tratamiento dialítico. El adecuado control del calcio, fósforo y PTH desde etapas tempranas de la ERC puede prevenir o atenuar el desarrollo de osteodistrofia renal(69).

El hiperparatiroidismo secundario determina un recambio óseo acelerado por aumento del número y actividad de los osteoclastos y osteoblastos e incremento de la resorción ósea. Estos cambios se vinculan a la aparición de lesiones de osteítis fibrosa quística que son típicas en este entorno. Clínicamente se manifiesta como dolor óseo y a nivel de las radiografías se puede visualizar resorción subperióstica la que es más evidente en el borde radial de las falanges medias de los dedos índice y medio, en el extremo distal de las clavículas y en la sínfisis pubiana. En casos graves pueden observarse quistes en los huesos largos o planos y lesiones escleróticas en la parte inferior de las vértebras. En el hueso craneano se pueden observar lesiones en "sal y pimienta" como consecuencia de la combinación de áreas de osteopenia y osteoesclerosis(70)(71).

La osteomalacia es un patrón lesional caracterizado por bajo recambio óseo, disminución en el número de osteoblastos y osteoclastos y aumento en el volumen de osteoide consecuencia de defectos en la mineralización ósea. Clínicamente determina dolor y fracturas óseas. Es consecuencia principalmente del déficit de vitamina D. Era más frecuente cuando se utilizaban quelantes de fosforo con aluminio con la consiguiente acumulación de aluminio a nivel de la matriz ósea(72)(73).

La enfermedad ósea adinámica es otra manifestación del bajo recambio óseo, pero a diferencia de la osteomalacia no se vincula a la acumulación de osteoide. Es la lesión más frecuentemente hallada en estadios tempranos de la ERC. Clínicamente puede manifestarse como hipercalcemia consecuencia de la captación disminuida de calcio en el hueso, asociándose a mayor riesgo de fracturas y calcificación vascular(74). 
Las calcificaciones extraoseas vasculares y no vasculares son otra manifestación clínica de las alteraciones del metabolismo mineral y óseo vinculado a la ERC. Las calcificaciones arteriales suelen detectarse radiológicamente y afectar cualquier eje arterial. Las calcificaciones de las pequeñas arteriolas pueden manifestarse como pequeñas máculas o pápulas de consistencia firme(75)(76). La calcifilaxis (infrecuente pero grave) se caracteriza por calcificación de la capa media de las arterias, isquemia distal y desarrollo progresivo de necrosis y úlceras en la piel de los dedos de pies y manos, muslos, piernas y tobillos. Se vincula usualmente a etapas avanzadas de ERC, generalmente en pacientes bajo tratamiento sustitutivo(77)(78).

\section{4 • Frecuencia de Hiperparatiroidismo Secundario en Enfermedad Renal Crónica.}

Un subanálisis que incluyó a 7 países (Francia, Alemania, Italia, Japón, España, Reino Unido y Estados Unidos) del total de participantes del estudio Dialysis Outcomes and Practice Patterns Study (DOPPS)(43), describe la asociación entre las alteraciones del metabolismo mineral y óseo y la mortalidad en pacientes en hemodiálisis. Se seleccionó una muestra aleatoria de pacientes de cada establecimiento al inicio del estudio, representando una sección transversal prevalente $(\mathrm{N}=8615)$. Se utilizó la muestra completa de 17.236 pacientes para realizar el modelo estadístico. Se evaluó la prevalencia de alteraciones de laboratorio, destacando que $51,6 \%(\mathrm{~N}=8265)$ se encontraban con valores de fosforo plasmático por encima del recomendado $(3.5-5.5 \mathrm{mg} / \mathrm{dL}), 50,2 \%(\mathrm{~N}=6898)$ con valores de calcemia por encima del recomendado $(8.4-9.6 \mathrm{mg} / \mathrm{dL})$ y $26,7 \%(\mathrm{~N}=5240)$ con valores de PTH por encima de lo recomendado $(150-300$ $\mathrm{pg} / \mathrm{mL})$. La prevalencia de paratiroidectomía en cada centro fue: Francia $(\mathrm{N}=981) 14 \%$, Alemania $(\mathrm{N}=908) 6 \%$, Italia $(\mathrm{N}=869) 5 \%$, Japón $(\mathrm{N}=2784) 4.1 \%$, España $(\mathrm{N}=936) 5.7 \%$, Reino Unido $(\mathrm{N}=897) 9.2 \%$, Estados Unidos $(\mathrm{N}=$ 9861) 4\%. Durante el seguimiento de la cohorte la necesidad de paratiroidectomía tuvo una incidencia/100 pacientes años de 1.8 en Francia, 1 en Alemania, 0.9 en Italia, 0.6 en Japón, 1.5 en España, 1.5 en Reino Unido y 0,5 en Estados Unidos.(79)

Un reciente estudio realizado en China(80), dirigido a evaluar la epidemiología de las alteraciones del metabolismo mineral y óseo en individuos incidentes en hemodiálisis, evaluó una población de 3725 pacientes. Objetivó la presencia de hipocalcemia en 34,3\%, hiperfosfatemia en 50\% y PTH intacta superior a $300 \mathrm{pg} / \mathrm{mL}$ en 50\%(80). En otro estudio en el que se evaluó la alteración de parámetros bioquímicos, enfermedad ósea y calcificaciones vasculares en 2238 pacientes con ERC no dialítica, se encontró datos consistentes con hiperparatiroidismo en $8.9 \%$ de pacientes con ERC estadio $1,13 \%$ en estadio $2,22.4 \%$ en estadio 3a, 33.3\% en estadio 3b, $72.2 \%$ en estadio 4 y $87.8 \%$ en estadio 5(81).

En Uruguay no tenemos datos directos de prevalencia e incidencia de hiperparatiroidismo en pacientes con ERC. Contamos con datos provenientes del Registro Uruguayo de Diálisis que en el informe del ejercicio 2015 registró que $66 \%$ de pacientes presentaban alguna alteración del metabolismo mineral y óseo(44). En un estudio descriptivo que incluyó 8732 pacientes con ERC no dialítica, registrados en el Programa de Salud Renal de Uruguay entre octubre de 2004 y octubre de 2011, se valoró las alteraciones del metabolismo mineral y óseo y su relación con el desarrollo de eventos cardiovasculares y mortalidad. Tenian hiperfosfatemia $(>4.6 \mathrm{mg} / \mathrm{dL}) 11,9 \%$ de pacientes con ERC en estadios 1 y $2,9,6 \%$ en estadio $3 a, 10.4 \%$ en estadio 3 b, $18.3 \%$ en estadio 4 y $33.7 \%$ en estadio $5(81)$. 


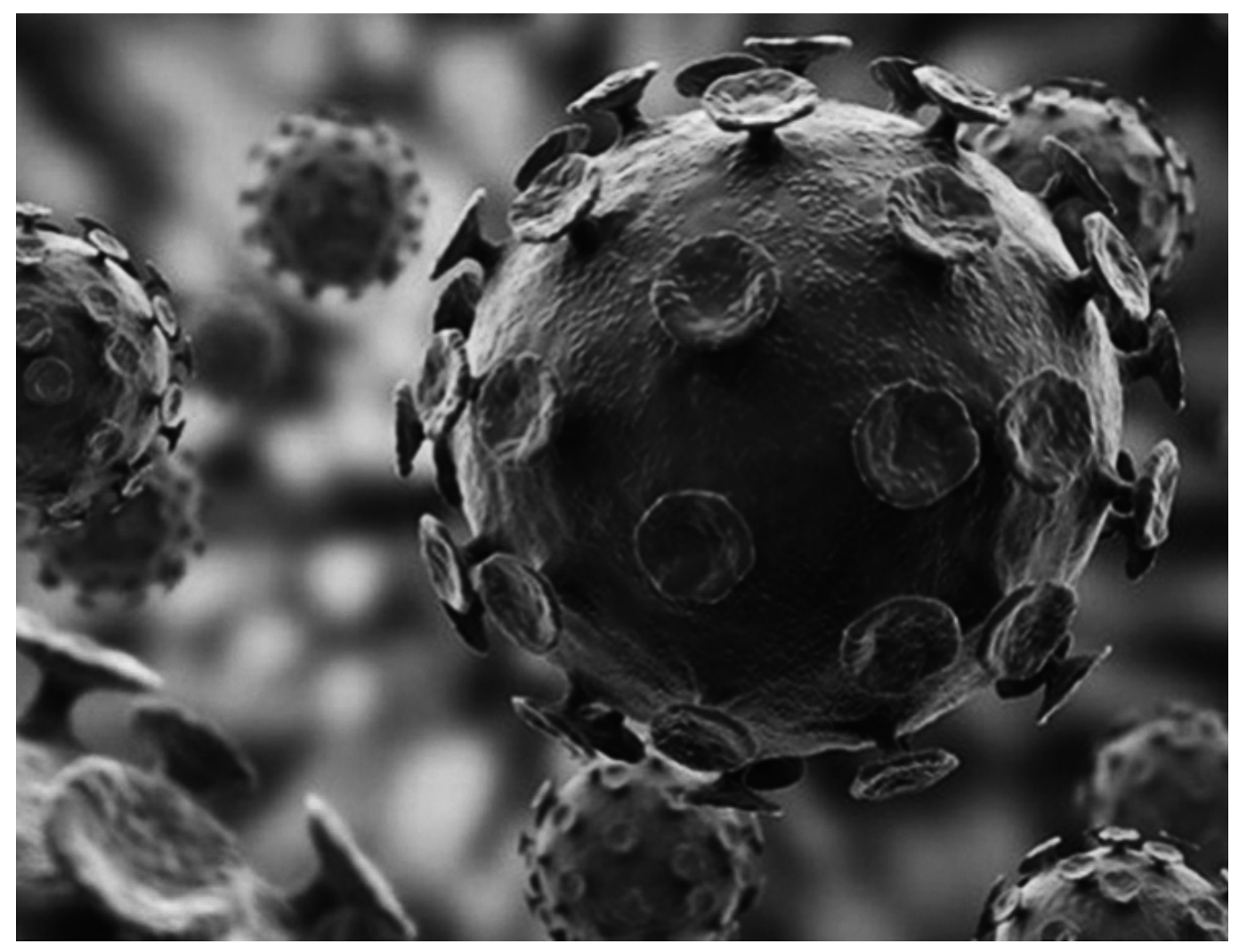

\section{TRATAMIENTO MÉDICO DEL HIPERPARATIROIDISMO SECUNDARIO}

Dr. Ricardo Silvariño

- Control de los niveles de Fósforo y Calcio

- Control de los niveles de PTHi

- Indicación de Tratamiento Quirúrgico 


\section{7 • TRATAMIENTO MÉDICO DEL HIPERPARATIROIDISMO SECUNDARIO EN PACIENTES CON ERC}

En los últimos años, la investigación clínica ha demostrado que, junto con la regulación de la PTH, el control de la homeostasis mineral (calcio, fósforo) puede reducir la morbilidad y la mortalidad en pacientes con HPT2.

\section{1 • Tratamiento dirigido a controlar los niveles de fósforo y calcio.}

El punto de inflexión, o rango en el que la concentración de fósforo se asocia de manera significativa con una elevada mortalidad por todas las causas, varía entre los diferentes estudios: 5,0-5,5 mg/dl (1,6-1,8 mmol/1), > 5,5 mg/dl (> 1,8 $\mathrm{mmol} / \mathrm{l})$ 6,0-7,0 mg/dl (1,9-2,3 mmol/1) y > 6,5 mg/dl (> 2,1 mmol/1)(82)(83)(84)(85). El estudio DOPPS mostró que la relación entre la elevación del fósforo sérico y el riesgo relativo de mortalidad es consistente en todos los países analizados(82). En base a estos datos se recomienda mantener valores de fósforo plasmático dentro de niveles normales en todas las etapas de la ERC. En una revisión sistemática de los estudios aleatorizados controlados que examinan quelantes de fosfato(83), se mostró que todas las medicaciones actualmente en uso como quelantes de fosfatos (sales de calcio, sales de aluminio, sevelamer y carbonato de lantano) son efectivas para reducir las concentraciones de fósforo sérico. En 3 ensayos clínicos aleatorizados, uno de ellos en pacientes con ERC 3-5 y dos en pacientes con ERC estadio $5 \mathrm{D}(86)(87)(88)$, se encontró que el sevelamer puede atenuar la progresión de la calcificación arterial en comparación con los quelantes a base de calcio. Sin embargo, dicho efecto no fue observado en ensayos clínicos más recientes que compararon el sevelamer con acetato de calcio(89)(90). Aun así, y dado el elevado riesgo cardiovascular de estos pacientes, se sugiere limitar la dosis de quelantes que contienen calcio en los sujetos con evidencia de calcificación vascular, así como en aquellos que presentan PTH persistentemente disminuida o enfermedad ósea adinámica, ya que esto parece favorecer la progresión de la calcificación vascular. En la tabla 1 se esquematizan las diferentes opciones de tratamiento quelante de fosforo.

Tabla 1. Comparación de diferentes quelantes de fósforo.

\begin{tabular}{|c|c|c|c|c|}
\hline \multicolumn{5}{|c|}{$\begin{array}{l}\begin{array}{l}\text { Modificado de Bellorin-Font E. Guías de práctica clínica para la prevención, diagnóstico, evaluación y tratamiento de los trasto rnos minerales yóseos en la enfermedad renal crónica (TM O-ERC) en } \\
\text { adultos. Nefrologia 2013;33(Suppl.1):128 }\end{array} \\
\end{array}$} \\
\hline Quelante & Presentación & Contenido mineral & Efectividad y ventajas potenciales & Desventajas \\
\hline $\begin{array}{l}\text { Carbonato de } \\
\text { aluminio }\end{array}$ & Cápsulas & Aluminio & Alta capacidad quelante de fósforo & $\begin{array}{l}\text { Potencialmente tóxico: trastornos óseos (enfermedad } \\
\text { adinámica, osteomalacia), anemia microcítica, demencia, } \\
\text { efectos gastrointestinales }\end{array}$ \\
\hline $\begin{array}{l}\text { Hidróxido de } \\
\text { aluminio }\end{array}$ & \begin{tabular}{|l|} 
Suspensión \\
Tabletas \\
Cápsulas \\
\end{tabular} & 100 a $200 \mathrm{mg}$ por tableta & Muy efectivo como quelante de fósforo & $\begin{array}{l}\text { Potencialmente tóxico: trastornos óseos (enfermedad } \\
\text { adinámica, osteomalacia), anemia microcítica, demencia, } \\
\text { efectos gastrointestinales }\end{array}$ \\
\hline $\begin{array}{l}\text { Acetato de } \\
\text { calcio }\end{array}$ & $\begin{array}{l}\text { Cápsulas } \\
\text { Tabletas }\end{array}$ & $\begin{array}{l}25 \% \text { de calcio elemental }(169 \\
\mathrm{mg} \text { de calcio por tableta de } 667 \\
\mathrm{mg})\end{array}$ & $\begin{array}{l}\text { Efectivo como quelante de fósforo. Mayor } \\
\text { capacidad quelante y menor absorción } \\
\text { intestinal que el carbonato de calcio }\end{array}$ & $\begin{array}{l}\text { Causa potencial de hipercalcemia, riesgo de calcificaciones } \\
\text { extraóseas y supresión de PTH, efectos adversos } \\
\text { gastrointestinales. Mayor costo que el carbonato de calcio }\end{array}$ \\
\hline $\begin{array}{l}\text { Carbonato de } \\
\text { calcio }\end{array}$ & $\begin{array}{l}\text { Suspensión } \\
\text { Tabletas } \\
\text { Cápsulas } \\
\text { masticables } \\
\end{array}$ & $\begin{array}{l}40 \% \text { de calcio elemental }(200 \\
\mathrm{mg} \text { de calcio elemental por } \\
\text { tableta de } 500 \mathrm{mg})\end{array}$ & $\begin{array}{l}\text { Efectivo como quelante } \\
\text { Bajo costo } \\
\text { Disponible fácilmente }\end{array}$ & $\begin{array}{l}\text { Causa potencial de hipercalcemia, riesgo de calcificaciones } \\
\text { extraóseas y supresión de PTH, efectos adversos } \\
\text { gastrointestinales }\end{array}$ \\
\hline $\begin{array}{l}\text { Citrato de } \\
\text { calcio }\end{array}$ & \begin{tabular}{|l|} 
Suspensión \\
Tabletas
\end{tabular} & $22 \%$ de calcio elemental & No recomendable en ERC & Aumenta la absorción intestinal de aluminio \\
\hline $\begin{array}{l}\text { Carbonato de } \\
\text { calcio/magnesio }\end{array}$ & Tabletas & $\begin{array}{l}28 \% \text { de magnesio elemental }(85 \\
\mathrm{mg} \text { de magnesio) y } 25 \% \mathrm{de} \\
\text { calcio elemental }(100 \mathrm{mg} \text { de } \\
\text { calcio) }\end{array}$ & $\begin{array}{l}\text { Efectivo como quelante de fósforo. } \\
\text { Potencialmente menor carga de calcio que las } \\
\text { sales de calcio puras }\end{array}$ & $\begin{array}{l}\text { Efectos adversos gastrointestinales, potencialmente } \\
\text { inductor de hipermagnesemia }\end{array}$ \\
\hline $\begin{array}{l}\text { Hidrocloruro de } \\
\text { sevelamer }\end{array}$ & $\begin{array}{l}\text { Tabletas } \\
\text { Cápsulas }\end{array}$ & No contiene & $\begin{array}{l}\text { Efectivo como quelante de fósforo. No } \\
\text { contiene calcio elemental. No absorbible. } \\
\text { Disminuye LDL en plasma. Puede inducir } \\
\text { acidosis }\end{array}$ & $\begin{array}{l}\text { Alto costo. Puede disminuir niveles de bicarbonato. Puede } \\
\text { requerir suplementos de calcio cuando hay hipocalcemia. } \\
\text { Efectos adversos gastrointestinales }\end{array}$ \\
\hline $\begin{array}{l}\text { Carbonato de } \\
\text { sevelamer }\end{array}$ & $\begin{array}{l}\text { Tabletas } \\
\text { Polvo }\end{array}$ & No contiene & $\begin{array}{l}\text { Similar al hidrocloruro de sevelamer. } \\
\text { Potencialmente mejora el equilibrio acido-base } \\
\text { comparado con hidrocloruro de sevelamer }\end{array}$ & $\begin{array}{l}\text { Alto costo. Puede requerir suplementos de calcio cuando } \\
\text { hay hipocalcemia. Efectos adversos gastrointestinales }\end{array}$ \\
\hline $\begin{array}{l}\text { Crabonato de } \\
\text { lantano }\end{array}$ & $\begin{array}{l}\text { Tabletas } \\
\text { masticables }\end{array}$ & $\begin{array}{l}\text { Contiene } 250 \text { o } 500 \mathrm{mg} \text { de } \\
\text { lantano elemental por tableta }\end{array}$ & Efectivo como quelante de fósforo & $\begin{array}{l}\text { Alto costo. Riesgo potencial de acumulación de lantano } \\
\text { por su absorción intestinal. Efectos adversos } \\
\text { gastrointestinales. }\end{array}$ \\
\hline
\end{tabular}




\section{2 • Tratamiento dirigido a reducir los niveles anormales de PTHi.}

Las opciones terapéuticas para disminuir los niveles de PTHi incluyen esteroles de la vitamina D (ergocalciferol, colecalciferol y calcitriol), análogos de la vitamina D activa, derivados sintéticos de la vitamina D2 (paricalcitol y doxercalciferol), derivados sintéticos de la vitamina D3 (alfacalcidiol) y calcimiméticos (cinecalcet)(91).

Vitamina D. Las formas terapéuticas de esteroles de vitamina D incluyen: ergocalciferol, colecalciferol y calcitriol. También se cuenta con análogos de vitamina D activa, derivados sintéticos de vitamina D2 (paricalcitol y doxercalciferol) y de vitamina D3 (alfacalcidol). El doxercalciferol y alfacalcidol requieren de la 25-hidroxilación a nivel hepático para convertirse en análogos activos. La vitamina $\mathrm{D}$ y sus análogos han sido empleados en sujetos con ERC 3-5D con el propósito de mejorar las anomalías en la homeostasis mineral y reducir el desarrollo o progresión del hiperparatiroidismo secundario(91).

\begin{tabular}{|c|}
\hline Modificado de (55)(57) \\
\hline Tratamiento dirigido a controlar concentraciones séricas de fósforo y calcio \\
\hline $\begin{array}{l}\text { - En los pacientes con ERC 3a-5D, los tratamientos de las alteraciones del metabolismo mineral y óseo deben basarse en evaluaciones seriadas de los niveles de fosforo, } \\
\text { calcio y PTH séricos, considerados en conjunto (Sin grado) }{ }^{(\mathrm{KDIGO})} \text {. }\end{array}$ \\
\hline - En pacientes con ERC 3a-5D, se sugiere reducir los niveles elevados de fosforo sérico hasta el rango normal (2C) ${ }^{(\mathrm{KDIGO})}$. \\
\hline - En pacientes adultos con ERC 3a-5D, sugerimos evitar la hipercalcemia (2C) ${ }^{(\mathrm{KDIGO})}$. \\
\hline $\begin{array}{l}\text { - Los quelantes de fósforo que contienen calcio son efectivos para disminuir las concentraciones séricas de fósforo. Sin embargo, su uso puede asociarse con hipercalcemia } \\
\text { y con may or incidencia de calcificación vascular }(2 \mathrm{C})^{(\mathrm{SLANH})} \text {. }\end{array}$ \\
\hline - En pacientes adultos con ERC 3a-5D que reciben tratamiento para reducir el fósforo, se sugiere restringir la dosis de quelantes de fosfato basados en calcio (2B) ${ }^{(\mathrm{KDIGO})}$. \\
\hline $\begin{array}{l}\text { - Se recomienda restringir la dosis de quelantes de fósforo que contienen calcio hasta un máximo de } 1.500 \mathrm{mg} \text { de calcio elemental/día }(1 \mathrm{~B}){ }^{(\mathrm{SLANH})} \cdot \text { También se recomienda } \\
\text { restringir o evitar el uso de quelantes de fósforo con calcio en presencia de hipercalcemia, calcificaciones vasculares, enfermedad ósea adinámica o niveles persistentemente } \\
\text { bajos de PTHi }(2 \mathrm{C})^{(\mathrm{KDIGO})} \text {. }\end{array}$ \\
\hline - Los quelantes de fósforo que contienen aluminio no deberían usarse $(1 \mathrm{C})^{(\mathrm{SLANH})}$ \\
\hline $\begin{array}{l}\text { - En pacientes con ERC 3-5 con fósforo sérico normal o elevado, sugerimos no exceder la ingesta de fósforo en la dieta de } 800-1.000 \mathrm{mg} / \mathrm{día} \text {, de forma aislada o en } \\
\text { combinación con otros tratamientos (2D) }{ }^{(\mathrm{SLANH})} \text {. }\end{array}$ \\
\hline Tratamiento dirigido a controlar concentraciones séricas anormales de PTHi \\
\hline $\begin{array}{l}\text { - Se desconoce el nivel óptimo de PTHi en pacientes con ERC 3-5. No obstante, sugerimos que aquellos pacientes con niveles de PTHi por encima de lo normal sean } \\
\text { evaluados para determinar la presencia de hiperfosfatemia, hipocalcemia y valores bajos (deficiencia) de } 25(\mathrm{OH}) \mathrm{D}(2 \mathrm{C}){ }^{(\mathrm{KDIGO})} \text {. Si están presentes, es razonable corregir } \\
\text { estas anormalidades con una dieta baja en fósforo, quelantes de fósforo, suplementos de calcio y/o vitamina D (sin grado) }{ }^{(\mathrm{SLANH})} \text {. }\end{array}$ \\
\hline - En pacientes adultos con ERC 3a-5 (no diálisis), se sugiere no utilizar de rutina análogos de calcitriol y vitamina D (2C) ${ }^{(\mathrm{KDIGO})}$ \\
\hline - Es razonable reservar el uso de análogos de calcitriol y vitamina D para pacientes con ERC 4-5 con hiperparatiroidismo severo y progresivo (Sin grado) ${ }^{(\mathrm{KDIGO})}$. \\
\hline - En pacientes con ERC 5D, sugerimos mantener los niveles de PTHi en un rango aproximado de entre 2 y 9 veces el límite superior normal (sin grado) ${ }^{(\mathrm{KDIGO})}$. \\
\hline $\begin{array}{l}\text { - En pacientes con ERC 5D que presenten cambios importantes en los niveles de PTHi en ambas direcciones (superior e inferior) dentro del rango sugerido ( } 2 \text { a } 9 \text { veces el } \\
\text { límite superior normal), se sugiere el inicio o un cambio en la terapia para evitar la progresión de las alteraciones hacia niveles fuera de este rango (2C) }{ }^{(\mathrm{KDIGO})} \text {. }\end{array}$ \\
\hline $\begin{array}{l}\text { - En aquellos pacientes con ERC 5D que presenten una elevación o un incremento progresivo de la PTHi sérica, sugerimos iniciar el uso de calcitriol, análogos de vitamina } \\
\text { D, calcimiméticos o la combinación de estos dos grupos de agentes con el fin de reducir los niveles de PTHi }(2 \mathrm{~B}){ }^{(\mathrm{KDIGO})} \text {. }\end{array}$ \\
\hline $\begin{array}{l}\text { O Es razonable que la selección inicial del fármaco para el control de la PTHi elevada esté basada en las concentraciones séricas de calcio y fósforo, así como otros } \\
\text { aspectos de la TMO-ERC ( } \sin \text { grado) }{ }^{(\mathrm{KDIGO})} \text {. }\end{array}$ \\
\hline $\begin{array}{l}\text { Es razonable que las dosis de los quelantes de fósforo, cálcicos y no cálcicos, sean ajustadas de manera que no comprometan las concentraciones séricas normales de } \\
\text { fósforo y calcio (sin grado) }{ }^{(\mathrm{KDIGO})} \text {. }\end{array}$ \\
\hline $\begin{array}{l}\text { - Se recomienda que, en aquellos pacientes con hipercalcemia }(1 \mathrm{~B})^{(\mathrm{KDIGO})} \text { o hiperfosfatemia }(2 \mathrm{D}){ }^{(\mathrm{KDIGO})} \text {, el uso de calcitriol y/o análogos de vitamina } \mathrm{D} \text { sea reducido } \\
\text { u omitido. }\end{array}$ \\
\hline $\begin{array}{l}\text { - Se sugiere que, en pacientes con hipocalcemia, el uso de calcimiméticos sea reducido u omitido, dependiendo de su severidad, de la medicación concomitante y de la } \\
\text { presencia de síntomas y signos clínicos (2D) }{ }^{(\mathrm{KDIGO})} \text {. }\end{array}$ \\
\hline $\begin{array}{l}\text { - Se sugiere que, si los niveles de PTHi disminuyen por debajo de } 2 \text { veces el límite superior normal, el uso de calcitriol, análogos de vitamina D y/o calcimiméticos sea } \\
\text { reducido u omitido }(2 \mathrm{C})^{(\mathrm{KDIGO})} \text {. }\end{array}$ \\
\hline - En pacientes con ERC 3-5D e hiperparatiroidismo severo que no responda al tratamiento médico/farmacológico, se sugiere considerar la paratiroidectomía (2B) ${ }^{(\mathrm{KDIGO})}$. \\
\hline
\end{tabular}


Calcimiméticos. Actúan como moduladores alostéricos del receptor de calcio, incrementado la sensibilidad del receptor de calcio en la célula paratiroidea al calcio extracelular. La administración de calcimiméticos disminuye la síntesis y secreción de la PTH, reduce la proliferación de las células de la glándula paratiroidea, modula la regulación de genes involucrados en sobreexpresión de los receptores de calcio y del receptor de vitamina D. Sin embargo, se requieren estudios adicionales sobre el impacto del uso de los calcimiméticos en la morbimortalidad en pacientes con ERC(91). En la tabla 2 se recogen las recomendaciones de tratamiento farmacológico de la hiperfosfatemia y del hiperparatiroidismo secundario en pacientes con ERC

\subsection{Indicación quirúrgica en el Hiperparatiroidismo secundario en pacientes con ERC.}

La paratiroidectomía mejora drásticamente el HPT2, aumentando las tasas de supervivencia y la calidad de vida del paciente en candidatos adecuados(92). Debido a la falta de estudios controlados y al azar que permitan una adecuada comparación entre la terapia médica vs la quirúrgica del hiperparatiroidismo secundario, estas estrategias de manejo son difíciles de comparar, y asu vez, es difícil definir la mejor opción terapéutica. En pacientes aptos para cirugía, generalmente se plantea una paratiroidectomía cuando el hiperparatiroidismo es grave y refractario al control por fármacos, usualmente después de un ensayo terapéutico con calcitriol, un análogo de la vitamina $\mathrm{D}$ o cinacalcet(91). La paratiroidectomía también puede plantearse cuando el control médico para reducir los niveles de PTHi trae como resultado aumento inaceptable de los niveles séricos de calcio y/o de fósforo (como ocurre con frecuencia cuando se usa calcitriol o análogos de la vitamina D) o cuando no hay tolerancia debido a los efectos adversos(91). Mientras más elevada sea la PTH, es menos probable que la glándula involucione en respuesta a la terapia médica (92)(93). 


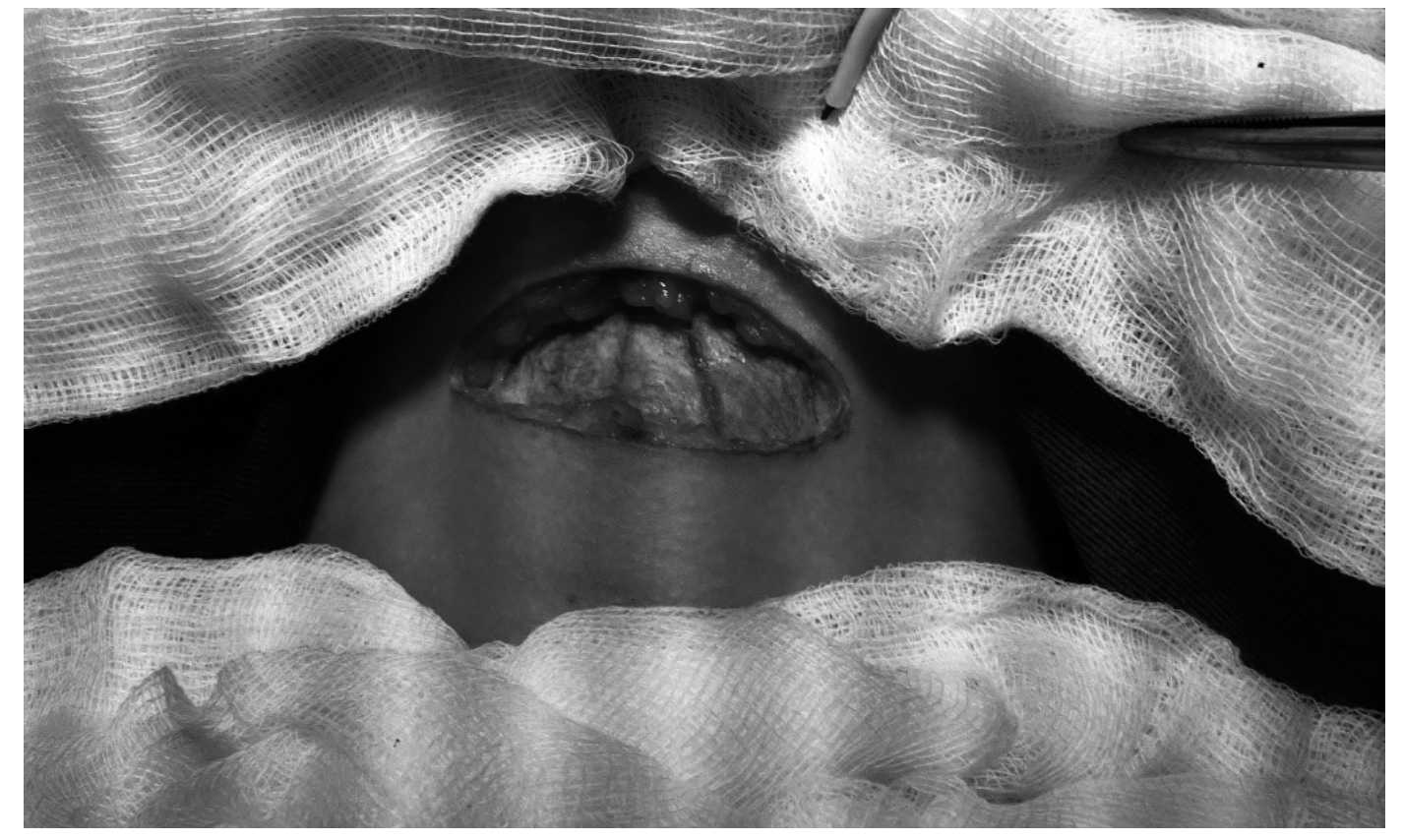

\section{ESTADO ACTUAL DEL TRATAMIENTO QUIRURGICO DEL HIPERPARATIROIDISMO SECUNDARIO}

- Paratiroidectomia Subtotal vs Total, con o sin autotrasplante

- Elección de la Táctica Quirúrgica

- Criopreservación

- Dosificación de PTH intraoperatoria

- Resección del Timo

- Nervio Laríngeo Recurrente 


\section{ESTADO ACTUAL DEL TRATAMIENTO QUIRÚRGICO DEL HIPERPARATIROIDISMO SECUNDARIO}

Existen algunos puntos en el tratamiento del HPT2 que aún hoy, siguen siendo controversiales. En estos puntos, la evidencia actual no nos permite optar por un único camino, sino que debemos conocer la variantes posibles, la diferentes opciones terapéuticas, y elegir en cada caso, el mejor tratamiento.

\subsection{Paratiroidectomía Subtotal vs Total con/sin autotrasplante}

A partir del primer tratamiento quirúrgico para el HPT2 realizado por Stanbury en 1960 (19), múltiples variantes tácticas y técnicas han sido intentadas. Hoy en día, podemos analizar y agrupar esas diferentes técnicas en 3 opciones principales:

1 - Paratiroidectomía Subtotal

2 - Paratiroidectomía Total con autotransplante

3 - Paratiroidectomía Total sin autotransplante

\section{1 - Paratiroidectomia Subtotal}

La Paraitiroidectomía subtotal (PST) implica la resección de gran parte del tejido paratirodeo, $7 / 8$ o 75\% del total según diferentes autores, dejando fragmentos de 40 a $80 \mathrm{mg}$, macroscópicamente sanos y bien vascularizados. Este remanente debe ser marcado con clips metálicos o con sutura irreabsorbible. Se recomienda, de ser posible, que el remanente sea de una glándula inferior, ya que habitualmente están situadas mas anteriormente en el cuello, y por tanto haciéndolo más accesible en el casos de requerir una re intervención por recurrencia o persistencia. La resección del Timo, para algunos autores, es un parte fundamental de esta técnica en el esfuerzo de resecar cualquier glándula supernumeraria que pudiera existir. Existe controversia en este punto, y esta resección no es realizada por todos los autores que realizan la PST.

\section{2 - Paratiroidectomia Total con autotransplante}

La Paratiroidectomía Total con autotransplante (PT+AT) implica la cuidadosa disección, identificación y resección de las 4 glándulas. También se discute aquí la necesidad de asociar un timectomía, siendo realizada por algunos autores y descartada por otros. Para el autotransplante se debe utilizar la glándula más sana macroscópicamente. Debe ser cortada en 10 a 20 fragmentos de $1 \mathrm{~mm}$ cubico aproximado para su reimplante, luego de confirmada su naturaleza por el patólogo (94)(95). Los sitios potenciales para reimplante son 3, el musculo esternocleidomastoideo, músculos braquiales del antebrazo del miembro superior no dominante y la grasa subcutánea de la pared anterior del abdomen. La utilización del miembro superior para el implante, ha sido progresivamente dejada de lado ya que son pacientes habitualmente sometidos a hemodiálisis y en los que preservar los miembros superiores para la confección de fistulas arteriovenosas es un elemento clave. Sin importar el lugar que se elija para el reimplante, este debe ser marcado con clip metálicos o sutura irreabsorbible, con el objetivo de lograr identificarlos en caso de requerir una re intervención por un nuevo HPT2, consecuente a la hipertrofia del implante.

\section{3 - Paratiroidectomía Total sin autotransplante}

En el año 1967(96) se describió la Paratiroidectomía total sin autotransplante (PT) como una nueva opción. Esta es una alternativa a los procedimientos anteriormente descritos y más ampliamente difundidos. En este procedimiento, las cuatro glándulas deben ser resecadas. Este planteo táctica surge del hecho de que es frecuente que existen residuos microscópicos de tejido paratiroideo suficientes para cumplir su función, y al mismo tiempo, no demasiados grandes como para condicionar una recidiva o persistencia. De esta manera se evita la subjetividad al definir el volumen del remanente en PST o del implante en la PT+AT.

\section{2 • Elección de la Táctica Quirúrgica}

No existe, a la fecha, ningún trabajo o revisión que sea suficiente para recomendar uno u otro procedimiento y los trabajos que existen son de series pequeñas o con algún defecto metodológico. Sin embargo, hay algunos elementos que empiezan a definirse y tendencias que parecen instalares. Así podemos mencionar 3 puntos que parecen definirse en los últimos años y que impresiona ser el camino que la cirugía del HPT2 debe seguir. 
En primer lugar, sin importar que procedimiento se haga, al momento de realizar un PST o PT+AT, parece clave que el remanente o el implante sea pequeño, dentro de la subjetividad implicada en esta decisión (97). Es probable que nuestro remanente o implante ya tenga una hiperplasia, por tanto el volumen dejado definirá la evolución del paciente.

En segundo lugar, es claro que la cuidadosa y detallada exploración cervical debe ser parte del procedimiento, independientemente de la técnica utilizada. La resección tímica de rutina debe ser analizada ya que la evidencia más reciente lo implica como un hecho importante al determinar el éxito o fracaso de esta cirugía (98)(99).

En tercer lugar, debemos tener en cuenta que los dos procedimientos más extendidos en el mundo (PST o PT+AT), tienen, hasta la fecha, resultados comparables. A la hora de optar por uno u otro, más allá de la experiencia del cirujano y de lo que el cirujano este habituado a hacer, el pronóstico de ese paciente en cuanto a tiempo de hemodiálisis y posibilidad de trasplante renal debe ser determinante en esa decisión.

Así en pacientes en oportunidad de trasplante y con trasplante "probable", la técnica de elección debería ser la PST. E1 fundamento de esta elección es que el remanente a dejar no va a tener tiempo de ir a la hiperplasia o hipertrofia ya que a corto plazo cesará el estímulo para ello y por tanto el riesgo de hipoparatiroidismo será real si la resección fue excesiva. Por otro lado, en pacientes fuera de posibilidad de trasplante y con largo tiempo de hemodiálisis por delante, la técnica de elección debería ser una más radical en cuanto a la cantidad de tejido paratiroideo a resecar y a dejar como implante. En estos pacientes, el estimulo para la hipertrofia e hiperplasia del implante persistirá por mucho tiempo, por tanto la recurrencia es más factible. En estos pacientes se propone la PT+AT, o incluso la PT sin autotrasplante como la técnica de elección. (97)(98)(99)(100)(101)(102).

Ajustar la táctica quirúrgica al pronóstico de cada paciente parecería ser lo más sensato. Pero la elección de la técnica, para un mismo paciente, siempre ha sido tema de controversia. Es decir, cuál de los procedimientos tiene mejor resultado en un paciente con la misma expectativa de trasplante y tiempo de hemodiálisis. Aquí ya hay más variables en juego, y la experiencia personal de cada cirujano, es lo que en general, decide la táctica. Múltiples trabajos con variado diseño han intentado definir la mejor táctica para un mismo paciente. Así, contamos con un estudio prospectivo randomizado, publicado por Rothmund en 1991, que comparo PST vs PT+AT en 40 pacientes.(100). Este trabajo arroja como conclusión principal, mejores resultados para la $\mathrm{PT}+\mathrm{AT}$ en cuanto a recurrencia, normalización del calcio y remisión de síntomas como prurito y debilidad muscular. Si bien las conclusiones son claras y destacan la PT+AT como el mejor procedimiento, el diseño metodológico y el bajo número de pacientes incluidos no permitió en ese momento, establecer esto como un hecho y por tanto recomendarlo como la mejor opción terapéutica. Trabajos más recientes parecen apoyar estos resultados, si bien siguen siendo series chicas de pacientes a veces no comparables, ya que son, por ejemplo, diferentes tiempo de seguimiento, con o sin resección tímica, etc.

Una reciente revisión retrospectiva, del año 2015, de 53 publicaciones (501 pacientes) de reintervenciones por HPT2 recurrente o persistente, arrojo que $1 / 3$ (36\%) de esos pacientes habían recibido como tratamiento inicial una PST, mientras que 2/3 (64\%) una PT+AT, por tanto el fracaso de la PT+AT duplico al fracaso en los que se optó por PST (101). Ambos procedimientos tienen también otros pros y contras demostrados. Por ejemplo, está claramente establecido que los pacientes sometidos a una PST tiene menos requerimiento de calcio intravenoso y vía oral en el postoperatorio inmediato, comparándolos con los que se les realizo PT+AT. Este se debe a que el implante no comienza a funcionar inmediatamente. Esta revisión retrospectiva, si bien incluye un buen número de pacientes, falla en el hecho de que los procedimientos fueron realizados por equipos diferentes, con diferentes estándares de calidad y con diferentes capacidad y experiencia técnica. Por tanto, si bien los números son claros, no se puede concluir que la PST tiene la mitad de fracasos que la PT+AT. A su vez, estos trabajos abrieron otra discusión en cuanto a la calidad de la cirugía. Así algunos autores promulgan que el principal determinante de la recidiva o recurrencia es la calidad de la cirugía inicial, y no la táctica aplicada. (99)(100)(101)(102)

Los autores que defienden la PT+AT, sostienen que la gran ventaja de este procedimiento es que se evita la morbilidad de una re intervención de cuello ante a una persistencia o recurrencia. Además de que la recurrencia es muy factible en los que persisten en su insuficiencia renal y diálisis por mucho tiempo. En esos casos solo se aborda el sitio de implante marcado con clips metálicos o hilos irreabsorbibles.

Hasta la fecha, existe una sola publicación que comprara las 3 principales opciones tácticas: PST, PT+AT y PT (103) (104). Se trata de un trabajo retrospectivo del año 2012, en el que analiza a 606 pacientes portadores de un HPT2 con indicación formal de tratamiento quirúrgico y sometidos a estricto seguimiento durante 57 meses. Analiza dos variables, persistencia y recurrencia, para definir el éxito o fracaso del procedimiento. En cuanto a la persistencia, la peor opción fue la de los pacientes tratados con PST llegando a un 4,8\%. El mejor resultado lo obtuvo la PT con un 0\% de persistencia y la PT+AT con resultado intermedio de $0,4 \%$. En cuanto a la recurrencia, los resultados fueron los si- 
guientes: 9,5\% para la PST, 5,4\% para la PT+AT y 0\% para los que fueron tratados con PT solo. Los autores concluyen que la $\mathrm{PT}$ con o sin autotrasplante es el mejor procedimiento quirúrgico para pacientes en hemodiálisis permanente. Un defecto de este trabajo es que no aporta suficiente información en cuanto al eventual hipoparatiroidismo de esos pacientes tratados con PT sin autotrasplante y la calidad de los equipos quirúrgicos no fue homogénea (Tabla 3).

\begin{tabular}{|l|c|c|}
\hline \multicolumn{3}{|c|}{ Tabla 3. } \\
\hline & Persistencia & Recurrencia \\
\hline P. Subtotal & $4,80 \%$ & $9,50 \%$ \\
\hline P.Total con AT & $0,40 \%$ & $5,40 \%$ \\
\hline P.Total sin AT & $0 \%$ & $0 \%$ \\
\hline
\end{tabular}

EL TOPARPILOT (105) es un estudio prospectivo, randomizado controlado, multicéntrico, realizado entre 2007 y 2013, comparando PT vs PT+AT. Los resultados preliminares surgen de una comunicación oral de sus autores (Schlosser et al) en el Congreso de la Sociedad Alemana de Cirugía, en Munich, abril del 2015. Establecen que no existen diferencias estadísticamente significativas en persistencia y recurrencia entre ambos procedimientos.

La paratiroidectomía, como tratamiento paliativo y sintomático del HPT2, tiene excelentes resultados, pero la mejor técnica aun está por definirse. Independientemente de la técnica utilizada, el objetivo primario del tratamiento quirúrgico del HPT2 es eliminar el exceso de PTH y controlar la hipercalcemia y en ello, la calidad de la primera cirugía es determinante en el pronóstico de ese paciente. Partiendo de la base de que no existe aún la "la mejor opción técnica", es que se propone que debe discutirse e individualizarse para cada paciente, y por tanto el cirujano dedicado a su tratamiento debe conocer y saber completar los 3 principales procedimientos, garantizando una cirugía de alta calidad.

\subsection{Criopreservación}

La postura frente a la criopreservación, varía en la bibliografía analizada. La viabilidad del tejido criopreservado y la técnica utilizada en la criopreservación son temas de discusión. Por ejemplo, estudios han demostrado que la preservación de tejido macroscópico tiene mejor resultado que cuando se hace con láminas de células aisladas. Las variables son múltiples.

Las series publicadas de pacientes autotrasplantados son pequeñas. Caccitolo et al (106) publican 15 pacientes autotrasplantados. En solo 6 de ellos tuvieron PTH dosificable en sangre en el postoperatorio. Wagner et al (107) refieren un función estable del auotrasplante en 16 de 25 pacientes. La serie más grande publicada es de 2083 pacientes (HPT1 y HPT2), tratados quirúrgicamente entre 2001 y 2010 (108). Se realizo la criopresevación de tejido paratiriodeo en 442 pacientes (21\%). El autotrasplante diferido fue realizado en solo 4 pacientes. En 3 de ellos, el autotrasplante fallo, no logrando tener PTH dosificable. Solo en uno de los pacientes autotrasplantado se logro corregir el hipoparatiroidismo. Se destaca que este paciente recibió el implante a los 4 días de la cirugía inicial.

La tendencia mundial parece ser hacia no utilizar la criopreservación de tejido paratiroideo como parte del tratamiento quirúrgico de HPT2. En los últimos años, se lo planteaba como una posibilidad en los pacientes portadores de un HPT2 con indicación quirúrgica y a su vez, con alto riesgo de evolucionar al hipoparatiroidismo. El ejemplo más claro es el paciente que espera recibir un trasplante renal a corto plazo. Se ha demostrado que el autoimplante (PT+AT) tiene una viabilidad mayor que el tejido criopreservado, por tanto, el pronóstico de trasplante renal y el riesgo de hipoparatiroidismo, deben definir la táctica quirúrgica inicial, y no la eventual necesidad de criopreservar tejido. (105)(106) $(107)(108)(109)$ 


\subsection{Dosificación intraoperatoria de PTH}

La PTH circulante es una mezcla de péptidos. La forma completa 1-84 y fragmentos de menor tamaño resultado del catabolismo de la PTH, denominados fragmentos no 1-84 o carboxiterminales. Solo la PTH 1-84 (proteína completa) es responsable de su actividad. Por otra parte, ciertos fragmentos carboxiterminales tienen una acción antagónica a la PTH 1-84. Los métodos actualmente usados en la práctica clínica son de dos tipos: el denominado de 2. a generación, llamado PTH intacta (PTHi) que mide la molécula 1-84 y multitud de fragmentos no 1-84, y de 3. ${ }^{\text {a }}$ generación también llamada PTHbiointacta, comercializado recientemente, y que determinan solo la PTH 1-84. Su uso no se está aún generalizado e implicaría revisar los valores que consideramos patológicos de PTH. La dosificación de intraoperatoria de PTH (llamada PTH rápida), ha demostrado ser un instrumento efectivo aunque aún existen autores que cuestionan su utilidad. Es claro su beneficio en el HPT1, pero no tan evidente en el HPT2. Su utilización debe estar asociada inevitablemente a una completa y detallada exploración cervical quirúrgica, y de ninguna manera debe ser utilizado como método de localización. Simplemente debe considerarse como una forma de evaluar el éxito o fracaso de la cirugía durante el procedimiento quirúrgico, brindándonos así, la oportunidad de corregir ese fracaso sin la necesidad de reintervenir al paciente. Si el cirujano no logra identificar las glándulas en la disección, el método pierde completamente su valor.

Su utilización se fundamenta en la corta vida media de la PTH. La caída de su valor en sangre permite confirmar la cura quirúrgica una vez resecada la glándula o las glándulas hiperfuncionantes. Luego de completar una PST o una PT el descenso de este valor, nos confirma, en el intraoperatorio, el éxito de nuestro tratamiento. Existen muchos protocolos de dosificación de PTH (110). La interpretación de su valor también abre otra discusión. Cual valor consideramos como exitoso? Cual como insuficiente?, cual como riesgoso de hipoparatiroidismo?(111). Así se establecen diferentes criterios por diferentes autores intentando definir el mejor punto de corte. Barczynski et al realizan un extensa revisión de estos criterios (112). Los utilizados habitualmente son los siguientes:

1 - Criterio de Miami: caída al 50 \% o más del valor mayor registrado o del preoperatorio inmediato, 10 minutos post recesión.

2 - Criterio de Halle: caída a un valor normal de PTH, a los 15 minutos postreseccion.

3 - Criterio de Roma: caída mayor al 50\% con respecto al valor más alto preoperatorio, en muestra obtenida 20 minutos después de la resección.

4 - Criterio de Viena: caída del 50\% o más con respecto al valor preoperatorio, en muestra obtenida 10 minutos post resección.

Incluso para algunos autores, la caída a más de un 50\% del valor preoperatorio era predictor de hipoparatiroidismo postoperatorio. En esta revisión, se concluye que los criterios de Miami son los de mayor sensibilidad para predecir el éxito de la cirugía. El criterio de normalización del valor (Halle) ha demostrado mejores resultados en especificidad y falsos negativos (112). No hay consenso en cual debería ser el criterio a utilizar. Algunos autores proponen combinar los criterios de Miami con los de normalización, obteniendo así un mejor resultado en sensibilidad y especificidad. También se acepta que la exploración de cuello debe continuar y asociar la eventual timectomía, en los casos en que no se logra esa caída de PTH. (113)

\section{5 - Resección de Timo por vía transcervical}

La localización más frecuente de glándulas paratiroideas ectópicas o supernumerarias es el Timo. Se ha reportado hasta un 14\% de glándulas supernumerarias en pacientes portadores de un HPT2, y de ellas, la gran mayoría son de localización intratímica. (114)

Por este motivo es que muchos autores proponen la timectomía transcervical como un procedimiento de rutina en el tratamiento quirúrgico del HPT2. Los detractores de esta técnica, sostienen que este procedimiento agrega morbilidad y solo logra la resección de un 30 a 40\% del tejido tímico, ya que su resección completa, es anatómicamente imposible por vía transcervical exclusiva.

Si no se hace la timectomía transcervical de rutina, el cirujano se puede ver enfrentado a dos situaciones en las que puede existir indicación de este procedimiento. La primera es que en la exploración cervical, solo se puedan identificar 3 glándulas (o menos). En este caso, y luego de completar la disección y exploración cervical, se deberá continuar con la timectomía transcervical, en el intento de identificar paratiroides ectópicas en su ubicación más frecuente. La segunda situación en la que existirá indicación de timectomía es en el caso en que identificamos las cuatro glándulas, son 
resecadas y confirmadas por el patólogo en sala de operaciones, pero no obtenemos una caída significativa de la PTH intraoperatoria. En este caso, y apoyados en el laboratorio y la PTH intraoperatoria, debemos sospechar la existencia de una quinta glándula y agotar esfuerzos para identificarla y resecarla. La disección transcervical tiene también limitantes importantes, ya que por esta vía, es factible resecar glándulas que se encuentren a no más de $6 \mathrm{~cm}$ del borde superior de la clavícula. Se puede intentar la resección de glándulas por debajo de los $6 \mathrm{~cm}$ asociada a la timectomía, pero en general se requiere una esternotomía para ello, procedimiento que no se justifica si no contamos con algún método de localización pre o intraoperatoria. (114)

\subsection{Nervio Laríngeo Recurrente}

El nervio Laríngeo Recurrente(NLR) es el responsable de la inervación motora de todos los músculos laríngeos menos el cricotiroideo que es inervado por la rama externa del nervio laríngeo superior. También es responsable de la inervación sensitiva de la tráquea y la laringe, distal a las cuerdas vocales. Durante la cirugía de tiroides y paratiroides, el cirujano suele buscarlo e identificarlo en un triangulo limitado entre el eje carotideo, la tráquea y la arteria tiroidea inferior. El punto crítico es el de la entrada del NLR en la laringe, ya que allí se encuentra en íntimo contacto con la glándula tiroides. La lesión del NLR puede ser uni o bilateral. La segunda, y principalmente cuando son inadvertidas, son los casos más graves. En estos casos, se produce de forma aguda una obstrucción de la vía aérea tras la extubación que se manifiesta con estridor e insuficiencia respiratoria. Requerirán una re intubación y/o una traqueostomía de urgencia/emergencia. Las lesiones más frecuentes son las unilaterales, y la gran mayoría transitorias. El lado afectado tendrá como consecuencia, una cuerda vocal paralizada en posición para medial, lo que no permite la oclusión completa de las cuerdas vocales. Su traducción clínica será una disfonía persistente. Esta, en general, mejora por compensación laríngea y con foniatría y re educación de la voz y la respiración. (115)

A partir de la clásica publicación de Lahey y Hoover en 1938, disminuyó la incidencia de la lesiones del NLR en las exploraciones cervicales. Ellos sugieren la visualización e identificación intraoperatoria sistemática del nervio (116). A partir de esa publicación, múltiples trabajos multicéntricos en centros de referencia, han confirmado la necesidad de la localización visual intraoperatoria del nervio, ya que de esta forma, se disminuye el riesgo de lesión. (117)(118)(119) (120)

La localización visual del nervio, considerada obligatoria, no siempre es fácil y depende de tres factores: su localización anatómica, las condiciones quirúrgicas y la experiencia del cirujano. Para evitar lesiones del NLR, es fundamental que el cirujano tenga un correcto conocimiento de la anatomía y sus variantes, los puntos críticos en la disección (en los que existe mayor riesgo de lesión) y el tipo de maniobra que producen lesión (tracción, elongación, trauma con el aspirador, ligadura, etc). Las reintervenciones de cuello, los grandes bocios y las patologías malignas son los casos de mayor dificultad. Por este motivo, se han desarrollados varios métodos de localización y monitorización intraoperatoria. Desde 1996, la monitorización electromiográfica con electrodos de superficie, se ha convertido en el método estándar, ya que es un método fácilmente reproducible y que no produce trauma directo sobre las cuerdas vocales (121). Múltiples métodos de monitorización han sido descritos, pero el de mejor resultados y exento de complicaciones propias, es la utilización de electrodos de superficie colocados sobre el tubo endotraqueal (117)(121).(figura10 y 11)

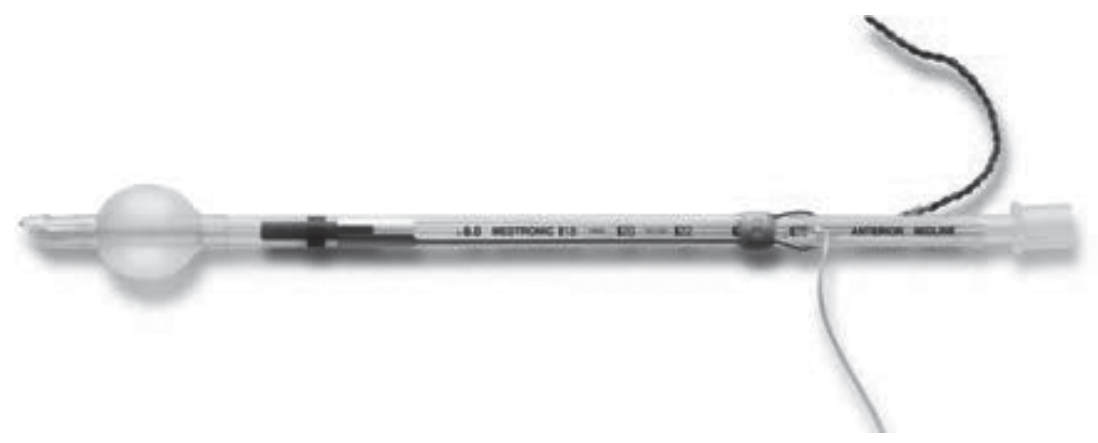

Figura 10. Sonda orotraqueal con electrodos de superficie 


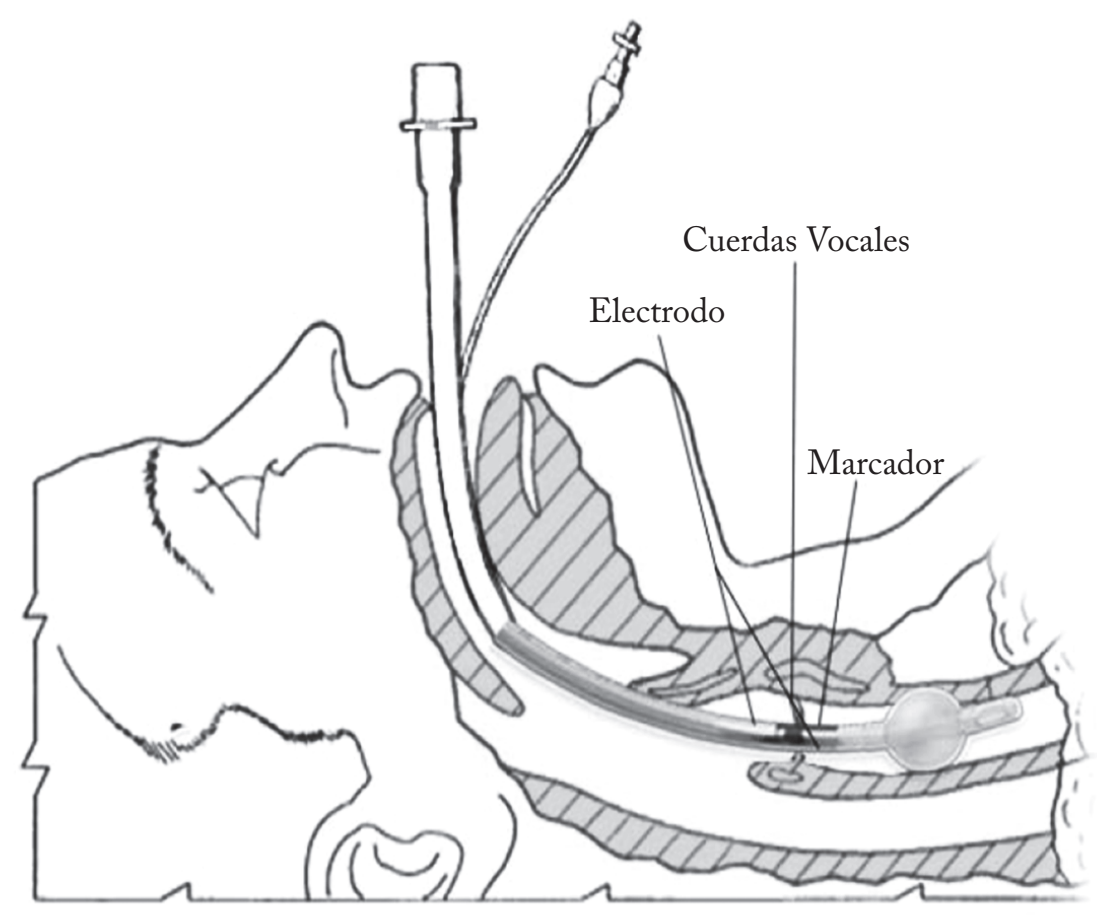

Figura 11. Posicionamiento de la sonda

Parece indiscutible que la monitorización intraoperatoria del nervio laríngeo recurrente, podría disminuir el riesgo de lesión recurrencial, pero hasta la fecha, no se ha podido demostrar que esta diferencia sea estadísticamente significativa (117). Recientemente se ha publicado un meta análisis en el que evalúan 64699 casos y se demuestra que no hay una diferencia estadísticamente significativa en la tasa de parálisis verdadera de cuerda vocal usando neuromonitorización intraoperatoria frente a la identificación visual. Este meta análisis se realizo en pacientes sometidos a una tiroidectomía, pero sus resultados pueden extrapolarse a la cirugía del HPT2 (123). Sin embargo, se considera la monitorización intraoperatoria, como una herramienta muy útil en la identificación de los nervios, pero debe ser complementario a una adecuada exploración visual intaroperatoria y no sustituirla. Es de especial utilidad en los casos de alto riesgo de lesión nerviosa, como la reintervención de cuello, grandes bocios y especialmente cuando existe una lesión recurrencial unilateral previa. Algunas publicaciones informan una menor tasa de lesión recurrencial transitoria en paciente de alto riesgo que fueron operados con monitorización intraoperatoria, comparativamente con pacientes de alto riesgo, operados solo con exploración visual ( $2.0 \%$ vs 4,9\%) (122). Como elemento en contra de esta técnica, debemos mencionar el costo de la misma, el tiempo que demanda y la baja sensibilidad que alcanza. Algunos autores sostienen que una monitorización representa el 8\% del costo total de una tiroidectomía (123), aunque no hay estudios concluyentes de costo/beneficio. Además, la monitorización no es un requerimiento médico legal en la cirugía tiroidea y paratiroidea, ya que no hay evidencia científica que lo avale, y este termina siendo un argumento de mucho peso.

En líneas generales, en la literatura no hay datos suficientes que revelen que su uso disminuye la lesión nerviosa. Es decir, no hay diferencias estadísticamente significativas en la tasa de lesión nerviosa utilizando este sistema. (123) 


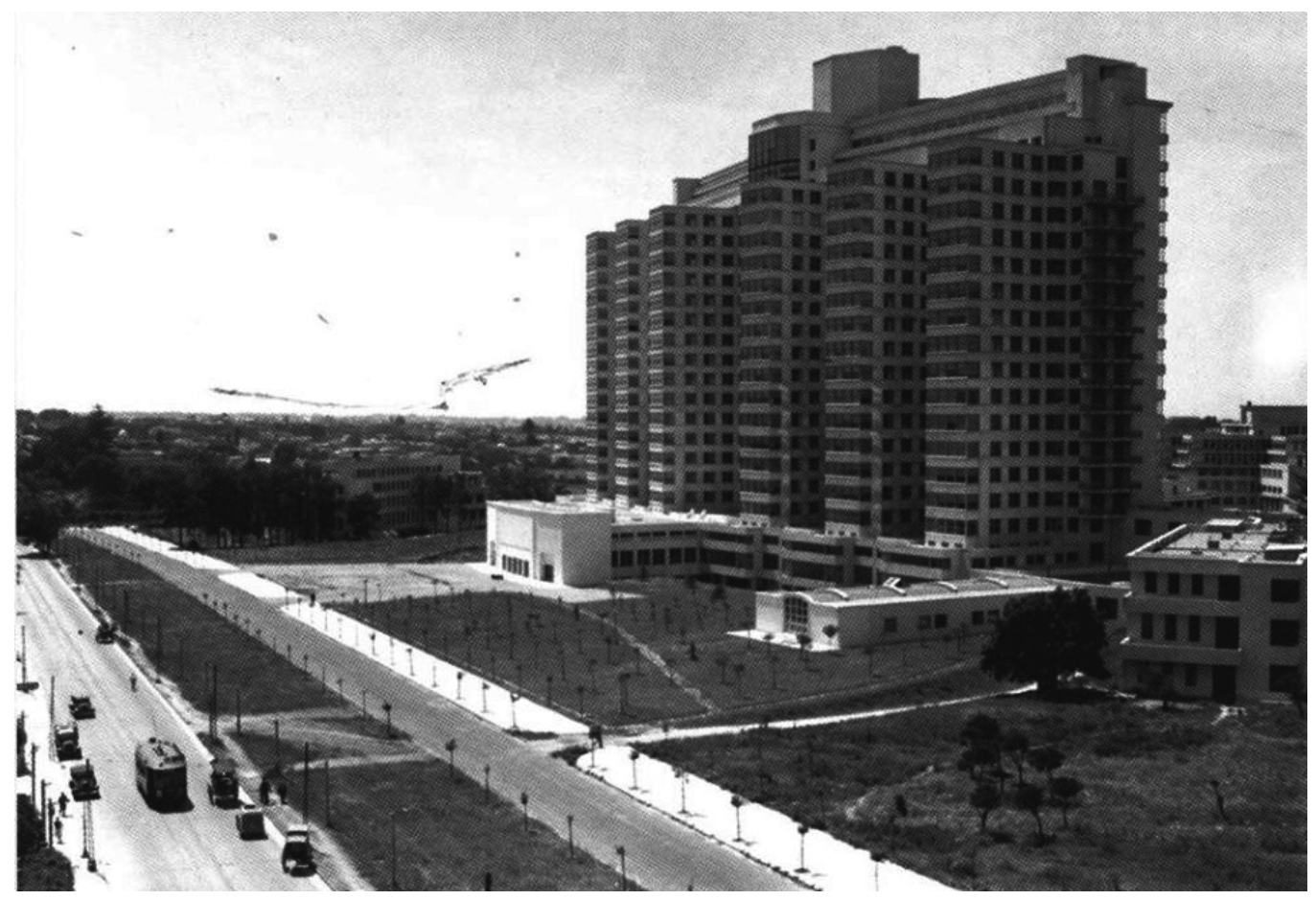

\section{EXPERIENCIA PERSONAL Y DE LA CLÍNICA QUIRÚRGICA “F” DEL HOSPITAL DE CLÍNICAS}

- Técnica Quirúrgica

- Criopreservación

- Dosificación de PTH intraoperatoria

- Resección del Timo 


\section{EXPERIENCIA PERSONAL Y DE LA CLÍNICA QUIRÚRGICA “F” DEL HOSPITAL DE CLÍNICAS.}

Nuestra experiencia en el tratamiento del HPT2 se puede resumir en 15 años, en el periodo comprendido entre $1^{\circ}$ de abril del 2002 y el 31 de marzo del 2017. Este periodo de tiempo abarca nuestra Residencia de cirugía, el cargo de Asistente y finalmente el de Profesor Adjunto, todos cargos desempeñados en la Clínica Quirúrgica " $F$ " del Hospital de Clínicas. No podemos dejar de reconocer aquí a dos cirujanos que nos han transmitido el interés por esta patología. Cuando comenzamos nuestra residencia, el servicio era dirigido por el Profesor Raul Morelli. Su estudio y dedicación a esta patología es harto conocido, y siempre fue un tema de discusión en ateneos, visitas y demás actividades del servicio. Así fue que desde nuestro primer día de residente el hiperparatiroidismo formo parte de nuestra formación. Posteriormente, el Dr Rubens Neirotti fue quien asumió la continuidad y el desarrollo de esta área en el servicio. Trabajando con él en los últimos 10 años es cuando hemos adquirido mayor experiencia, volumen quirúrgico y desarrollo técnico.

En este periodo de tiempo, fueron operados en nuestro servicio, un total de 112 pacientes, incluyendo hiperparatiroidismos primarios, secundarios y terciarios. No es el objetivo de este relato analizar los números ni los resultados, estos ya han sido motivo de otras publicaciones nacionales e internacionales. Simplemente queremos mencionar que a lo largo de estos años hemos tendido éxitos y fracasos, persistencias y recurrencias y casi todas las complicaciones posibles, pero con franco predominio de un buen resultado en cuanto al control del calcio y la clínica de estos pacientes. En cierta forma, esta experiencia es la que nos hablita a hacer este relato.

\section{1 - Técnica Quirúrgica}

La técnica utilizada en estos 15 años siempre fue la Paratiroidectomia Subtotal (Paratirodectomia 7/8). La decisión de aplicar esta táctica quirúrgica surgió del equipo multidisciplinario que se formo inicialmente con nefrólogos, patólogos y el INDT. El temor al hipoparatiroidismo fue determinante, junto con malas experiencias previas vinculadas con hipertrofia del implante en miembro superior y pared anterior de abdomen.

Analizaremos aquí algunos aspectos técnicos que consideramos interesantes y en los que hemos logrado evolucionar en base a experiencia y volumen.

En primer lugar, debemos decir, que no toda cirugía de cuello es igual. La cirugía de tiroides es completamente diferente a la de paratiroides, y a su vez, la del HPT1 completamente diferente a la del HPT2. Si reconocemos, que la experiencia en la disección de cuello y el abordaje de la logia tiroidea, le aporta al cirujano, la capacidad necesaria para resolver situaciones difíciles, ya sea actuando sobre la tiroides, las paratiroides o incluso haciendo vaciamientos ganglionares o resecciones tímicas. También es claro, que el conocimiento anatómico de esta región sumado a la experiencia del cirujano que opera cuello, muchas veces resultan fundamentales en casos de urgencias y emergencias.

La cirugía del HPT2 implica algunas situaciones particulares, que a nuestro entender, agregan dificultad al procedimiento. En general, la indicación de tratamiento quirúrgico en pacientes con HPT2 es tardía y surge luego de un largo tiempo de diálisis, abordajes venosos, fistulas arteriovenosas y todas las consecuencias de una hipercalcemia mantenida.

La posición del paciente ya nos genera dificultades. La rigidez de la columna cervical, secundaria al HPT2, muchas veces imposibilita la hiperextensión de cuello. Si además se trata de un paciente con un Índice de Masa Corporal elevado, y con cuello corto, la dificultad en la exposición se multiplica de forma exponencial. La multiplicidad de abordajes vasculares (vía venosa central, catéteres para diálisis, etc) genera, muchas veces, trombosis venosas en la circulación Cava superior, determinando hipertensión venosa de venas del cuello. La disección es dificultosa, a veces, por la magnitud del sangrado venoso, que se manifiesta desde el abordaje y con la red venosa subcutánea.

La incisión es una cervicotomía transversa. No realizamos abordajes unilaterales ni abordajes mini invasivos, especialmente indicados para HPT1. La incisión ha ido progresivamente disminuyendo su tamaño, utilizando actualmente incisiones de $30 \mathrm{~mm}$ aproximadamente. Esta incisión es suficiente en la mayoría de los casos para completar el tratamiento con éxito. La incisión se extiende solamente si tenemos alguna dificultad técnica o en la localización de las glándulas o si tenemos que ampliar la disección en sentido cefálico o caudal. (figura 12 y 13) 


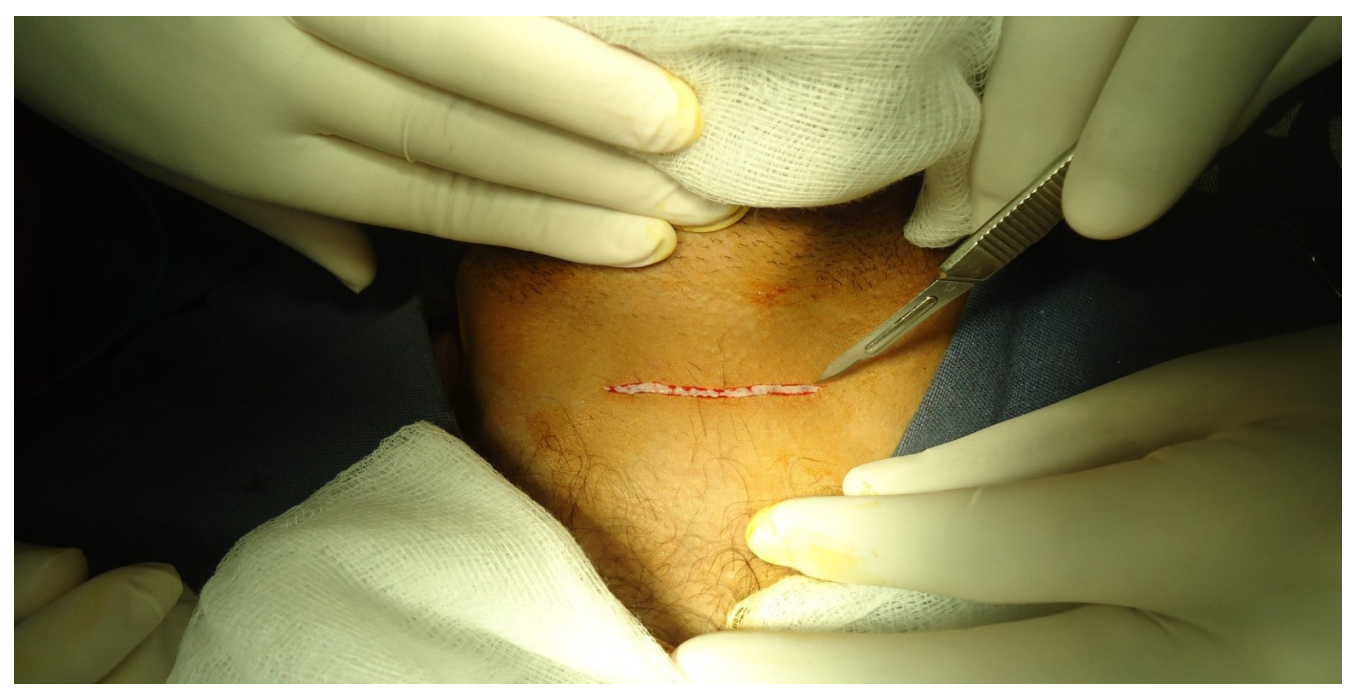

Figura 12. Incisión de 30mm aproximadamente

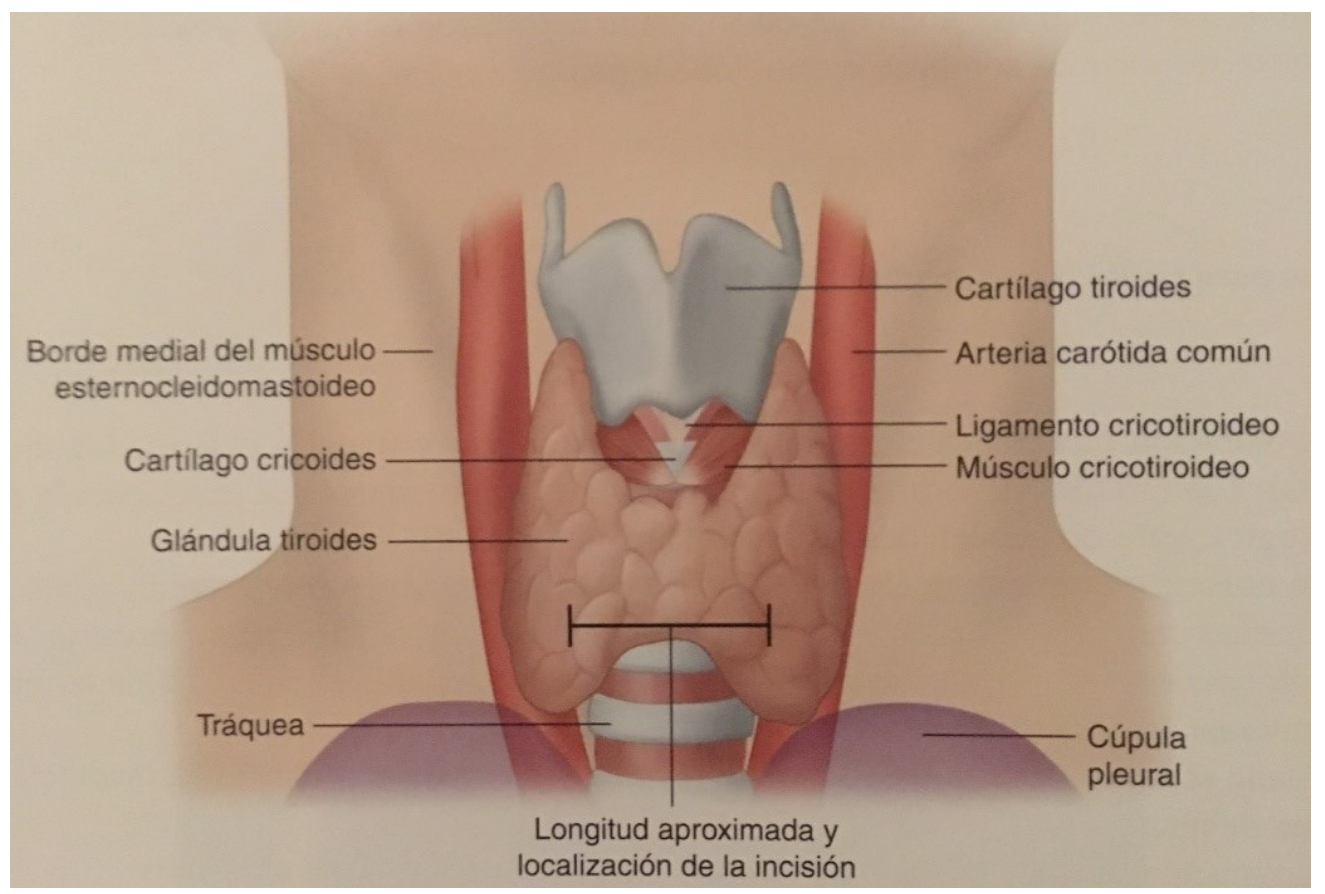

Figura 13.

Los decolamientos y labrados de colgajos cefálico y caudal son pequeños y en general no realizamos los grandes decolamientos propuestos para una exploración cervical exhaustiva ya que en general no son necesarios. Al comienzo de este periodo asociábamos grandes incisiones a grandes decolamientos que llegaban hasta el hiodes por arriba y el manubrio esternal por debajo, según el clásico abordaje de la logia tiroidea.

Algunas cosas no han cambiado en estos años. De forma rutinaria, abordamos la logia tiroidea por la línea media, y localizamos las cuatro glándulas antes de emprender la resección. Esto nos ha demostrado ser un procedimiento más seguro, ya que por más patológica que parezca la primera que encontramos, la siguiente puede ser peor. Intentamos evitar así, el dejar "la ultima" que encontramos en la disección. No debe suceder nunca, que luego de resecar 3 glándulas, la ultima, de la cual pensamos dejar un remanente, sea la de peor aspecto macroscópico. 
Luego de localizar las 4 glándulas y exponerlas con mucho cuidado de no desvacularizarlas ni fragmentarlas, debemos elegir de cual glándula dejaremos el remanente. En caso de optar por una PT+AT, el procedimiento debe ser similar, y debemos disecar las 4 antes de definir de cual obtendremos tejido para el implante. El remanente siempre es de la glándula más sana macroscopicamente, y de ser posible de alguna de las inferiores, ya que como mencionamos, en caso de requerir la resección del remanente, estas están situadas anteriormente a las superiores, y por tanto con menor dificultad en su identificación.

Debemos asegurarnos la vitalidad del tejido remanente, para lo cual la cuidadosa disección es capital. El remanente debe ser siempre marcado con clip metálico o sutura reabsorbible. Esto nos ha resultado de gran utilidad para los casos de recidiva o persistencia, ya que nos permite la fácil identificación del tejido, incluso utilizando el apoyo de la radioscopia en el intraoperatorio. Por este motivo, es que preferimos el marcado con clip metálico y no con suturas irreabsorbibles. Utilizamos la consulta intraoperatoria con el anatomopatologo para la confirmación del tejido resecado en todos los casos. Si bien la descripción original de Wang se realiza con un objetivo diferente, nosotros la hacemos de forma rutinaria. La glándula normal tiene un alto contenido graso, por tanto al colocarla en un recipiente con suero fisiológico (solución de manitol en la descripción original) esta flota en la superficie. Lo mismo ocurre en el caso en que se reseca erróneamente tejido adiposo. En la glándula patológica, ese tejido graso intraglandular es sustituido precozmente por tejido secretanta, haciéndola más densa. Esto determina que el tejido no flote en la superficie al realizar esta prueba (figura 14). La sensibilidad y especificidad de esta prueba es baja y nunca modifica la táctica ni la intención de que el tejido resecado sea evaluado en tiempo real por el patólogo en sala.

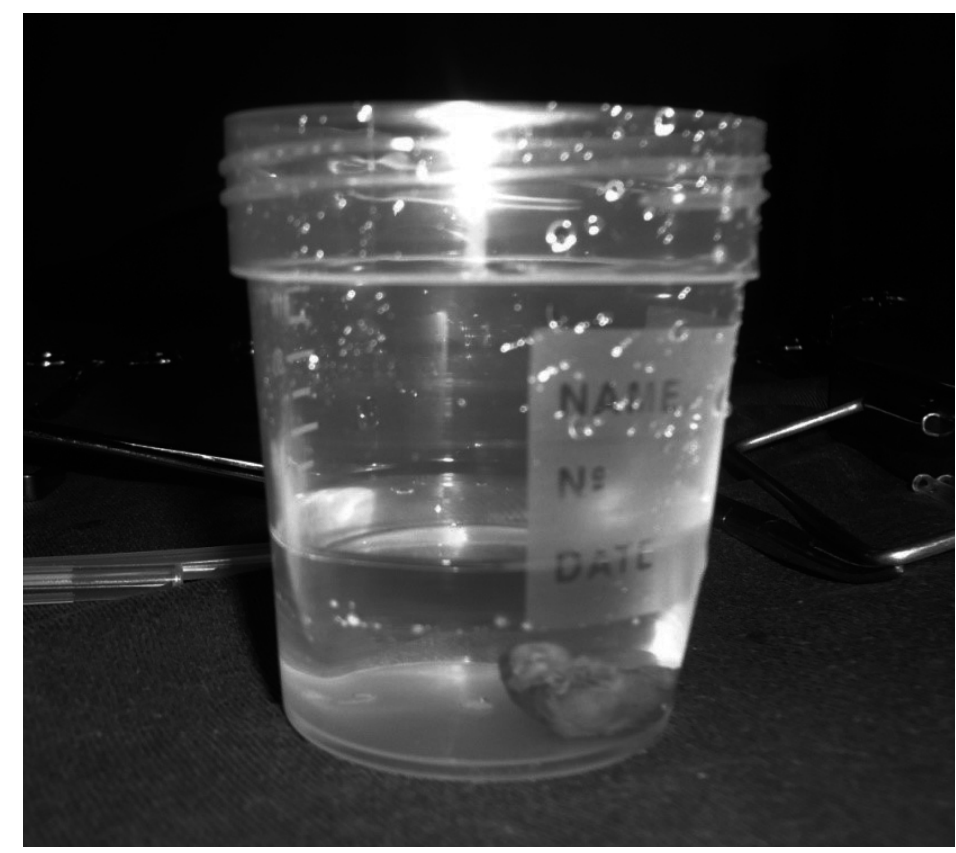

Figura 14. Prueba de Wang

Mantenemos y aplicamos 3 normas básicas en la disección y búsqueda de las paratiroides que nos han demostrado su utilidad.

La primera es la clásica localización en espejo comparativa a izquierda y derecha. Esto se cumple en la mayoría de los casos y es una herramienta de gran utilidad.

La segunda es la localización anteroposterior de las glándulas. Las dos glándulas inferiores siempre están localizadas anteriormente al plano del nervio Laríngeo Recurrente, mientras que las dos superiores son posteriores al dicho plano. (figura 15). Rutinariamente entonces, también siempre identificamos el nervio Laríngeo Recurrente por dos motivos: evitar su lesión y como guía de localización de las glándulas. El nervio no ha demostrado ser un problema en este procedimiento. Para ello, la disección debe ser cuidadosa y limitar las ligaduras a los pedículos paratiroideos que deben ser identificados. No utilizamos electrodos de superficie ni ningún otro método de monitorización electromiográfica intraoperatoria. 


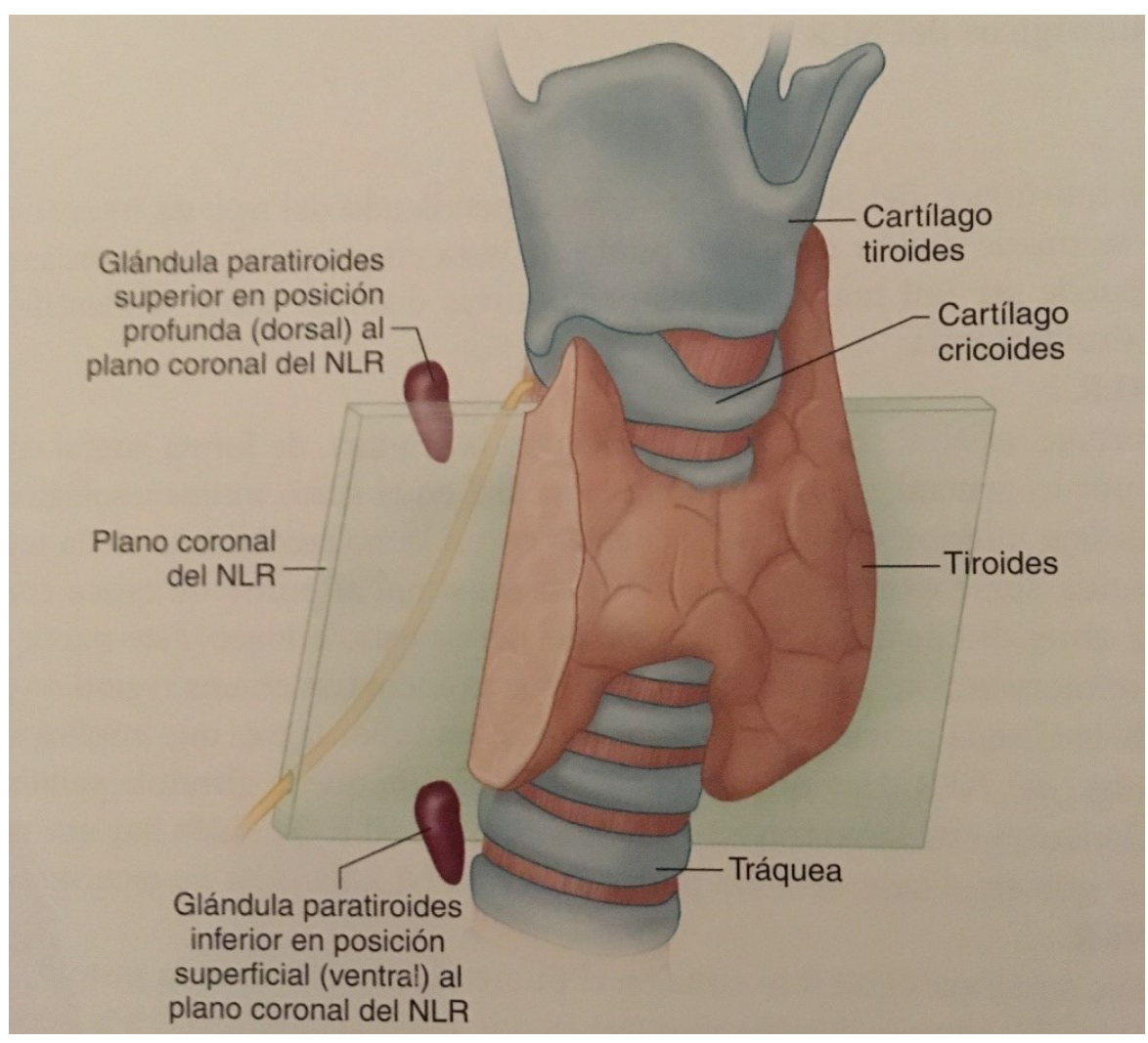

Figura 15. Plano anteroposterior definido por el trayecto del Nervio Laringeo Recurrente

Finalmente, la tercera, es que promovemos la no "intoxicación" en la disección. Cuando no encontramos una glándula, luego de un tiempo prudencial de disección, no insistimos inicialmente en esa localización y pasamos a disecar en otro sector. Un hecho no menor y que siempre debemos tener en cuenta, es que nuestra disección altera la anatomía del cuello, relaciones y reperes, haciendo aún más dificultosa la identificación de una glándula. Así debemos mantener un fino equilibrio entre la "disección y destrucción" para lograr nuestro cometido.

Estas consideraciones son basadas en nuestra experiencia personal y del grupo, y por tanto pueden ser discutidas y refutadas libremente.

\section{2・ Criopreservación}

La criopreservación del tejido resecado fue una norma desde el comienzo de nuestra experiencia. En conjunto con el Instituto Nacional de Donación y Trasplante de Células, Tejidos y Órganos (INDT) y luego de mucho esfuerzo, se logro la criopreservación de parte del tejido resecado con el objetivo de poder realizar un implante de tejido paratiroideo en caso de evolucionar al hipoparatiroidismo. El primer caso data del año 1998 y el último del 2014, realizándose la criopreservación en 69 pacientes. La evolución y el tiempo nos demostraron que el hipoparatiroidismo no fue un problema para la técnica utilizada (PST) y por tanto el programa de criopreservación cayó a partir del año 2014. Varios puntos motivaron esta decisión. El costo de la criopreservacion fue un elemento determinante, ya que representa un alto costo para mantener la viabilidad de un tejido que nunca fue necesario utilizar ya que en estos 15 años, el hipoparatiroidismo no fue una complicación en ninguno de nuestros pacientes. En ese largo periodo de tiempo, se realizo el implante del tejido criopreservado en un solo paciente. El mismo fue previo al comienzo de nuestra experiencia y fue realizado en el Hospital de Clínicas por otro equipo quirúrgico. Es importante destacar, que ese paciente que evoluciono al hipoparatiroidismo, había sido tratado quirúrgicamente por un HPT2, utilizando la técnica de PT sin implante. Aparentemente el seguimiento inicial fue bueno, logrando dosificar PTH pero posteriormente el paciente emigra a España, perdiéndose el contacto. 
La viabilidad del tejido es también un hecho relevante. Estudios del material criopreservado arrojaron una baja viabilidad de esos tejidos a partir de los 2-4 años de criopreservados. Existe además un vacío legal en cuanto a la normativa de preservación y utilización de este material. Es nuestro creer, además, que de existir un programa de criopreservación de tejido paratiroideo, debería ser nacional, y no solo limitado a los pacientes tratados en el Hospital de Clínicas. Debería ser una posibilidad en todos los centros nacionales donde se realicen tratamientos quirúrgicos del HPT2.

\section{3 - Dosificación intraoperatoria de PTH}

A partir del año 2005, fue posible realizar la dosificación de PTH intraoperatoria en el Hospital de Clínicas, primera experiencia en nuestro medio, y en estrecha colaboración con el Departamento de Laboratorio de Patología Clínica. El método disponible es la dosificación de la PTH intacta (PTHi). Desde esa fecha y hasta hoy, la hemos utilizado siempre y ha demostrado su utilidad. Desde el comienzo de nuestra experiencia, optamos por afiliarnos a los criterios de Miami y consideramos la caída de más del 50\% del valor preoperatorio inmediato como el necesario para predecir el éxito de la cirugía. Contamos siempre con valores de PTH previos, los que probablemente hicieron el diagnóstico de Hiperparatiroidismo, pero no los usamos como referencia en el preoperatorio. Realizamos una dosificación preoperatoria inmediata, con el paciente ya en sala de operaciones y una segunda dosificación intraoperatoria posterior a la resección del tejido glandular. Inicialmente esta muestra era obtenida 10minutos luego de completada la resección, pero actualmente, y por razones logísticas exclusivas del Hospital de Clínicas, lo hacemos luego de 15 minutos de resecadas las glándulas.

Cuando no obtenemos la adecuada caída del valor, luego de completada la PST,extendemos la disección al mediastino superior y completamos una nueva exploración de cuello pensando en glándulas supernumerarias y/o ectópicas. Ningún paciente evolucionó al hipoparatiroidismo. Hemos realizado un estrecho seguimiento en los pacientes en los que la caída de la PTH intraoperatoria fue mayor al 50\%, pero no ha surgido esta complicación. Más interesante aún, es en esos pacientes, en los que aparentemente, el control del calcio y los síntomas parece más efectivo y duradero.

\subsection{Resección de Timo por vía transcervical}

En estos 15 años de experiencia, nunca realizamos la timectomía transcervical como un procedimiento de rutina en la cirugía del HPT2. En la etapa inicial de este periodo, en la que no contábamos con la dosificación intraoperatoria de PTH, extendíamos la disección al mediastino superior, sin considerarla una timectomía transcervical, de necesidad, en los casos que no lográbamos identificar las cuatro glándulas a nivel cervical. Siempre consideramos más factible que esa cuarta glándula no encontrada, estuviera a nivel cervical en topografía atípica y no a nivel del Timo o mediastino. Por este motivo, no consideramos justificado extender la disección al mediastino, intentando la timectomía transcervical o incluso realizando una esternotomía, sin tener algún método de localización preoperatorio que nos orientara a dicha topografía .En la segunda etapa, y ya con la PTH intraoperatoria disponible, a la situación anterior, se sumo el caso de una caída insuficiente de la PTH luego de identificadas las cuatro glándulas y completada la PST. En esos casos, realizamos la disección del mediastino superior por vía transcervical, pero nunca completamos la timectomía ni continuamos la disección con una esternotomía.

La resección del Timo y la disección mediastinal, se reservó para fracasos iniciales, y luego de comprobar la localización de mediastinal de glándulas supernumeriarias o ectópicas con algún método paraclínico de localización. Estos pacientes fueron re intervenidos, en su mayoría, con el equipo de Cirugía de Tórax del Hospital de Clínicas.

A modo de conclusión, debemos decir que en estos 15años, realizamos siempre la PST con anatomopatologo en sala y marcando el remanente con clip metálico. Criopreservamos tejido paratiroideo hasta el año 2014, actualmente no lo hacemos. En los últimos 12 años de nuestra experiencia, comenzamos a utilizar la dosificación intraoperaoria de PTH con excelente resultado. Realizamos la disección del mediastino superior por vía transcervical solo de necesidad. El abordaje mediastinal fue realizado solo en los casos en que se comprobó dicha topografía con métodos paraclínicos, y en conjunto con equipo de Cirugía de Tórax. 


\section{PET}
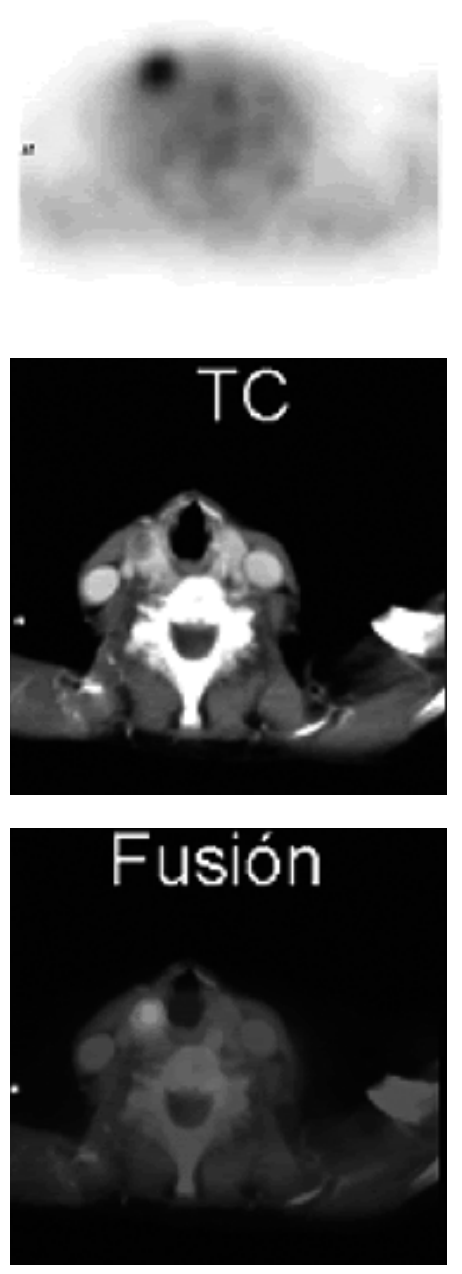

\section{MÉTODOS DE LOCALIZACIÓN PREOPERATORIA}

- Ecografía

- Centellograma

- Tomografia Computada y Resonancia Nuclear Magnetica

- Tomografía por Emisión de Positrones 


\section{0 • MÉTODOS DE LOCALIZACIÓN PREOPERATORIA}

Este es un capítulo controversial en el HPT2. Las posturas son variadas y la evidencia científica no es contundente. No existe correlación entre la localización preoperatoria y el hallazgo intraoperatorio y este es quizás, uno de los puntos principales. Actualmente una de las controversias en el tratamiento quirúrgico del HPT2 gira en torno a la necesidad o no de solicitar un método diagnóstico de localización de las glándulas paratiroideas en el preoperatorio. Es por ello que algunos cirujanos abogan por la exploración cervical bilateral sistemática, considerando innecesarias las pruebas preoperatorias por imágenes. Por otro lado, hay quienes sostienen que la localización preoperatoria facilita la exploración quirúrgica ya que puede orientar (por tamaño o por función) a la identificación de las glándulas patológicas. Por tanto, facilitaría la exploración quirúrgica y permitiría resecar inicialmente la o las glándulas más patológicas, independientemente de que se continúe con la exploración bilateral de cuello. Además, con valor médico legal, avala una exploración cervical negativa por la evidencia imagenológica de glándulas patológicas en el preoperatorio.

Cualquier sea el método de localización glandular preoperatoria, deberá tener una elevada sensibilidad y especificidad para poder compararse con los éxitos superiores al 90\% que el cirujano experimentado obtiene con una cervicotomía. A pesar de las nuevas tecnologías, la localización preoperatoria de la paratiroides puede ser dificultosa. Esto es debido a su pequeño tamaño, la variabilidad de su ubicación y la existencia de glándulas supernumerarias hiperfuncionantes. En pacientes con patología tiroidea asociada, además, puede ser difícil diferenciar una glándula paratiroides patológica de un nódulo tiroideo. (124)(125)

Los métodos más frecuentemente utilizados son la ecografía de cuello y el centellograma. Pero se han intentado una infinidad de métodos buscando una mayor sensibilidad y especificidad en la detección de las glándulas.

\section{1 $\cdot$ Ecografía}

La ecografía presenta claras ventajas. Su bajo costo, su alta disponibilidad, el no ser invasiva ni exponer al paciente a radiación destacan como los principales. Otro beneficio importante de la ecografía es poder analizar la glándula Tiroides y descartar patología asociada a dicho nivel. Dentro de sus limitaciones, en lo referido a la localización de glándulas paratiroides, quizá la principal sea la dificultad para visualizar el mediastino. Es además, un método técnico dependiente, y la experiencia y capacidad del técnico es fundamental en la precisión de la localización, tanto de las normosituadas como de las ectópicas y supernumerarias, así como también de la paratiroides intratiroideas. Pierde sensibilidad en pacientes obesos o en patología tiroidea asociada, principalmente si se trata de grandes bocios multinodulares. También pierde sensibilidad en los casos de un fracaso quirúrgico con persistencia del HPT2 y ante la necesidad de reintervención de cuello. Aporta una imagen anatómica.

Tambien, recientemente, se ha abierto una posibilidad en el intervencionismo guiado por ecografía. Estaría indicado en pacientes con mal terreno o con alto riego para la cirugía y consiste en la inyección percutánea de alcohol o calcitriol en la paratiroides patológica. Los recientes resultados en esta técnica parecen ser más auspiciosos que los obtenidos inicialmente. (126)

\section{Ecografía modo B}

La ecografía en modo B representa la evolución a partir del modo A en la que solo se ven imágenes unidimensionales. El modo B permite una visualización anatómica, pero no es suficiente para visualizar paratiroides normales debido a su pequeño tamaño y a su similitud con el tejido tiroideo

Las glándulas paratiroides aumentadas de tamaño son objetivables como una imagen nodular, hipoecoica, homogénea, redondeada u oval, de contornos lisos con una fina cápsula glandular. Cuando son ovales su eje longitudinal es paralelo al eje longitudinal del tiroides. En algunos casos, la estructura puede ser heterogenea, vinculado econ areas de necrosis, hemorragia y/o calcificaciones, principalmente en las glándulas de gran tamaño.(127)

\section{Ecografía-Doppler y Doppler-color}

La asociación de ecografía y Doppler permitió el estudio de estructuras vasculares junto a la imagen, lo que permite valorar velocidades y flujos.

Con el Doppler-color se realiza la conversión a color de los datos de velocidades y frecuencias obtenidos. La dirección del flujo se expresa en rojo si es positivo y en azul si es negativo, independientemente de que se trate de arteria o vena. Las gladulas patológicas presentan habitualmente, un patrón hipervascular. 


\section{Ecografía power-Doppler}

Se basa en el análisis de la amplitud de ecos móviles en el interior del vaso y, por ello, las estructuras vasculares aparecen contrastadas, permitiendo identificar vasos de menor tamaño, lo que facilita no sólo identificarlos sino también evaluar la vascularización. La combinación de esto métodos y según el patrón de flujo vascular, permitiría identificar las glándulas patológicas y hasta diferenciar una hiperpalasia difusa de una nodular.(128)

\section{$10.2 \cdot$ Centellograma}

En la década del 80 se realizan los primeros estudios de función del tejido paratiroideo utilizando análogos del potasio como el 201-talio(129).Hoy en día se opta por otros radiofármacos como el tecnecio-99m metoxiisobutil isonitrilo (MIBI) o el tecnecio-99m tetrofosmin (TTF). El centellograma MIBI, fue inicialmente utilizado para estudios cardiovasculares y posteriormente en la patología tiroidea y paratiroidea. Es un catión monovalente lipofílico que se acumula a nivel mitocondrial, siendo la alta densidad mitocondrial del tejido paratiroideo el motivo por el cual es captado por estas glándulas. El MIBI utiliza como marcador al Tecnecio- $-99 \mathrm{~m}$, que es de vida media muy corta y que evita someter al paciente altas exposiciones radiactivas. Aporta además imágenes de mejor calidad(130). El MIBI es captado por la tiroides y por el tejido paratiroideo hiperfuncionante, pero lo hacen en diferentes tiempos. Así se describe una fase inicial (fase tiroidea) a los 15 minutos y una fase tardía (fase paratiroidea) a los 60 minutos. Para ese momento, habitualmente, la actividad tiroidea desaparece y solo se evidencian las paratiroides patológicas, ya que el tejido paratiroideo normal no capta en ninguna de las fases. En las imágenes precoces, la actividad en el tejido paratiroideo hiperfuncionante puede ser más intensa, igual de intensa o tener menor intensidad que el tejido tiroideo. En las imágenes tardías, el tejido paratiroideo hiperfuncionante es más fácilmente identificable ya que la actividad presente en la tiroides se ha lavado. Hay que tener en cuenta que el lavado del Tecnecio-99m MIBI de las lesiones paratiroideas puede variar, pudiendo en ocasiones, ser éste muy rápido por lo cual no es posible visualizarlas en las vistas tardías. La mayor limitación para su uso es la coexistencia de nódulos tiroideos o de otros tejidos metabólicamente activos que puedan simular adenomas paratiroideos. (131)(132)

El centellograma paratiroideo permite además la detección de glándulas supernumerarias y/o ectópicas que pueden estar presentes en hasta un 15\% de los casos y pueden potencialmente modificar el área de disección y el riesgo de fracaso quirúrgico. También el centellograma paratiroideo puede ayudar al cirujano a elegir la glándula más apropiada para ser parcialmente preservada ya que aquel tejido paratiroideo con una alta captación del radiotrazador puede representar un alto riesgo de hipertrofia y posterior recurrencia.

En pacientes portadores de hiperparatiroidismo secundario con insuficiencia renal crónica se ha descrito el empleo del centellograma con Tecnecio-99m MIBI sensibilizado con dobutamina, la cual aumentaría su retención y posibilitaría la detección del paratiroides hiperfuncionantes

El uso de fármacos bloqueadores cálcicos es causa de falso negativo ya que pueden inhibir la captación del isótopo por las células paratiroideas. Otra limitante del estudio MIBI es la gran variación en la calidad de los estudios entre las diferentes instituciones que lo realizan. (133)(134). Aporta información funcional o metabólica.

\section{3 - Tomografía computada y Resonancia Nuclear Magnética}

La Tomografía computada (TC) y Resonancia Nuclear Magnética (RNM) son estudios frecuentemente utilizados en el afán de obtener una localización preoperatoria de las paratiroides. Especialmente cuando se trata de pacientes con cierta complejidad, como cervicotomías previas, HPT2 persistente o recurrente y ante la sospecha con otros métodos, de la existencia de glándulas ectópicas o supernumerarias.

Con la TC se obtiene mayor sensibilidad en la localización de glándulas retro traquealeas, retro esofágicas y de mediastino superior que con la ecografía. Pero esta, tiene mayor rendimiento a nivel cervical bajo, en topografías próximas a la tiroides e incluso discriminando paratiroides superior de inferior. (135)(136)

La sensibilidad de la TC para el diagnostico preoperatorio de glándulas hiperplasicas esta en un rango entre 46 y $80 \%$.

El uso de contrastes intravenosos la lleva próximo al 80\% ya que las glándulas hiperplasicas presentan un aumento en su vascularización normal. Cirugías previas de cuello afectan francamente la sensibilidad, principalmente si existen clips metálicos dejados en cirugías previas marcando remanentes. (135)(136) 
La RNM tiene un muy pobre rendimiento en el diagnóstico de glándulas normales debido a su pequeño tamaño. Este método tiene la capacidad de caracterizar lesiones nodulares basándose en los cambios de intensidad entre T1 y T2, así como la posibilidad de utilizar contraste y realizar reconstrucciones en 3D. En esto radica el principal atractivo de la RNM. Glándulas paratiroides aumentadas de tamaño dan un imagen de densidad media en T1 (similar a tiroides o músculos), pero aumentan considerablemente en T2. Estas imágenes no logran discriminar entre adenomas, hiperplasia o carcinoma de paratiroides. Estudios comparativos han demostrado que la sensibilidad de la RNM es similar a la del centellograma, pero la especificidad en francamente menor. La mayoría de los autores proponen utilizar la RNM cuando el centellograma preoperatorio fue negativo, dudoso y cuando identifica glándulas ectópicas o supernumerarias. Por otro lado, también se plantea utilizar ambos métodos en simultáneo con el objetivo de aumentar la precisión y confiablidad de la localización, sin olvidar el alto costo que ello implicaría. (137)(138)

\subsection{Tomografía por emisión de positrones (PET)}

El PET es un método no invasivo que lleva la actividad funcional a imágenes. Los llamados emisores de positrones suelen tener una vida media muy corta, lo que acorta el periodo de exposición y exploración. Para las glándulas paratiroides se utiliza con Carbono-11 marcado con metionina. Este puede ser un método útil en el HPT2 cuando la ecografía y el centellograma son negativos así como en casos de recurrencia o persistencia. El mecanismo de la captación de Carbono-11 Metionina por las paratiroides no se encuentra del todo elucidado, pero puede estar involucrado en la síntesis de pre-pro PTH, un precursor de la PTH que da lugar a una captación intensa y específica de las glándulas paratiroides hiperfuncionantes (139)(140). La sensibilidad y especificidad para Carbono-11 Metionina reportada en aquellos pacientes con HPT2 con estudios con Tecnecio-99m MIBI negativo o inconcluso fue de $86 \%$ y $86 \%$ respectivamente. Parece tener mayor precisión en la localización de glándulas ectópicas o supernumerarias ya que aporta imágenes tridimensionales.

Los estudios comparativos evidencian que la ecografía tiene una sensibilidad algo menor al MIBI. También hay reportes de una similar sensibilidad, precisión y valor predictivo. Esta variabilidad se atribuye a la capacidad del técnico y a la calidad del MIBI. Muchos autores proponen que la combinación de 2 técnicas como la ecografía y el MIBI, mejoran francamente la localización preoperatoria de las paratiroides. Se fundamenta en el que el MIBI detecta la actividad funcional y la ecografía una imagen anatómica.

La PET se reservaría para localizar hiperplasia/adenoma de paratiroides cuando tanto la ecografía , el MIBI y la exploración quirúrgica han sido negativas. (141)(142) 


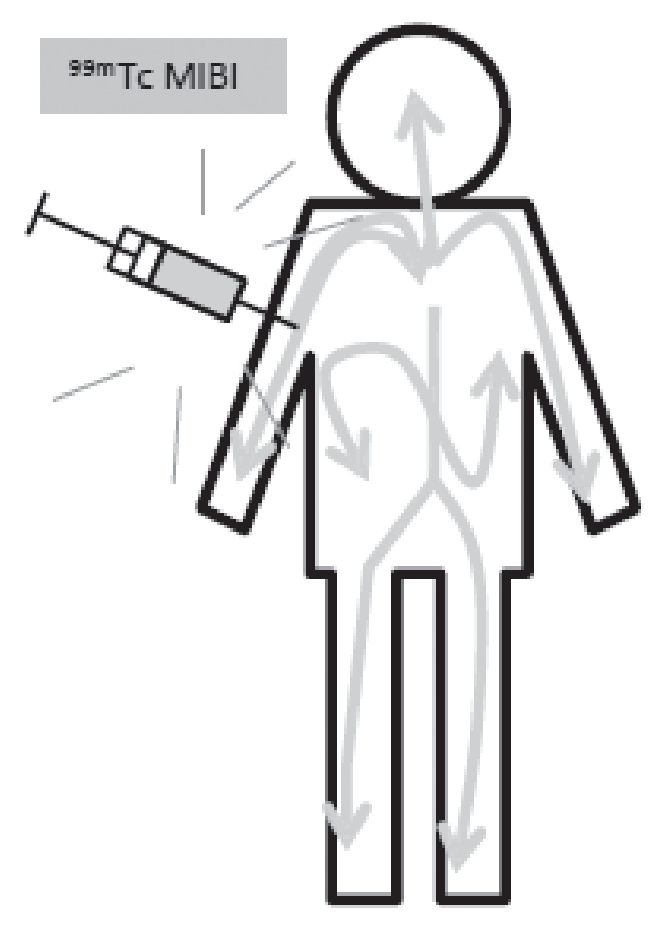

\section{MÉTODOS DE LOCALIZACIÓN INTRAOPERATORIA}

Dr. Juan P. Gambini 


\section{1・LOCALIZACIÓN INTRAOPERATORIA}

La Imagenología molecular (IM) comprende la visualización, caracterización y medida de los procesos biológicos a nivel celular y molecular en seres humanos y otros sistemas vivos. Estas imágenes incluyen imagines 2 o $3 \mathrm{D}$ así como su cuantificación en el tiempo. Las técnicas de IM incluyen a la Medicina Nuclear, resonancia magnética, espectroscopia resonancia magnética, imágenes ópticas, ultrasonido y otras (143). La IM intraoperatoria comprende el empleo de todas estas técnicas en el intraoperatorio para facilitar al cirujano la identificación del tejido de interés. En particular para la localización intraoperatoria de las paratiroides vamos a encontrar de utilidad el empleo de la cirugía radioguiada con Tecnecio-99m MIBI y las imágenes ópticas intraoperatoria de las paratiroides basadas en autofluorescencia de las paratiroides, empleo del azul de metileno y verde de indocianina.

Para llevar adelante la cirugía radioguiada es necesario contar con equipamiento capaz de detectar el tejido radiomarcado. Para ello es posible contar con un gamma probe o gamma cámaras intraoperatorias. El gamma probe consta de una sonda detectora de radiación, una unidad de visualización y control, y un cable que interconecta ambas. La sonda detectora posee la suficiente resolución espacial y eficiencia de conteo de radiación requerida para la localización del tejido radiomarcado. La unidad de control y visualización de datos recibe las señales provenientes de la sonda detectora, las analiza y muestra la tasa de conteo digitalmente por medio de un display numérico y por una señal audible cuya frecuencia es proporcional a la tasa de conteo de radiación. Las gamma cámaras intraoperatorias permiten obtener imágenes en tiempo real durante el acto quirúrgico.

Es posible empelar la cirugía radioguiada para la localización de paratiroides adenomatosas como hiperplásicas (144). Asimismo se la ha empleado con éxito en la búsqueda de paratiroides en cuellos previamente operados (145).

En el caso de pacientes portadores de HPT1 es posible llevar adelante una cirugía minimamente invasiva radioguiada. De esta forma, el cirujano cuenta con información de que el tejido removido se corresponde con tejido paratiroideo, y no se corresponde a otro tejido (grasa, ganglios, timo, etc). Esto tiene el potencial de reducir los tiempos operatorios, evitar disecciones innecesarias y disminuir la morbilidad operatoria (146).

En el caso de pacientes portadores de HPT2 y HPT3 el empleo del gama probe permite localizar glándulas ectópicas o supernumerarias, disminuyendo el riesgo de enfermedad recurrente o persistente. En estos pacientes el procedimiento quirúrgico de elección es la exploración bilateral de cuello asociado a paratiroidecotomía total o subtotal. Como los dos lados del cuello son explorados, habitualmente a estos pacientes puede no realizárseles imágenes de localización preoperatoria. Sin embargo estos pacientes a menudo tienen glándulas supernumerarias, y el probe es útil para asegurar que áreas adicionales que presentan actividad aumentada sean identificadas y removidas.

Asimismo es de utilidad en cuellos reintervenidos donde el tejido cicatrizal y las alteraciones anatómicas dificultan el hallazgo del tejido paratiroideo. El empleo de la cirugía radioguiada permite realizar una localización intraoperatoria del tejido paratiroideo facilitando el realizar una disección mínima, siendo el mismo un procedimiento seguro y efectivo con tasas de curación que se aproximan a los de las paratiroidectomias en cuellos sin intervenciones quirúrgicas 145).

El trazador a emplear en la cirugía radioguiada de paratiroides, es el Tecnecio-99m MIBI, el cual como vimos anteriormente se acumula en el tejido paratiroideo hiperfuncionante, presente en las localizaciones habituales como anormales del cuello y del mediastino superior.

Es recomendable previamente a la cirugía tener confirmación que las paratiroides patológicas capten Tecnecio-99m MIBI, aunque se ha visto que pacientes con HPT1 con centellograma con Tecnecio-99m MIBI negativo beneficiarse de la cirugía radioguiada (146). Estos autores encontraron las paratiroides ectópicas patológicas en un $22 \%$ de estos pacientes mediante el empleo de cirugía radioguiada.

El radiotrazador se administra de forma intravenosa 1 a 3 horas antes del acto quirúrgico. El mismo se distribuye por el organismo y se acumula en el tejido paratiroideo patológico. La actividad a administrar es similar a la que se administra en la realización de los centellogramas paratiroideos, aunque se ha descrito protocolos de dosis bajas en pacientes portadores HPT1 con adenomas paratiroideos solitarios (147). Cabe destacar que la exposición a la radiación del equipo participante de la cirugía radioguiada con Tecnecio-99m MIBI es insignificante y puede ser realizado con seguridad (148).

En el intraoperatorio, el cirujano contando con la información provista por el centellograma paratiroideo y del gamma probe tiene la posibilidad de realizar un abordaje minimamente invasivo en el HPT1 o la identificación de glándulas ectópicas o supernumerarias en el HPT2. El gamma probe le permitirá determinar antes de comenzar la cirugía el 
sitio de mayor actividad relacionada con el área donde se encuentra el tejido paratiroideo hiperfuncionante así como la actividad de fondo (background). La misma se puede medir por ejemplo a nivel de muslo. Posteriormente durante la cirugía se realiza el conteo in vivo (midiendo donde se encuentra el tejido de interés en el paciente), ex vivo (midiendo el tejido removido teniendo en cuenta que al realizar la medida no debe realizarse la misma sobre el paciente) así como del lecho de resección (en el sitio donde se encontraba el tejido removido). Es posible visualizar en el display del gamma probe el conteo de radioactividad en cps así como oír una señal auditiva que aumenta su intensidad a medida que se acerca al sitio de mayor radioactividad.

Se ha descrito que una relación de radioactividad paratiroides/tiroides mayor que 1.5 sugiere fuertemente la presencia de un adenoma paratiroideo, mientras que la relación paratiroides/background (excluyendo el tejido tiroideo) se encuentra entre 2,5 a 4,5. Luego de que el adenoma paratiroideo es removido, el conteo ex vivo es de al menos $20 \%$ superior al background (149)(150), (regla del 20\%). Posteriormente se procede a evaluar el lecho quirúrgico para asegurarse la completa remoción del adenoma o las paratiroides patológicas, al encontrar valores próximos al background. Se ha visto que esta regla del $20 \%$ es posible empelarla tanto en paratiroides adenomatosas como hiperplásicas (144).

Las ventajas de la cirugía radioguiada pueden ser resumidas en los siguientes puntos:

a. El gamma probe guía al cirujano al sitio del tejido paratiroideo, por lo tanto facilita el abordaje y disminuye los tiempos quirúrgicos, especialmente en las glándulas ectópicas o supernumerarias. (151)(152).

b. La guía del gamma probe es útil en evaluar la remoción completa del tejido paratiroideo (151)(152)(153).

c. El empleo del gamma probe al medir la radioactividad ex vivo del tejido removido ayuda a verificar la efectividad de la remoción del tejido paratiroideo y el éxito de la cirugía. La regla del 20\% propuesta por Murphy y Norman (149), presenta una precisión del 100\% en distinguir paratiroides adenomatosas.

Los métodos de IM óptica se emplean para mejorar la precisión de las resecciones quirúrgicas al producir imágenes de alta resolución en tiempo real (154). Las imágenes de fluorescencia en el infrarrojo cercano (NIR) son particularmente atractivas porque toman ventaja de la ventana óptica entre 700 y $900 \mathrm{~nm}$ donde la luz puede penetrar en el tejido con poca absorción o dispersión (155). Recientemente se ha descubierto un fluoroforo NIR intrínseco a altas concentraciones en las paratiroides normales como patológicas (156)(157). De esta forma es posible durante la cirugía, empleando un sistema de detección de fluorescencia en el infrarrojo cercano, llevar adelante su localización y visualizarlo en una pantalla el resultado de la misma (158). Cabe destacar que a simple vista no es posible visualizar dicha fluorescencia ya que nuestros ojos no son capaces de detectar dichas longitudes de onda.

Por otra parte se han empleado sustancias que se acumulan en las paratiroides que permiten su visualización en el intraoperatorio. En este sentido cabe destacar el empleo de azul de metileno $(7,5 \mathrm{mg} / \mathrm{kg})$ via venosa periférica durante el acto quirúrgico. La tinción de las glándulas paratiroides con azul de metileno se encuentra entre 83 a 100 \% (159). Sin embargo está descrito la presencia de neurotoxicidad relacionada con la administración de azul de metileno, sobre todo en aquellos pacientes que reciben inhibidores de la recaptación de seratonina (159)(160)(161). Es así que se ha empleado protocolos en los cuales se ha disminuido su dosis $(3,5 \mathrm{mg} / \mathrm{kg})$ lo cual ha permitido visualizar $78 \%$ de las paratiroides, con menores efectos adversos (162). Más recientemente aprovechando las propiedades de fluoresencia del azul de metileno a bajas dosis $(0,5 \mathrm{mg} / \mathrm{kg})$ ha sido posible, mediante el empleo de sistemas de detección de fluorescencia intraoperatorios, detectar paratiroides patologicas en 9 de los 13 pacientes. Asimismo fue posible detectar en 3 de estos pacientes, 6 paratiroides normales, sin efectos adversos (163).

Otro compuesto que es empleado para visualizar las glándulas paratiroides normales o patológicas es la indocianina verde. La misma se administra en forma intravenosa por vía venosa periférica $(5 \mathrm{mg})$ durante el acto quirúrgico y posteriormente se procede a visualizarlas mediante un equipo de detección de fluorescencia en el infrarrojo cercano. Para ello es necesario que durante la realización del procedimiento se apague la luz de la sala de operaciones para que no interfiera con la detección de la fluorescencia de las paratiroides. Se la ha empleado en la detección de paratiroides en pacientes con HPT1 e HPT2 (164). Los autores encontraron que más del 90\% de las paratiroides encontradas, presentaba fluorescencia, destacando el hecho de que en las imágenes precoces también hay captación de ICG por la glándula tiroides. Ellos encontraron que las imágenes de fluorescencia de las paratiroides con ICG fue más útil en aquellos pacientes con glándulas ectópicas o en situaciones de reintervenciones en donde la tiroides ha sido removida. También plantean la utilidad de la ICG en aquellos pacientes que requieren PST por hiperplasia multiglandular. En estos casos la fluorescencia de la ICG permitió una valoración confiable de la perfusión del remanente paratiroideo. Cabe destacar que hasta el momento la viabilidad del tejido paratiroideo se basa en la experiencia del cirujano al valorar el color y sangrado del mismo. Estos autores encontraron que la sensibilidad de la detección de fluorescencia con ICG en el intraoperatorio fue del 91.1\%. Ellos encontraron que las imágenes en el infrarrojo cercano pueden reducir el tiempo operatorio y mejorar la tasa de resección completa. En el Hospital de Clínicas, hemos estado trabajando en imágenes en el infarrojo cercano empleando ICG y un sistema de detección de fluorescencia que hemos desarrollado. 
De esta forma hemos podido evaluar en el intraoperatorio en tiempo real la perfusión de colgajos, de anastomosis digestivas, en procedimientos de ganglio centinela empleando trazador hibrido (radioactivo y fluorescente) y recientemente visualización de paratiroides de forma exitosa. Figura 16
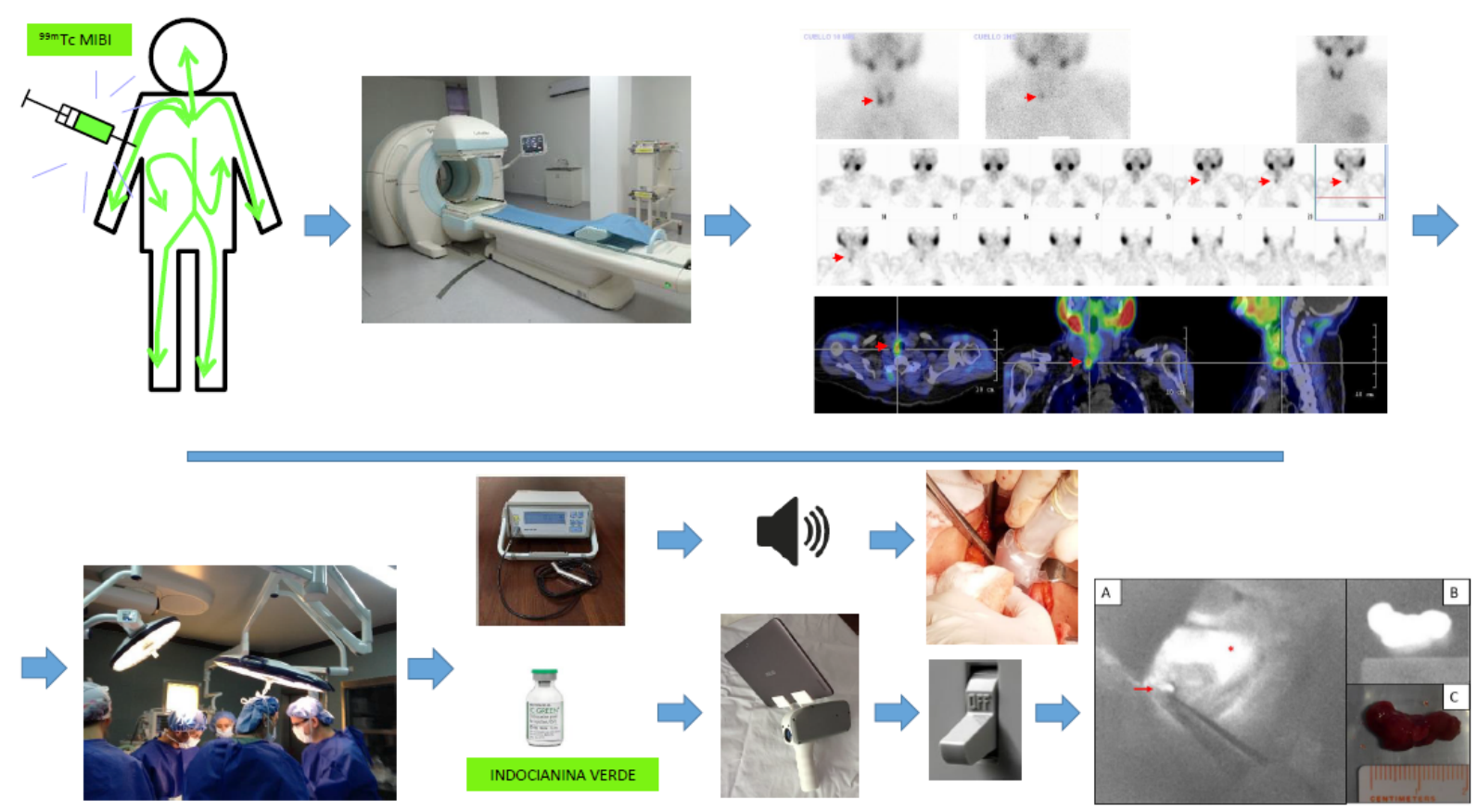

Figura 16. Esquema de procedimiento de centellograma y cirugía de paratiroides.

Luego de la inyección del 99mTc MIBI, se realizan las imágenes centellográficas y SPECT CT. Posteriormente en el día de la cirugía se vuelve a administrar 99mTc MIBI y durante la cirugía mediante el gamma probe se localiza el tejido de interés. Por otro lado, es posible inyectar indocianina verde (ICG) en forma intravenosa vía venosa periférica y empleando un equipo portátil capaz de detectar la fluorescencia de la ICG visualizarla.

En A se observa la localización in vivo por fluorescencia de ICG en el intraoperatorio. La flecha indica la paratiroides. $\mathrm{La}^{*}$ el tejido tiroideo.

B. Examen de fluorescencia ex vivo, nótese la fluorescencia del tejido resecado. Anatomía patológica posteriormente confirmó corresponder a tejido paratirodeo.

C. Examen de la pieza resecada ex vivo. 


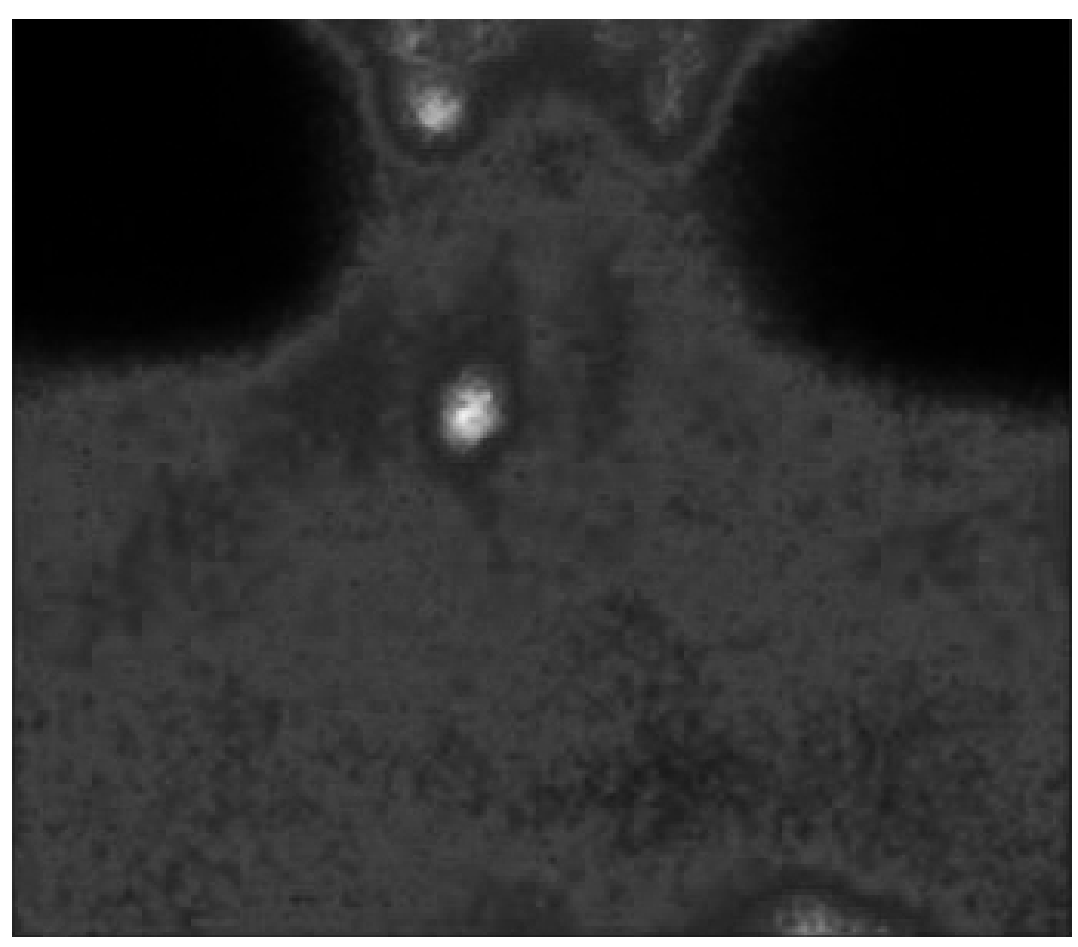

PERSISTENCIAY RECURRENCIA 


\section{2・PERSISTENCIA Y RECURRENCIA}

Estos términos están claramente definidos y son motivo de consenso internacional. La PERSITENCIA se define como el mantenimiento de las concentraciones de PTH por encima de $60 \mathrm{pg} / \mathrm{ml}$, luego de la resección quirúrgica. Por RECURRENCIA se entiende a la elevación de la PTH, luego de una normalización inicial postquirúrgica, tras un periodo de como mínimo de 6 meses. Algunos autores utilizan 3 variables para definir recurrencia y persistencia, el valor de PTH, el nivel de calcemia y el cuadro clínico.

La persistencia es un fracaso quirúrgico. No se logra el objetivo planteado previo a la cirugía y por tanto el paciente persistirá con el problema, pero ya con una exploración cervical completa. En la etiología de la persistencia se pueden identificar dos situaciones claras. La primera es la falla en la localización de las glándulas paratiroideas, lo que habitualmente va asociado a una ectopia de las mismas. En estos casos, la disección cervical no logra identificar las cuatro glándulas y no se obtiene una caída significativa de la PTH intraoperatoria. Es probable que el cirujano experiente continúe aquí su disección cervical y la extienda hacia el mediastino superior con el objetivo de detectar esa ectopia.

Más allá de su relativa constancia anatómica, el origen embriológico paratiroideo determina que se puedan hallar glándulas paratiroides en cualquier localización dentro de un área delimitado por la región hioidea arriba, el pericardio por debajo y los ejes carotideos a los lados. Las ectopias paratiroideas se pueden dividir arbitrariamente en 2 grupos, las cervicales y las mediastinales y todas sus posibles localizaciones deben ser reconocidas por quien practique la cirugía tiroidea y paratiroidea(32)(33).

Ya mencionamos que las ectopias son más frecuentes para las glándulas inferiores, consecuente a su mayor distancia de migración. Las ectopias superiores serán halladas dentro de la tiroides, en posición retrotraqueal, retroesofagica o retro carotidea. Las ectopias inferiores pueden ubicarse en posición caudal al polo inferior tiroideo, pretraqueal, en la grasa mediastinal o intratimica. Las ectopias mediastinales son en su mayoría superiores, cerca del $75 \%$, pre aorticas. Solo un $25 \%$ de ellas estarán más profundas en el mediastino, en la ventana aortopulomar. (32)(123)(124)

La segunda situación que determina una persistencia es la existencia de glándulas supernumerarias. Esta situación no es tan frecuente como la anterior pero se han descrito glándulas supernumerarias hasta en $13 \%$ de los pacientes con HPT2, llegándose a describir hasta 8 glándulas en un mismo paciente (125). En estos casos, el cirujano identifica y completa la resección planificada de las paratiroides y por tanto da por concluido el procedimiento. En el postoperatorio, no se logra el control de los niveles de calcio, la caída de la PTH ni la remisión clínica, por lo que se concluye que existen glándula/s supernumerarias y se condiciona una reintervención del paciente luego de agotar los métodos de localización preoperatoria. Actualmente, en los casos que se utiliza la dosificación de PTH intraoperatoria, este puede ser un diagnóstico intraoperatorio, y al igual que en la situación anterior, continuar la disección cervical y mediastinal y así evitar una reintervención.

La disposición ectópica, incluso en el mediastino, se puede determinar mediante estudio preoperatorio de localización con MIBI, con el fin de evitar una exploración quirúrgica incompleta, si bien los resultados, realizados de forma preoperatoria, hasta el momento no son de gran rendimiento, sí lo son para estudiar los casos de recidiva o persistencia tras la intervención inicial (165)(166)(167). Todo ello puede resultar fundamental en el HPT2 en el que la resección del tejido paratiroideo es fundamental (141).

La recurrencia o recidiva es una situación diferente. En estos casos, el tratamiento quirúrgico inicial es exitoso. Se logra el control del calcio, de los síntomas y la caída de la PTH. Luego de 6 meses, estos valores vuelven a alterarse progresivamente, con aumento de la PTH y de la calcemia. Esta situación se da en pacientes tratados quirúrgicamente con éxito pero en los que persiste la insuficiencia renal y la hemodiálisis, persistiendo por tanto el estimulo para la producción y secreción de PTH. El procedimiento inicial realizado es capital en la génesis de la recurrencia. Así vimos que está prácticamente no existe en los pacientes tratados con una PT sin AT. Solo existirá en los casos en que se dejó un remanente paratiroideo, PST o PT + AT. La falla probablemente está determinada por el volumen de tejido paratiroideo dejado como remanente o como autotransplante. También se condicionara una reintervencion para resolver este problema evolutivo. Sera importante el método utilizado para marcar el remanente o autoimplante con el objetivo de localizarlo y resecarlo parcial o completamente. En este punto es que radica la inclinación de muchos cirujanos hacia no realizar la PST. Al mismo tiempo, los detractores de la PT+AT sostienen que la recidiva existirá igual ya que está determinada por la ERC y la hemodiálisis, con la contra de que al haber realizado este procedimiento, existirán 3 lugares potenciales de recurrencia, el cuello, el mediastino y el aérea del implante.(167) 


\section{1 $\cdot$ Nuestra experiencia}

En estos años, hemos tenido la oportunidad de tratar pacientes propios con persistencia o recurrencia así como pacientes tratados por otros equipos que nos fueron referidos. Consideramos que el fracaso en la cirugía del HPT2 no debe considerarse como tal. Las variables son múltiples e infinitas, y aún ajustándose a protocolos, métodos de localización pre e intraoperatorios, exploración extensa y demás, estos existen y seguirán existiendo. Nuestra experiencia nos ha demostrado que la reintervención de cuello no tiene gran morbilidad. Consideramos 2 elementos determinantes en ello. El primero, es que por más que sea una re intervención de cuello, nuestro abordaje se limitara a un solo lado, por tanto un NLR no corre riesgo de lesión. El segundo, es el marcado del remanente con clip metálico en la primera cirugía. En este punto es que se produce la persistencia si el fragmento dejado fue muy grande, o la recurrencia en caso de hipertrofia en la evolución. Esto facilita enormemente la identificación de esa paratiroides, con imágenes preoperatorias y con radioscopia en el intraoperatorio.

Referiremos aquí, algunos pacientes que marcaron nuestra evolución y que nos dejaron un gran aprendizaje.

El primero, es un paciente propio, de nuestra serie. Se opero con el planteo de HPT2 y la plan táctico fue realizar una PST, con patólogo intraoperatorio. En esa fecha, aún no contábamos con la dosificación de PTH intraoperatoria. En la exploración quirúrgica, solo se localizaron y resecaron 3 de las 4 glándulas. Como era de esperar, el paciente evolucionó a una clara persistencia, sin descenso de la PTH y con mal control del calcio. Luego de múltiples discusiones en ateneos multidisciplinarios, se decidió la re exploración de cuello. Previo a ello, se intento localizar la glándula remanente con ecografía, centellograma y TC de cuello y tórax, no lográndose por ninguno de esos métodos. Finalmente se re exploro el cuello.

Se abordo por la misma cervicotomía transversa. Luego de una extensa exploración de cuello, se continuo la disección hacia el mediastino, incluso con la desarticulación clavicular. Por esta vía se completo la timectomía, pero en el análisis inicial del patólogo en sala, no se evidenciaron glándulas intratimicas. Ya vencidos y deseando que la exploración exhaustiva del timo en diferido arrojara otra conclusión, se decide concluir la cirugía. En el proceso de hemostasis y cierre de los planos disecados, se evidencia una estructura macroscópicamente compatible con una glándula paratiroides, pero situada por detrás del músculo esternocleidomastoideo. Se completa su resección y el patólogo confirma que se trata de una paratiroides. En el postoperatorio, el paciente evoluciona sin complicaciones, con un descenso de su PTH y del calcio, confirmando así el éxito de la cirugía.

Varias reflexiones surgen a partir de este caso. En primer lugar, que la dificultad en la localización de las 4 glándulas es un elemento siempre presente. Ante el fracaso quirúrgico y la persistencia del HPT2, ninguno de los métodos de localización preoperatoria fue útil en este caso. La segunda exploración, realizada por un equipo con amplia experiencia en cirugía de cuello y en cirugía del HPT2 tampoco logró resultados y desencadeno un procedimiento de gran magnitud con la extensa disección mediastinal, con una gran morbimortalidad potencial. Finalmente, la cuarta glándula fue localizada por fuera de la logia tiroidea, por detrás del músculo ECM. Esta es una localización anatómica no habitual y que probablemente sea consecuencia de la primer cirugía, en la que inadvertidamente, un fragmento de paratiroides (o una glándula) quedo en dicha topografía.

Luego de resecada dicha glándula, surge el temor al hipoparatiroidismo, ya que sin quererlo, habíamos realizado una PT sin implante. El paciente continuo en muchos años y hasta el dia de hoy en hemodiálisis, sin evidencia de hipoparatiroidismo y, hasta la fecha, sin recurrencia del HPT2.

El segundo paciente al que hacemos referencia, se trata de un hombre de 56 años al momento que lo contactamos. En hemodiálisis por 20 años aproximados, con un HPT2 que fue tratado quirúrgicamente 8 años antes por otro equipo quirúrgico. En ese momento, la técnica elegida fue una PT+AT que se realizó en antebrazo, sobre músculos epitrocleares en varios fragmentos.

El paciente continuo en hemodiálisis, sin posibilidad de recibir trasplante renal, lo que llevo a una gran hipertrofia e hiperplasia del implante. Tal fue el crecimiento que era evidente al examen físico, como una tumoración palpable, formando cuerpo con la masa muscular, y con una evidente recurrencia de su HPT2.

Se estudio con ecografía de cuello y MIBI, no evidenciado otras aéreas patológicas. Se planteo entonces la resección quirúrgica. La resección completa fue imposible porque implicaba vaciar completamente el compartimento muscular de antebrazo. Se realizo una resección parcial. El HPT 2 persistió, aunque el manejo del calcio con tratamiento médico fue exitoso y falleció por otro motivo a los 4 años de la intervención quirúrgica. 
Por último, referimos el caso de una paciete de sexo femenino de 43 años al momento de la intervención. Portadora de una ERC en hemodiálisis y un HPT2 con indicación quirúrgica, motivo por el cual nos fue referida. Con el planteo de realizar una PST se intervino de coordinación siguiendo los protocolos habituales. Luego de completada la resección, se realizo una PTHi cuyo valor fue levemente menor al preoperatorio. Se interpretó inicialmente como un remanente muy grande. Se re reseco el remanente marcado con clip metálico dejando como tejido remanente un fragmento menor a los habituales. Una nueva medición de PTHi arrojo valores similares al previo, Se comenzó a pensar entonces, en la existencia de una quinta glándula. La misma fue encontrada en topografía inferior, a izquierda, retrotraqueal. La PTHi en este caso, evito un seguro fracaso quirúrgico, persistencia y reintervención de cuello. 


\section{BIBLIOGRAFÍA}

1) Cope O. The Story of Hyperparathyrodism at the Massachusetts General Hospital. N Engl J Med 1966; 274: 1174

2) Ruda JM, Hollenbeak C, Stack B. A systematic review of diagnosis and treatment of primary hyperparathyroidism from 1995 to 2003. Otolaryngol Head Neck Surg 2005;132:359-372.

3) Martin KJ, Olgaard K, Coburn JW, et al. Diagnosis, assessment, and treatment of bone turnover abnormalities in renal osteodystrophy, Am. J. Kidney Dis 2004;43: 558-565.

4) Cusumano A et al. 2000. Sobrevida prolongada en hemodiálisis: cómo vivir más alla de la primera década. Revnefrol diálisis transpl 50:5-14.

5) Owen R. On the anatomy of the Indian rhinoceros. Trans Zool Soc Lond. 1862; IV: 31-58.

6) Thompson NW. The history of hyperparathyroidism. Acta Chir Scand. 1990; 156: 5-21.

7) Sandström I. On a new gland in a man and several mammals (glandulae parahtyroideae). Upsala Lakforenings Forth. 1880; 15: 441-71.

8) Gley E. Sur les fonctions du corps thyroide. C R Seanc Soc Biol. 1891; 43: 841-3.

9) Mac Callum WG. The physiology and pathology of the parathyroid glands. Proc Pathol Soc Phil. 1908; 11: 115-28.1289.

10) Mac Callum WG, Voetling C. On the relation of the parathyroid to calcium metabolism and the nature of tetany. Bull Johns Hopkins Hospital. 1908; 19: 91-2

11) Mandl F. Therapeutic trial in a case of osteitis fibrosa generalisata by means of removal of a parathyroid tumour. Presentation at the Medical Society of Vienna, December 4, 1925

12) Hannon RR, Shor E, McClellan WS, DuBois EF. A case of osteitis fibrosa cystica (osteomalacia?) with evidence of hyperactivity of the parathyroid bodies. Metabolic study I J Clin Invest. 1930; 8: 215-27

13) Albright F, Bloomberg E, Castleman B, Churchill ED. Hyperparathyroidism due to a diffuse hyperplasia of all parathyroid glands rather than to a parathyroid adenoma of one gland. Arch Int Med. 1934; 54: 315-29

14) Cope O, Keynes WM, Roth SI, Castleman B. Primary chief cell hyperplasia of the parathyroid glands. Ann Surg. 1958; 148: 375-88

15) Boonstra CE, Jackson CE. Hyperparathyroidism detected by routine serum calcium analysis. Ann Int Med. 1965; 63: 468-74.

16) Boonstra CE, Jackson CE. Serum calcium survey for hyperparathyroidism: result in 50,000 clinic patients. Am J Clin Pathol. 1971; 55 (5): 523-6En

17) Berson SA, Yallow RS, Aurbach GD, Potts JR. Immunoassay of bovine and human parathyroid hormone. Proc Natl USA. 1963; 49: 613-7.

18) Hop N Le, JA Norton. Surgical management of hyperparathyroidism. En: LJ de Groot, JL Jameson, editores. Endocrinology. 4a ed. Philadelphia. WB Saunders Company; 2001. p.1111-20

19) Stanbury WS, Lumb GA, Nicholson WF. Elective Subtotal Parathyroidectomy for renal Hyperparathyroidism. Lancet 1960; 1:793

20) Wells SA, Ross AJ, Dale JR, Gray RS. Transplantaion of the Parathyroid glands. Currente Status. Surg Clin North AM 1979; 59: 167

21) Pyrah L, Hodgkinson A, Anderson C. Primary Hyperparathyrodism.Br J Surg 1966; 53:245

22) Purnell DC, Scholtz DA, Smith LM. Treatment of Primary Hyperparathyrodism. Am J Med 1974; 56:800

23) Romanus R, Heimann, Nilson O, Hansson G. Surgical Treatment of Primary Hyperparathyrodism. Prog Surg 1973; $12: 22$

24) Cope O. Hyperparathyrodism. Diagnosis and Management. Am J Surg 1960; 99:394

25) Egdahl S. Surgery of Parathyroid Glands. Surg Gynecol Obstet 1970; 130:901

26) Cazaban LA, Del Campo A, Servetti E, Gomez Fossati C, Crestanello F.Aplicación Clínica del Implante de paratiroides. Cir Uruguay 1972; 40:16

27) Morelli R. Tratamiento Quirurgico de Hiperparatiroidismo. Cir Uruguay 1994; 64:257-274

28) Bileziquian J., Marcus R., Levine M. The Parathyroids: Basic and Clinical concepts. Edition $2^{\circ}$, New York: Raven. 2001, 881 pages.

29) Abboud B. Anatomie topographique et vascularisation arterièlle des parathyroïdes. Presse Med 1996; 25:11561161.

30) Geis N. The Parathyroids Glands. Annals of Surgery: April 1908; 47(4):523-531.

31) Sitges-Serra A., Sancho J. Cirugía Endocrina. Guías Clínicas de la Asociación Española de Cirujanos.

32) Wang C. The Anatomic Basis of Parathyroid Surgery. Ann. Surg. March. 1976: 183 (3):271-275

33) Cummings: Otolaryngology: Head \& Neck Surgery, 4th ed. Mosby. 2005. Chapter 120

34) Delattre J.F., Flament J.B., Palot J.P., Pluot M. Les variations des parathyroïdes. Journal de Chirurgie 1982; 119 (11): 633-641 
35) Phitayakorn R., McHenry C. Incidence and location of ectopic abnormal parathyroid glands.The American Journal of Surgery. 2006; 119:418-423.

36) Haldsten W., Evans H. The parathyroid glandules: their blood supply, and their preservation in operation upon the thyroid gland. Annals of Surgery. 1907; 46(4):489-506.

37) Tfelt-Hansen J, Brown EM. The calcium-sensing receptor in normal physiology and pathophysiology: a review. Crit Rev Clin Lab Sci [Internet]. 2005 [cited 2017 Aug 15];42(1):35-70. Available from: http://www.ncbi. nlm.nih.gov/pubmed/15697170

38) Fraser WD. Hyperparathyroidism. Lancet (London, England). 2009;(374):145-58.

39) Kidney Disease: Improving Global Outcomes (KDIGO) CKD Work Group. KDIGO 2012 Clinical Practice Guideline for the Evaluation and Management of Chronic Kidney Disease. Kidney Int Suppl. 2013;3:150.

40) Martínez-Castelao A, Górriz-Teruel JL, Bover-Sanjuán J, Segura-de la Morena J, Cebollada J, Escalada J, et al. Documento de consenso para la deteccion y manejo de la enfermedad renal crónica. Aten Primaria [Internet]. 2014;46(9):501-19. Available from: http://www.ncbi.nlm.nih.gov/pubmed/24658201

41) Levey AS, Coresh J. Chronic kidney disease. Lancet [Internet]. 2012 Jan 14 [cited 2014 Jul 11];379(9811):16580. Available from: http://www.ncbi.nlm.nih.gov/pubmed/21840587

42) Brück K, Stel VS, Gambaro G, Hallan S, Völzke H, Ärnlöv J, et al. CKD Prevalence Varies across the European General Population. J Am Soc Nephrol [Internet]. 2016 Jul 1 [cited 2017 Aug 16];27(7):2135-47. Available from: http://www.jasn.org/cgi/doi/10.1681/ASN.2015050542

43) Delanaye P, Glassock RJ, De Broe ME. Epidemiology of chronic kidney disease: think (at least) twice! Clin Kidney J [Internet]. 2017 Jun [cited 2017 Aug 16];10(3):370-4. Available from: http://www.ncbi.nlm.nih.gov/ pubmed/28617483

44) González-Bedat C, Ferreiro-Funtes A, Chifflet-Bide L. Registro Uruguayo de Diálisis. INFORME ANUAL 2015.2017; Available from: http://www.nefrologia.hc.edu.uy/images/Informme_RUD_año_2015.pdf

45) Rios P. Informe Programa de Salud Renal 2016 [Internet]. 2016. Available from: http://www.fnr.gub.uy/sites/ default/files/programas/informe_renal_2016.pdf

46) Eckardt K-U, Kasiske BL. KDIGO Clinical practice guideline for the diagnosis, evaluation, prevention, and treatment of Chronic Kidney Disease-Mineral and Bone Disorder (CKD-MBD). Kidney Int [Internet]. 2009 Aug [cited 2017 Aug 24];76(113):S1-2. Available from: http://www.ncbi.nlm.nih.gov/pubmed/19644521

47) Canalejo R, Canalejo A, Martinez-Moreno JM, Rodriguez-Ortiz ME, Estepa JC, Mendoza FJ, et al. FGF23 fails to inhibit uremic parathyroid glands. J Am Soc Nephrol [Internet]. 2010 Jul 1 [cited 2017 Aug 31];21(7):1125-35. Available from: http://www.jasn.org/cgi/doi/10.1681/ASN.2009040427

48) Cunningham J, Locatelli F, Rodriguez M. Secondary Hyperparathyroidism: Pathogenesis, Disease Progression, and Therapeutic Options. Clin J Am Soc Nephrol [Internet]. 2011 Apr 1 [cited 2017 Aug 31];6(4):913-21. Available from: http://www.ncbi.nlm.nih.gov/pubmed/21454719

49) Tallon S, Berdud I, Hernandez A, Concepcion MT, Almaden Y, Torres A, et al. Relative effects of PTH and dietary phosphorus on calcitriol production in normal and azotemic rats. Kidney Int [Internet]. 1996 May [cited 2017 Aug 31];49(5):1441-6. Available from: http://www.ncbi.nlm.nih.gov/pubmed/8731112

50) Rodriguez M, Martin-Malo A, Martinez ME, Torres A, Felsenfeld AJ, Llach F. Calcemic response to parathyroid hormone in renal failure: role of phosphorus and its effect on calcitriol. Kidney Int [Internet]. 1991 Dec [cited 2017 Aug 31];40(6):1055-62. Available from: http://www.ncbi.nlm.nih.gov/pubmed/1762306

51) Brown AJ, Ritter CS, Finch JL, Slatopolsky EA. Decreased calcium-sensing receptor expression in hyperplastic parathyroid glands of uremic rats: Role of dietary phosphate. Kidney Int [Internet]. 1999 Apr [cited 2017 Aug 31];55(4):1284-92. Available from: http://www.ncbi.nlm.nih.gov/pubmed/10200992

52) Bellorin-Font E, Martin KJ, Freitag JJ, Anderson C, Sicard G, Slatopolsky E, et al. Altered adenylate cyclase kinetics in hyperfunctioning human parathyroid glands. J Clin Endocrinol Metab [Internet]. 1981 Mar [cited 2017 Aug 31];52(3):499-507. Available from: https://academic.oup.com/jcem/article-lookup/doi/10.1210/ jcem-52-3-499

53) Canaff L, Hendy GN. Human Calcium-sensing Receptor Gene. J Biol Chem [Internet]. 2002 Aug 16 [cited 2017 Aug 31];277(33):30337-50. Available from: http://www.ncbi.nlm.nih.gov/pubmed/12036954

54) Almaden Y, Canalejo A, Hernandez A, Ballesteros E, Garcia-Navarro S, Torres A, et al. Direct effect of phosphorus on PTH secretion from whole rat parathyroid glands in vitro. J Bone Miner Res [Internet]. 1996 Jul 3 [cited 2017 Aug 31];11(7):970-6. Available from: http://doi.wiley.com/10.1002/jbmr.5650110714

55) Slatopolsky E, Finch J, Denda M, Ritter C, Zhong M, Dusso A, et al. Phosphorus restriction prevents parathyroid gland growth. High phosphorus directly stimulates PTH secretion in vitro. J Clin Invest [Internet]. 1996 Jun 1 [cited 2017 Aug 31];97(11):2534-40. Available from: http://www.jci.org/articles/view/118701

56) Zhang MYH, Wang X, Wang JT, Compagnone NA, Mellon SH, Olson JL, et al. Dietary phosphorus transcriptionally regulates 25-hydroxyvitamin D-1alpha-hydroxylase gene expression in the proximal renal tubule. Endocrinology [Internet]. 2002 Feb [cited 2017 Aug 31];143(2):587-95. Available from: https://academic. oup.com/endo/article-lookup/doi/10.1210/endo.143.2.8627 
57) Imanishi $Y$, Inaba $M$, Nakatsuka K, Nagasue K, Okuno S, Yoshihara A, et al. FGF-23 in patients with end-stage renal disease on hemodialysis. Kidney Int [Internet]. 2004 May [cited 2017 Aug 31];65(5):1943-6. Available from: http://www.ncbi.nlm.nih.gov/pubmed/15086938

58) Denda M, Finch J, Slatopolsky E. Phosphorus accelerates the development of parathyroid hyperplasia and secondary hyperparathyroidism in rats with renal failure. Am J Kidney Dis [Internet]. 1996 Oct [cited 2017 Aug 31];28(4):596-602. Available from: http://www.ncbi.nlm.nih.gov/pubmed/8840952

59) Almaden Y, Felsenfeld AJ, Rodriguez M, Cañadillas S, Luque F, Bas A, et al. Proliferation in hyperplastic human and normal rat parathyroid glands: role of phosphate, calcitriol, and gender. Kidney Int [Internet]. 2003 Dec [cited 2017 Aug 31];64(6):2311-7. Available from: http://linkinghub.elsevier.com/retrieve/pii/ S0085253815496024

60) Kremer R, Bolivar I, Goltzman D, Hendy GN. Influence of calcium and 1,25-dihydroxycholecalciferol on proliferation and proto-oncogene expression in primary cultures of bovine parathyroid cells. Endocrinology [Internet]. 1989 Aug [cited 2017 Aug 31];125(2):935-41. Available from: https://academic.oup.com/endo/ article-lookup/doi/10.1210/endo-125-2-935

61) Fukuda N, Tanaka H, Tominaga Y, Fukagawa M, Kurokawa K, Seino Y. Decreased 1,25-dihydroxyvitamin D3 receptor density is associated with a more severe form of parathyroid hyperplasia in chronic uremic patients. J Clin Invest [Internet]. 1993 Sep 1 [cited 2017 Aug 31];92(3):1436-43. Available from: http://www.jci.org/ articles/view/116720

62) Garfia B, Cañadillas S, Canalejo A, Luque F, Siendones E, Quesada M, et al. Regulation of parathyroid vitamin D receptor expression by extracellular calcium. J Am Soc Nephrol [Internet]. 2002 Dec [cited 2017 Aug 31];13(12):2945-52. Available from: http://www.ncbi.nlm.nih.gov/pubmed/12444213

63) Shigematsu T, Kazama JJ, Yamashita T, Fukumoto S, Hosoya T, Gejyo F, et al. Possible involvement of circulating fibroblast growth factor 23 in the development of secondary hyperparathyroidism associated with renal insufficiency. Am J Kidney Dis [Internet]. 2004 Aug [cited 2017 Sep 1];44(2):250-6. Available from: http:// www.ncbi.nlm.nih.gov/pubmed/15264182

64) Hassan A, Durlacher K, Silver J, Naveh-Many T, Levi R. The fibroblast growth factor receptor mediates the increased FGF23 expression in acute and chronic uremia. Am J Physiol Renal Physiol [Internet]. 2016 Feb 1 [cited 2017 Sep 1];310(3):F217-21. Available from: http://ajprenal.physiology.org/lookup/doi/10.1152/ajprenal.00332.2015

65) Koh N, Fujimori T, Nishiguchi S, Tamori A, Shiomi S, Nakatani T, et al. Severely reduced production of klotho in human chronic renal failure kidney. Biochem Biophys Res Commun [Internet]. 2001 Feb 2 [cited 2017 Sep 1];280(4):1015-20. Available from: http://linkinghub.elsevier.com/retrieve/pii/S0006291X00942268

66) Galitzer H, Ben-Dov IZ, Silver J, Naveh-Many T. Parathyroid cell resistance to fibroblast growth factor 23 in secondary hyperparathyroidism of chronic kidney disease. Kidney Int [Internet]. 2010 Feb [cited 2017 Aug 31];77(3):211-8. Available from: http://www.ncbi.nlm.nih.gov/pubmed/20016468

67) Isakova T, Wahl P, Vargas GS, Gutiérrez OM, Scialla J, Xie H, et al. Fibroblast growth factor 23 is elevated before parathyroid hormone and phosphate in chronic kidney disease. Kidney Int [Internet]. 2011 Jun [cited 2017 Sep 1];79(12):1370-8. Available from: http://www.ncbi.nlm.nih.gov/pubmed/21389978

68) Hruska KA, Seifert M, Sugatani T. Pathophysiology of the chronic kidney disease - mineral bone disorder. Curr Opin Nephrol Hypertens. 2015;(24):303-9.

69) Babayev R, Nickolas TL. Bone Disorders in Chronic Kidney Disease: An Update in Diagnosis and Management. Semin Dial. 2015;28(6):645-53.

70) Jevtic V. Imaging of renal osteodystrophy. Eur J Radiol [Internet]. 2003 May [cited 2017 Sep 1];46(2):85-95. Available from: http://www.ncbi.nlm.nih.gov/pubmed/12714225

71) Adams JE. Renal bone disease: radiological investigation. Kidney Int Suppl [Internet]. 1999 Dec [cited 2017 Sep 1];73:S38-41. Available from: http://www.ncbi.nlm.nih.gov/pubmed/10633462

72) Mazzaferro S, Pasquali M, Pirrò G, Rotondi S, Tartaglione L. The bone and the kidney. Arch Biochem Biophys [Internet]. 2010 Nov 1 [cited 2017 Sep 1];503(1):95-102. Available from: http://www.ncbi.nlm.nih.gov/pub$\mathrm{med} / 20599669$

73) Cournot-Witmer G, Zingraff J, Plachot JJ, Escaig F, Lefêvre R, Boumati P, et al. Aluminum localization in bone from hemodialyzed patients: relationship to matrix mineralization. Kidney Int [Internet]. 1981 Sep [cited 2017 Sep 1];20(3):375-8. Available from: http://www.ncbi.nlm.nih.gov/pubmed/7300127

74) Miller PD. Bone disease in CKD: A focus on osteoporosis diagnosis and management. Am J Kidney Dis [Internet]. Elsevier Inc; 2014;64(2):290-304. Available from: http://dx.doi.org/10.1053/j.ajkd.2013.12.018

75) Watanabe R, Lemos MM, Manfredi SR, Draibe SA, Canziani MEF. Impact of cardiovascular calcification in nondialyzed patients after 24 months of follow-up. Clin J Am Soc Nephrol [Internet]. 2010 Feb 1 [cited 2017 Sep 1];5(2):189-94. Available from: http://cjasn.asnjournals.org/cgi/doi/10.2215/CJN.06240909 
76) London GM, Pannier B. Arterial functions: how to interpret the complex physiology. Nephrol Dial Transplant [Internet]. 2010 Dec 1 [cited 2017 Sep 1];25(12):3815-23. Available from: https://academic.oup.com/ndt/ article-lookup/doi/10.1093/ndt/gfq614

77) Adragao T, Pires A, Lucas C, Birne R, Magalhaes L, Gonçalves M, et al. A simple vascular calcification score predicts cardiovascular risk in haemodialysis patients. Nephrol Dial Transplant [Internet]. 2004 Jun 1 [cited 2017 Sep 1];19(6):1480-8. Available from: https://academic.oup.com/ndt/article-lookup/doi/10.1093/ndt/ gfh 217

78) Honkanen E, Kauppila L, Wikstrom B, Rensma PL, Krzesinski J-M, Aasarod K, et al. Abdominal aortic calcification in dialysis patients: results of the CORD study. Nephrol Dial Transplant [Internet]. 2008 Jul 16 [cited 2017 Sep 1];23(12):4009-15. Available from: http://www.ncbi.nlm.nih.gov/pubmed/18676346

79) Oung ERICWY, Lbert JUMA, Atayathum SUS, Oodkin DAAG, Isoni ROLP, Ort FRKP. Predictors and consequences of altered mineral metabolism : The Dialysis Outcomes and Practice Patterns Study. 2005;67:117987.

80) Sun Y-P, Yang W-J, Li S-H, Han Y, Liu J. Clinical Epidemiology of Mineral Bone Disorder Markers in Prevalent Hemodialysis Patients in the Xinjiang Uyghur Autonomous Region in China. Biomed Res Int [Internet]. 2017 [cited 2017 Sep 5];2017:1-5. Available from: http://www.ncbi.nlm.nih.gov/pubmed/28299319

81) Kim CS, Bae EH, Ma SK, Han SH, Lee KB, Lee J, et al. Chronic Kidney Disease-Mineral Bone Disorder in Korean Patients: a Report from the KoreaN Cohort Study for Outcomes in Patients With Chronic Kidney Disease (KNOW-CKD). J Korean Med Sci [Internet]. 2017 Feb [cited 2017 Sep 5];32(2):240-8. Available from: https://synapse.koreamed.org/DOIx.php?id=10.3346/jkms.2017.32.2.240

82) Tentori F, Blayney MJ, Albert JM, Gillespie BW, Kerr PG, Bommer J, et al. Mortality Risk for Dialysis Patients With Different Levels of Serum Calcium, Phosphorus, and PTH: The Dialysis Outcomes and Practice Patterns Study (DOPPS). Am J Kidney Dis [Internet]. 2008 Sep [cited 2017 Sep 6];52(3):519-30. Available from: http://www.ncbi.nlm.nih.gov/pubmed/18514987

83) Noordzij M, Korevaar JC, Boeschoten EW, Dekker FW, Bos WJ, Krediet RT, et al. The Kidney Disease Outcomes Quality Initiative (K/DOQI) Guideline for Bone Metabolism and Disease in CKD: Association With Mortality in Dialysis Patients. Am J Kidney Dis [Internet]. 2005 Nov [cited 2017 Sep 6];46(5):925-32. Available from: http://www.ncbi.nlm.nih.gov/pubmed/16253734

84) Kalantar-Zadeh K, Kuwae N, Regidor DL, Kovesdy CP, Kilpatrick RD, Shinaberger CS, et al. Survival predictability of time-varying indicators of bone disease in maintenance hemodialysis patients. Kidney Int [Internet]. 2006 Aug [cited 2017 Sep 6];70(4):771-80. Available from: http://linkinghub.elsevier.com/retrieve/pii/ S0085253815519959

85) Young EW, Albert JM, Satayathum S, Goodkin DA, Pisoni RL, Akiba T, et al. Predictors and consequences of altered mineral metabolism: The Dialysis Outcomes and Practice Patterns Study. Kidney Int [Internet]. 2005 Mar [cited 2017 Sep 6];67(3):1179-87. Available from: http://www.ncbi.nlm.nih.gov/pubmed/15698460

86) Russo D, Miranda I, Ruocco C, Battaglia Y, Buonanno E, Manzi S, et al. The progression of coronary artery calcification in predialysis patients on calcium carbonate or sevelamer. Kidney Int [Internet]. 2007 Nov [cited 2017 Sep 6];72(10):1255-61. Available from: http://www.ncbi.nlm.nih.gov/pubmed/17805238

87) Chertow GM, Burke SK, Raggi P, Treat to Goal Working Group. Sevelamer attenuates the progression of coronary and aortic calcification in hemodialysis patients. Kidney Int [Internet]. 2002 Jul [cited 2017 Sep 6];62(1):245-52. Available from: http://linkinghub.elsevier.com/retrieve/pii/S0085253815485424

88) Block GA, Spiegel DM, Ehrlich J, Mehta R, Lindbergh J, Dreisbach A, et al. Effects of sevelamer and calcium on coronary artery calcification in patients new to hemodialysis. Kidney Int [Internet]. 2005 Oct [cited 2017 Sep 6];68(4):1815-24. Available from: http://www.ncbi.nlm.nih.gov/pubmed/16164659

89) Barreto DV, Barreto F de C, de Carvalho AB, Cuppari L, Draibe SA, Dalboni MA, et al. Phosphate binder impact on bone remodeling and coronary calcification--results from the BRiC study. Nephron Clin Pract [Internet]. 2008 Nov 12 [cited 2017 Sep 6];110(4):c273-83. Available from: http://www.karger.com/?doi $=10.1159 / 000170783$

90) Qunibi W, Moustafa M, Muenz LR, He DY, Kessler PD, Diaz-Buxo JA, et al. A 1-year randomized trial of calcium acetate versus sevelamer on progression of coronary artery calcification in hemodialysis patients with comparable lipid control: the Calcium Acetate Renagel Evaluation-2 (CARE-2) study. Am J Kidney Dis [Internet]. 2008 Jun [cited 2017 Sep 6];51(6):952-65. Available from: http://linkinghub.elsevier.com/retrieve/pii/ S027263860800526X

91) Bellorin-Font E, Ambrosoni P, Carlini RG, Carvalho AB, Correa-Rotter R, Cueto-Manzano A, et al. Guías de práctica clínica para la prevención , diagnóstico, evaluación y tratamiento de los trastornos minerales y óseos en la enfermedad renal crónica (TMO-ERC) en adultos. Nefrologia. 2013;Supl(33):1-28.

92) Moe SM, Chertow GM, Coburn JW, Quarles LD, Goodman WG, Block GA, et al. Achieving NKF-K/DOQI bone metabolism and disease treatment goals with cinacalcet HCl. Kidney Int [Internet]. 2005 Feb [cited 2017 Sep 6];67(2):760-71. Available from: http://linkinghub.elsevier.com/retrieve/pii/S0085253815505140 
93) KDIGO 2017 Clinical Practice Guideline Update for the Diagnosis, Evaluation, Prevention, and Treatment of Chronic Kidney Disease - Mineral and Bone Disorder ( CKD-MBD ). 2017;7(1).

94) Wagner PK, Seesko HG, Rothmund M (1991) Replantation of cryopreserved human parathyroid tissue. World J Surg 15(6): 751-755 36.

95) Wells SA Jr, Ellis GJ, Gunnells JC, Schneider AB, Sherwood LM (1976) Parathyroid autotransplantation in primary parathyroid hyperplasia. N Engl J Med 295(2):57-62

96) Ogg CS (1967) Total parathyroidectomy in treatment of secondary (renal) hyperparathyroidism. Br Med J 4(5575):331-334

97) Nada Rayes, MD; Daniel Seehofer, MD; Ralf Schindler, PhD .Long-term Results of Subtotal vs Total Parathyroidectomy Without Autotransplantation in Kidney Transplant.. Arch Surg. 2008;143(8):756-761

98) Gürhan Sakman', Cem Kaan Parsak', Mustafa BalaF .Outcomes of Total Parathyroidectomy with Autotransplantation versus Subtotal Parathyroidectomy with Routine Addition of Thymectomy to both Groups: Single Center. Experience of Secondary Hyperparathyroidism.. Balkan MedJ, Vol. 31, No. 1, 2014

99) Parathyroidectomy for secondary hyperparathyroidism in chronic renal failure. Drs. JA Perez, M Gabrielli.

100) Rothmund M, Wagner PK, Schark C (1991) Subtotal parathyroidectomy versus total parathyroidectomy and autotransplantation in secondary hyperparathyroidism: a randomized trial. World J Surg 1991 15(6):745-750 40.

101) Kerstin L, Detlef K. Bartsch K, Sancho JJ, Guigard S. Surgical management of secondary hyperparathyroidism in chronic kidney disease- a consensus report of the EuropeanSociety of Endocrine Surgeons. Arch Surg (2015) 400:907-927

102) Lorenz K, Sekulla C, Dralle H (2013) Chirurgisches Management des renalen Hyperparathyreoidismus. Zentralbl Chir 138(Suppl 2):e47-e54

103) Schneider R, Slater EP, Karakas E, Bartsch DK, Schlosser K. (2012) Initial parathyroid surgery in 606 patients with renal hyperparathyroidism. World J Surg 36(2): 318-326

104) Schneider R, Bartsch DK, Schlosser K (2013) Relevance of bilateral cervical thymectomy in patients with renal hyperparathyroidism: analysis of 161 patients undergoing reoperative parathyroidectomy.World J Surg 37(9):2155-2161

105) Schlosser K, Veit JA, Witte S, Fernández ED. Comparison of total parathyroidectomy without autotransplantation and without thymectomy versus total parathyroidectomy with autotransplantation and with thymectomy for secondary hyperparathyroidism: TOPAR PILOT-Trial.

106) Caccitolo JA, Farley DR, Van Heerden JA. The current role of parathyroid cryopreservation and autotransplantation in parathyroid surgery: an institutional experience. Surgery 122:1062, 1997

107) Wagner PK, Seesko HG, Rothmund M. Replantation of cryopreserved human parathyroid tissue. World J Surg 15: 751, 1991

108) Shepet K, Alhefdhi A, Usedom R, Sippel R, Chen H. Parathyroid cryopreservation after parathyroidectomy: a worthwhile practice?. Ann Surg Oncol. 2013 Jul;20(7):2256-60. doi: 10.1245/s10434-013-2941-6. Epub 2013 Mar 16.

109) Ulrich F, Steinmuller N, Rayes A. Cryopreserved Human Parathyroid Tissue: Cell cultures for in vitro testing function. Transplatation Proceedings, 33, 666-667 (2001)

110) Christopher R, McHenry MD, Deborah B. The effect of cryopreservation on Parathyroid cell viability and function. Am J Surg 174: 481-484. 1997

111) José Miguel Domínguez, Soledad Velasco, Ignacio Goñi. Utilidad de la PTH intraoperatoria como predictor de curación quirúrgica en hiperparatiroidismo primario. Rev Méd Chile 2009; 137: 1591-1596

112) New Trens in Parathyroid Surgery. Curr Probl Surg. 2010;47:958-1017

113) Barczynski M, Konturek A, Hubalewska-Dydejcczyk A et al. Evaluation of Halle, Miami, Rome an Viena intraoperative $\mathrm{PTH}$ assay criteria in guiding minimally invasive parathyroidectomy. Langenbecks Arch Surg 2009;394(5):843-9

114) Kellen BS, Chrsitopher R, McHenry MD. The role of transcervical thymectomy in patients with hyperparathyroidism. Am J Surg (2012)203, 292-296

115) Calender G, Grubs E, Vu T et al. The Fallen one: the inferior paratgyroid gland that descends into de mediastinum. J Am Coll Surg. Vol. 208, N5, May 2009; 887-893

116) Morgan EG, Mikhail MS, Murray MJ. Manejo de la vía aérea. En: Anestesiología clínica. 4.a ed. México DF/ Bogotá DC: Manual Moderno; 2007.p. 91---114.

117) Lahey FH, Hoover WB. Injuries to the recurrent laryngeal nerve in thyroid operations: Their management and avoidance. Ann Surg. 1938;108:545-62.

118) Dralle H, Sekulla C, Haerting J, Timmermann W, Neumann HJ,Kruse E, et al. Risk factors of paralysis and functional outcome after recurrent laryngeal nerve monitoring in thyroid surgery. Surgery. 2004;136:1310--22. 
119) Hermann M, Alk G, Roka R, Glaser K, Freissmuth M. Laryngeal recurrent nerve injury in surgery for benign thyroid diseases: Effect of nerve dissection and impact of individual surgeon in more than 27,000 nerves at risk. Ann Surg. 2002;235:261---8.

120) Jatzko GR, Lisborg PH, Müller MG, Wette VM. Recurrent nerve palsy after thyroid operations-Principal nerve identification and a literature review. Surgery. 1994;115:139---44.

121) Moley JF, Lairmore TC, Doherty GM, Brunt LM, DeBenedetti MK. Preservation of the recurrent laryngeal nerves in thyroid and parathyroid reoperations. Surgery. 1999;126:673---7.

122) Eisele DW. Intraoperative electrophysiologic monitoring of the recurrent laryngeal nerve. Laryngoscope. 1996;106:443-9.

123) Barczynski M, Konturek A, Cichon S. Randomized clinical trial of visualization versusneuromonitoring of recurrent laryngeal nerves during thyroidectomy. Br J Surg.[Comparative Study Randomized Controlled Trial]. 2009;96:240-6.

124) Higgins TS, Grupta R, Ketcham AS, Sataloff RT, Wadsworth JT, Sinacori JT. Recurrent laryngeal nerve monitoring versus identification alone on post-thyroidectomy true vocal fold palsy: A meta-analysis. Laryngoscope. 2011;121:1009---17.

125) Dionigi G, Bacuzzi A, Boni L, Rausei S, Rovera F, Dionigi R. Visualization versus neuromonitoring of recurrent laryngeal nervesduring thyroidectomy: What about the costs? World J Surg.2012;36:748---54.

126) Solbiati L, Giagrande A, Pra LD, Bellotti E, Cantu P, et al. Percutaneous ethanol injection of parathyroid tumor under US guidance: Treatment for secondary hyperparathyroidism. Radiology 1985;155:607-10.

127) Fukagawa M, Kitaoka M, Yi H, Fukuda N, Matsumoto T, et al. Serial evaluation of parathyroid size by ultrasonography is another useful marker for the long-term prognosis of calcitriol pulse therapy in chronic dialysis patients. Nephron 1994;68:221-8.

128) Solbiati L, Rizzatto G, Ballarati E, Ierace T, Crespi L. Practical implications of color Doppler sonography of parathyroid glands: study of 203 tumors. Radiology 1993;189:210.

129) Ferlin G, Borsato N, Camerani M, Conte N, Zoiti D. New perspectives in localizing enlarged parathyroids by technetium-thallium substraction scan. J Nucl Med 1983;24:438-41.

130) Ishibashi M, Nishida H, Okuda S, Suekane $S$, Hayabuchi N. Localization of parathyroid glans in hemodialysis patients using Tc-99 sestamibi imaging. Nephron 1998;78:48-53

131) Ferrer-Ramírez M, Amoros-Sebastia L, Cano Terol C. Valor diagnóstico de las técnicas de localización paratiroidea en la cirugía del hiperparatiroidismo primario. Acta Otorrinolaringol Esp. 2003; 54(2): 220-24

132) Arkles L, Jones T, Hicks R, De Luise M, Chou S. Impact of complementary parathyroide scintigraphy and ultrasonography on the surgical management of hyperparathyroidism. Surgery. 1996; 120(5): 845-51

133) Berber E, Parikh N, Ballen N, Garner C, Siperstein A. Factors contributing to negative parathyroid localization: an analysis of 1000 patients. Surgery. 2008; 144(1): 74-79

134) Markarian M, Yelin G, Aparicio R, Marino J. Utilidad del centellograma TC 99-Sestamibi en la detección de adenomas e hiperplasias de glándulas paratiroides. Rev. Argent. Radiol. 2005;69(1): 69-77

135) Coakley A, Kettle A, Wells C. Technetium-99-sestamibi- a new agent for parathyroid imaging. Nucl Med Commun. 1989;10(11): 791-4

136) Koong HN, Choong LH, Soo KC. The role of preoperative localization techniques in surgery for hyperparathyroidism. Ann Acad Med Singapure, 1998; 27: 192-195

137) Levin KE, Clark OH. Localization of parathyroid glands. Ann Rev Med. 1988; 39: 29-40

138) Weber AL, Randolph G, Aksoy FG. The Thyroid and Parathyroid Glands: CT and MR imaging and correlation with pathology and clinical findings. Radiol Clin North Am 2000; 38: 1105-1129

139) Otto D, Boerner AR, Hofmann M, Brunkhorst T, Meyer GJ, Petrich T, et al. Pre-operative localisation of hyperfunctional parathyroid tissue with 11C-methionine PET. Eur J Nucl Med Mol Imaging. 2004;31:140512. [PubMed]

140) Habener JF, Maunus R, Dee PC, Potts JT.,Jr Early events in the cellular formation of proparathyroid hormone. J Cell Biol. 1980;85:292-8. [PMC free article] [PubMed]

141) Casas A, Burke G. Sathyanarayana M, Wei J. Prospective comparison of technetium-99m-sestamibi-iodine-123 radionuclide scan versus high-resolution ultrasonography for the preoperative localization of abnormal glands in patients with previously unoperated primary hyperparathyroidism. Am J Sug. 1993;166(4): 369-73

142) Perie S, Fessi H, Tassart M, Younsi N, Poli I, St Guily JL, et al. Usefuness of combination of high resolution ultrasonography and dualphase dual-isotope iodine 123/technetium Tc $99 \mathrm{~m}$ sestamibi scintigraphy for the preoperative localization of hyperplastic parathyroid glands in renal hyperparathyroidism. Am J Kidney Dis 2005;45:344-52.

143) Mankoff DA. A definition of molecular imaging. J Nucl Med. 2007 Jun;48(6):18N, 21N.

144) Chen H, Mack E, Starling JR. Radioguided parathyroidectomy is equally effective for both adenomatous and hyperplastic glands. Ann Surg. 2003 Sep;238(3):332-7; discussion 337-8 
145) Pitt SC, Panneerselvan R, Sippel RS, Chen H. Radioguided parathyroidectomy for hyperparathyroidism in the reoperative neck. Surgery. 2009 Oct;146(4):592-8; discussion 598-9. doi: 10.1016/j.surg.2009.06.031.

146) Chen H, Sippel RS, Schaefer S. The effectiveness of radioguided parathyroidectomy in patients with negative technetium tc 99m-sestamibi scans. Arch Surg. 2009 Jul;144(7):643-8. doi: 10.1001/archsurg.2009.104.

147) Rubello D, Piotto A, Medi F, Gross MD, Shapiro B, Erba P, Mariani G, Pelizzo MR. 'Low dose' 99mTc-Sestamibi for radioguided surgery of primary hyperparathyroidism. Eur J Surg Oncol. 2005 Mar;31(2):191-6.

148) Bekiş R, Celik P, Uysal B, Koçdor MA, Atila K, Saydam S, Harmancioğlu O, Durak H. Exposure of surgical staff in surgical probe applications in radioguided parathyroidectomy. Eur Arch Otorhinolaryngol. 2008 Dec;265(12):1545-8. doi: 10.1007/s00405-008-0716-7. Epub 2008 Jun 10.

149) Norman J. Recent trends becoming standard of care yielding smaller, more successful operations at a lower cost. Otolaryngol Clin North Am. 2004;37(4):683-688, vii.

150) Murphy C, Norman J. The $20 \%$ rule: a simple, instantaneous radioactivity measurement defines cure and allows elimination of frozen sections and hormone assays during parathyroidectomy. Surgery. 1999;126(6):1023-1029.

151) Rubello D, Casara D, Giannini $S$, et al. Importance of radio-guided minimally invasive parathyroidectomy using hand-held gamma probe and low $99 \mathrm{mTc}-\mathrm{MIBI}$ dose: technical considerations and long-term clinical results. QJ Nucl Med. 2003;47:224-232.

152) Rubello D, Casara D, Pelizzo MR. Symposium on parathyroid localization: optimization of peroperative procedures. Nucl Med Commun. 2003;24:133-140.

153) Norman J, Cheda H. Minimally invasive radioguided parathyroidectomy facilitated

by intraoperative nuclear mapping. Surgery. 1997;122:998-1004.

154) Kherlopian AR, Song T, Duan Q, et al. A review of imaging techniques for systems biology. BMC Syst Biol. 2008;2(1):74.

155) Hadjipanayis CG, Jiang H, Roberts DW, Yang L.Current and future clinical applications for optical imaging of cancer: from intraoperative surgical guidance to cancer screening. Semin Oncol. 2011;38:109-118.

156) Paras C, Keller M, White LM, Phay JE, Mahadevan-Jansen A. Nearinfrared auto-fluorescence for the detection of parathyroid glands. J Biomed Opt. 2011;16(6):067012.

157) McWade MA, Paras C, White LM, Phay JE, Mahadevan-Jansen A, Broome JT. A novel optical approach to intraoperative detection of parathyroid glands. Surgery. 2013;154(6):1371-1377.

158) Kim SW1, Song SH1, Lee HS1, Noh WJ1, Oak C1, Ahn YC1, Lee KD1. Intraoperative Real-Time Localization of Normal Parathyroid Glands With Autofluorescence Imaging. J Clin Endocrinol Metab. 2016 Dec;101(12):4646-4652.

159) Patel HP1, Chadwick DR, Harrison BJ, Balasubramanian SP. Systematic review of intravenous methylene blue in parathyroid surgery. Br J Surg. 2012 Oct;99(10):1345-51. doi: 10.1002/bjs.8814.

160) Rowley M, Riutort K, Shapiro D, Casler J, Festic E,Freeman WD. Methylene blue-associated serotonin syndrome: a 'green' encephalopathy after parathyroidectomy.Neurocrit Care 2009; 11: 88-93.

161) Pollack G, Pollack A, Delfiner J, Fernandez J. Parathyroid surgery and methylene blue: a review with guidelines for safe intraoperative use. Laryngoscope 2009; 119: 1941-1946.

162) Bewick J, Pfleiderer A. The value and role of low dose methylene blue in the surgical management of hyperparathyroidism. Ann R Coll Surg Engl. 2014 Oct;96(7):526-9. doi: 10.1308/003588414X13946184903883.

163) Tummers QR, Schepers A, Hamming JF, Kievit J, Frangioni JV, van de Velde CJ, Vahrmeijer AL. Intraoperative guidance in parathyroid surgery using near-infrared fluorescence imaging and low-dose Methylene Blue. Surgery. 2015 Nov;158(5):1323-30. doi: 10.1016/j.surg.2015.03.027.

164) Zaidi N, Bucak E, Okoh A, Yazici P, Yigitbas H, Berber E. The utility of indocyanine green near infrared fluorescent imaging in the identification of parathyroid glands during surgery for primary hyperparathyroidism. J Surg Oncol. 2016 Jun;113(7):771-4. doi: 10.1002/jso.24240. Epub 2016 Apr 4.

165) Cui L, Gao Y, Yu H, Li M, Wang B, Zhou T, Hu Q. Intraoperative Parathyroid Localization with Near-Infrared Fluorescence Imaging Using Indocyanine Green during Total Parathyroidectomy for Secondary Hyperparathyroidism. Sci Rep. 2017 Aug 15;7(1):8193. doi: 10.1038/s41598-017-08347-6.

166) Rodríguez-Gonzalez J, Ortiz S, Hernandez A, Claver M, Soria Cogollos T, Ramirez Romero A, et al. Utilidad y limitaciones del sestamibi99 TC como diagnóstico de localización en el hiperparatiroidismo. Cir. Esp. 1996; 60(1): 400-3

167) Dubost C, Bouteloup P: Mediastinal exploration by sternotomy in surgery for hyperparathyroidism. 36 cases.J Chir 1988; 125: 631-637 


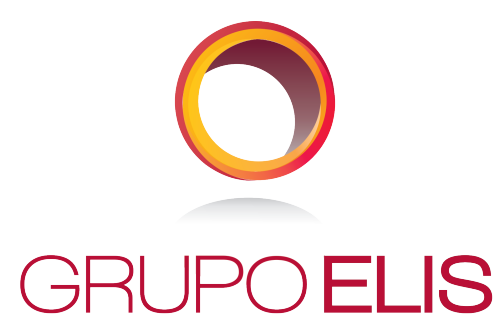

MEETINGS MANAGEMENT

\begin{tabular}{|c|c|c|c|c|c|}
\hline ताति & $\dot{y}$ & त & 0 & Local Partner & Miembro de \\
\hline 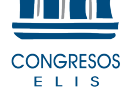 & Senior & $\begin{array}{l}\text { Gestión de } \\
\text { INSCRIPCIONES }\end{array}$ & 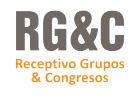 & 8. Maritz & 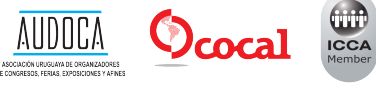 \\
\hline
\end{tabular}

